\title{
Phase-Transfer Catalyzed Alkylation of Guanidines by Alkyl Halides Under Biphasic Conditions: A Convenient Protocol for the Synthesis of Highly Functionalized Guanidines
}

\section{Supporting Information}

David A. Powell, Philip D. Ramsden and Robert A. Batey*

Davenport Research Laboratories, Department of Chemistry, University of Toronto, $80 \mathrm{St}$. George Street, Toronto, Ontario, M5S 3H6, Canada. rbatey@chem.utoronto.ca

$N^{1}, N^{2}$-Bis(tert-butoxycarbonyl)pyrrolidine-1-carboxamidine (3a): Obtained as an off-white solid in $96 \%$ yield. ${ }^{1} \mathrm{H}$ NMR $\left(300 \mathrm{MHz}, \mathrm{CDCl}_{3}\right) \delta 10.24(1 \mathrm{H}, \mathrm{bs}), 3.48(4 \mathrm{H}, \mathrm{bs}), 1.95-1.79(4 \mathrm{H}$, m), 1.41 (18H, s); MS (EI) m/e 314 (19, $\mathrm{MH}^{+}$), 201 (29), 184 (60), 70 (41), 57 (100); HRMS (EI) m/e $\left(\mathrm{M}^{+}\right)$calcd (for $\mathrm{C}_{15} \mathrm{H}_{27} \mathrm{~N}_{3} \mathrm{O}_{4}$ ) 313.2002, found 313.1999. This compound has been previously characterized. Feichtinger, K.; Zapf, C.; Sings, H. L.; Goodman, M. J. Org. Chem. 1998, 63, 3804-3805.

$N^{1}, N^{2}$-Bis(tert-butoxycarbonyl)guanidine (3c): Obtained as a white crystalline solid in $99 \%$ yield. mp 142-143 ${ }^{\circ} \mathrm{C} ; \mathrm{R}_{f}=0.25$ (80\% hexanes/20\% EtOAc); ${ }^{1} \mathrm{H}$ NMR $\left(300 \mathrm{MHz}, \mathrm{CDCl}_{3}\right) \delta 8.41$ $(3 \mathrm{H}, \mathrm{bs}), 1.39(18 \mathrm{H}, \mathrm{s})$. This compound has previously been characterized. Dodd, D. S.; Kozikowski, A. P. Tetrahedron Lett. 1994, 35, 977-980.

$N^{1}, N^{2}$-Bis(tert-butoxycarbonyl)- $N^{3}$-diethylguanidine (3d): Obtained in $88 \%$ yield as a white solid. mp 83-84 ${ }^{\circ} \mathrm{C} ; \mathrm{R}_{f}=0.13$ (80\% hexanes/20\% EtOAc); ${ }^{1} \mathrm{H}$ NMR (300 MHz, $\left.\mathrm{CDCl}_{3}\right) \delta 9.67$ $(1 \mathrm{H}, \mathrm{bs}), 3.48(4 \mathrm{H}, \mathrm{q}, J=7.0 \mathrm{~Hz}), 1.48(18 \mathrm{H}, \mathrm{s}), 1.20(6 \mathrm{H}, \mathrm{t}, J=7.0 \mathrm{~Hz}) ;{ }^{13} \mathrm{C} \mathrm{NMR}(75 \mathrm{MHz}$, 
$\left.\mathrm{CDCl}_{3}\right) \delta 154.2,42.4,28.2,13.0$ (4 quaternary carbons were not observed). This compound has been previously characterized. Ko, S. Y.; Lerpiniere, J.; Christofi, A. M. Synlett, 1995, 815-816.

$N^{1}, N^{2}$-Bis(tert-butoxycarbonyl)- $N^{3}$-phenylguanidine (31): Obtained as a white solid in $95 \%$ yield. mp 134-135 ${ }^{\circ} \mathrm{C} ; \mathrm{R}_{f}=0.61\left(80 \%\right.$ hexanes/20\% $\left.\mathrm{Et}_{2} \mathrm{O}\right) ;{ }^{1} \mathrm{H}$ NMR $\left(400 \mathrm{MHz}, \mathrm{CDCl}_{3}\right) \delta 11.62$ $(1 \mathrm{H}, \mathrm{bs}), 10.33(1 \mathrm{H}, \mathrm{bs}), 7.61(2 \mathrm{H}, \mathrm{d}, J=8.0 \mathrm{~Hz}), 7.31(2 \mathrm{H}, \mathrm{t}, J=8.0 \mathrm{~Hz}), 7.10(1 \mathrm{H}, \mathrm{t}, J=7.5$ $\mathrm{Hz}), 1.54(9 \mathrm{H}, \mathrm{s}), 1.51(9 \mathrm{H}, \mathrm{s})$. This compound has been previously characterized. Yong, Y. F.; Fui, Y.; Kowalski, J. A.; Lipton, M. A. J. Org. Chem. 1997, 62, 1540-1542.

$N^{1}, N^{2}, N^{3}$-Tri(tert-butoxycarbonyl)guanidine (8): Obtained as a white solid in $72 \%$ yield. $\mathrm{R}_{f}=$ 0.27 (70\% hexanes/30\% Et $2 \mathrm{O}) ;{ }^{1} \mathrm{H} \mathrm{NMR}\left(400 \mathrm{MHz}, \mathrm{CDCl}_{3}\right) \delta 8.62-8.10(2 \mathrm{H}, \mathrm{bs}), 1.51(27 \mathrm{H}, \mathrm{s})$; MS (EI) m/e 360 (10, $\mathrm{MH}^{+}$), 304 (15), 248 (27), 192 (54), 148 (45), 57 (100); HRMS (EI) m/e $\left(\mathrm{MH}^{+}\right.$) calcd. (for $\mathrm{C}_{16} \mathrm{H}_{30} \mathrm{~N}_{3} \mathrm{O}_{6}$ ) 360.2135, found 360.2139 .This compound has been previously characterized. Feichtinger, K.; Sings, H. L.; Baker, T. J.; Matthews, K.; Goodman, M. J. Org. Chem. 1998, 63, 8432-8439. 


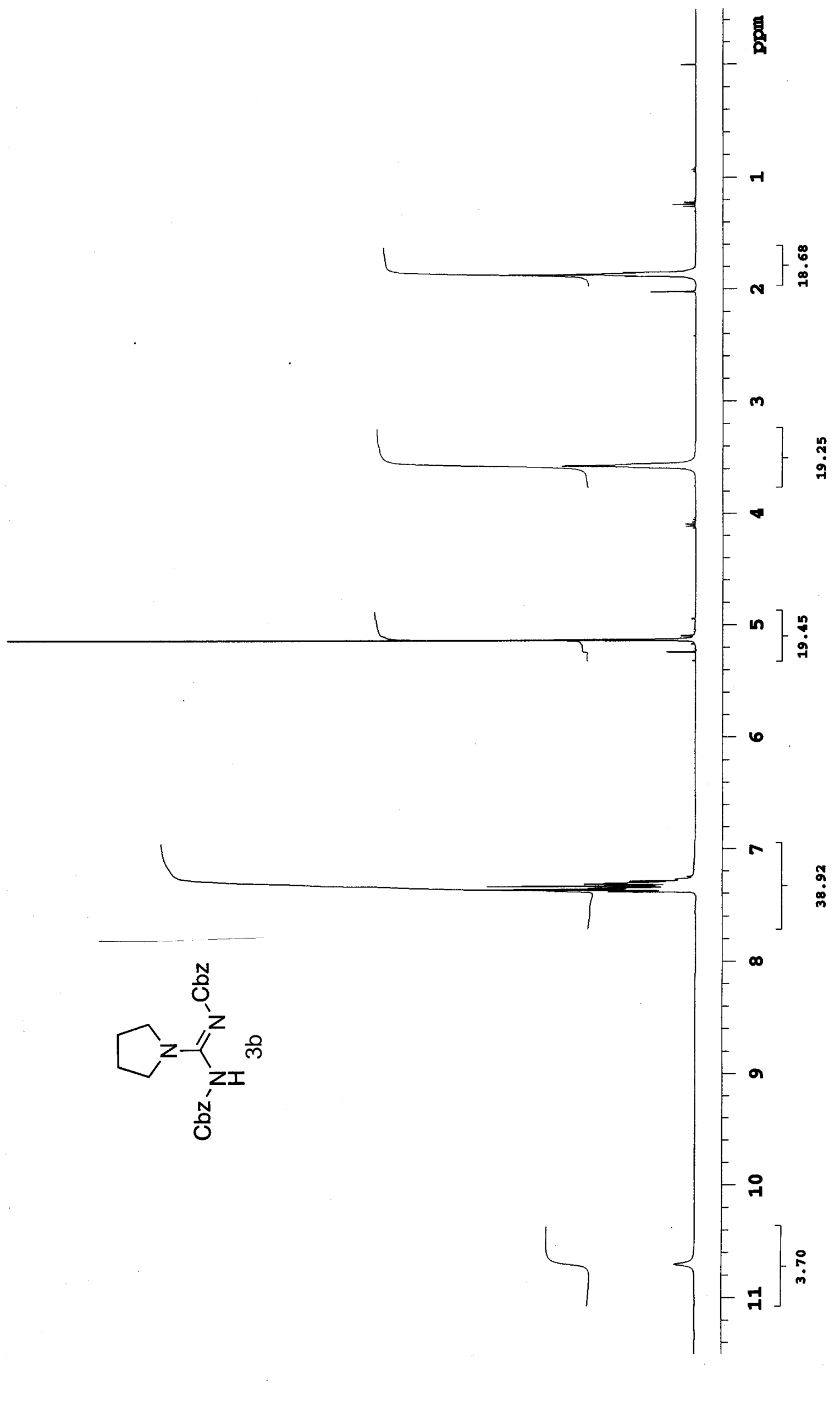




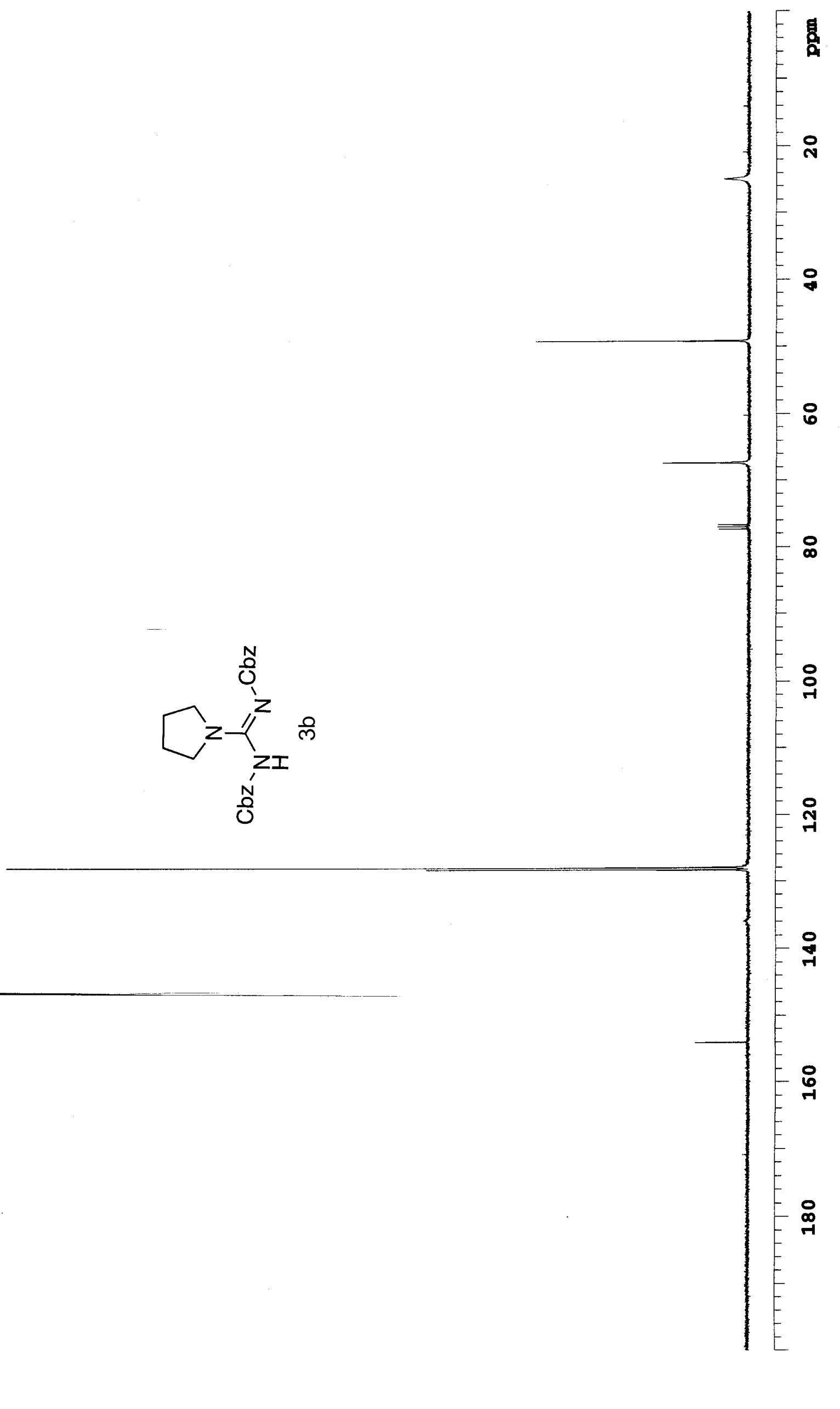




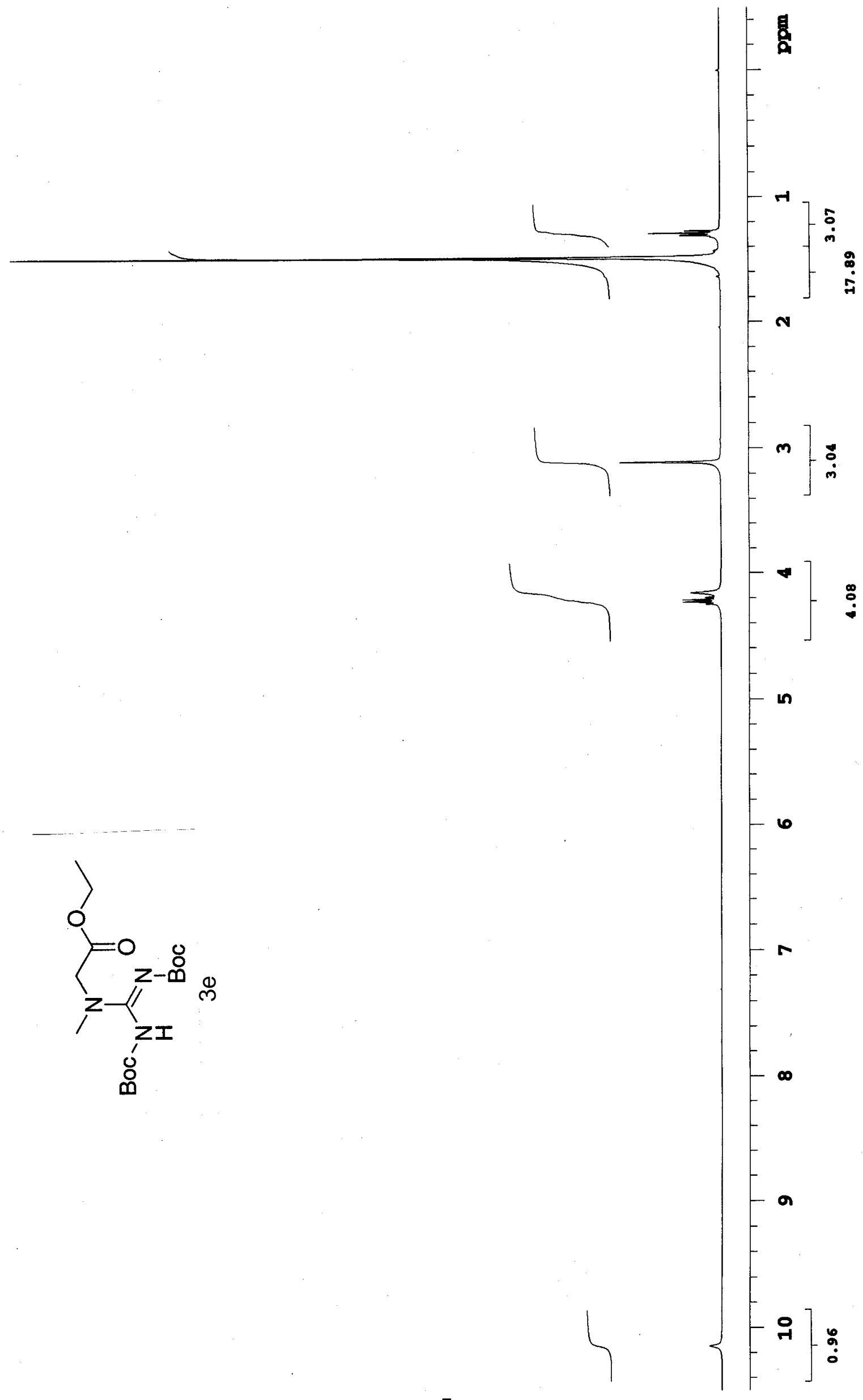




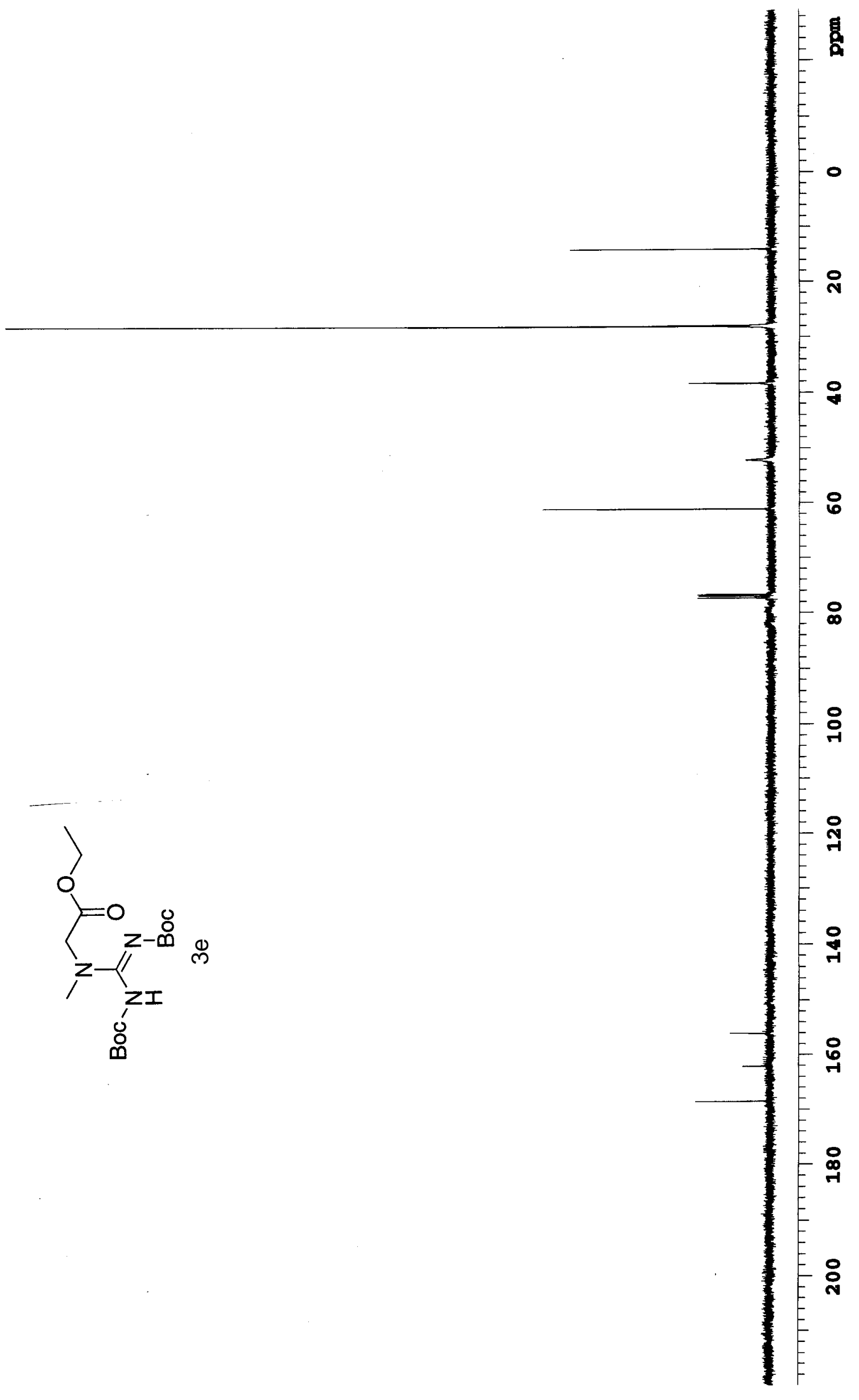




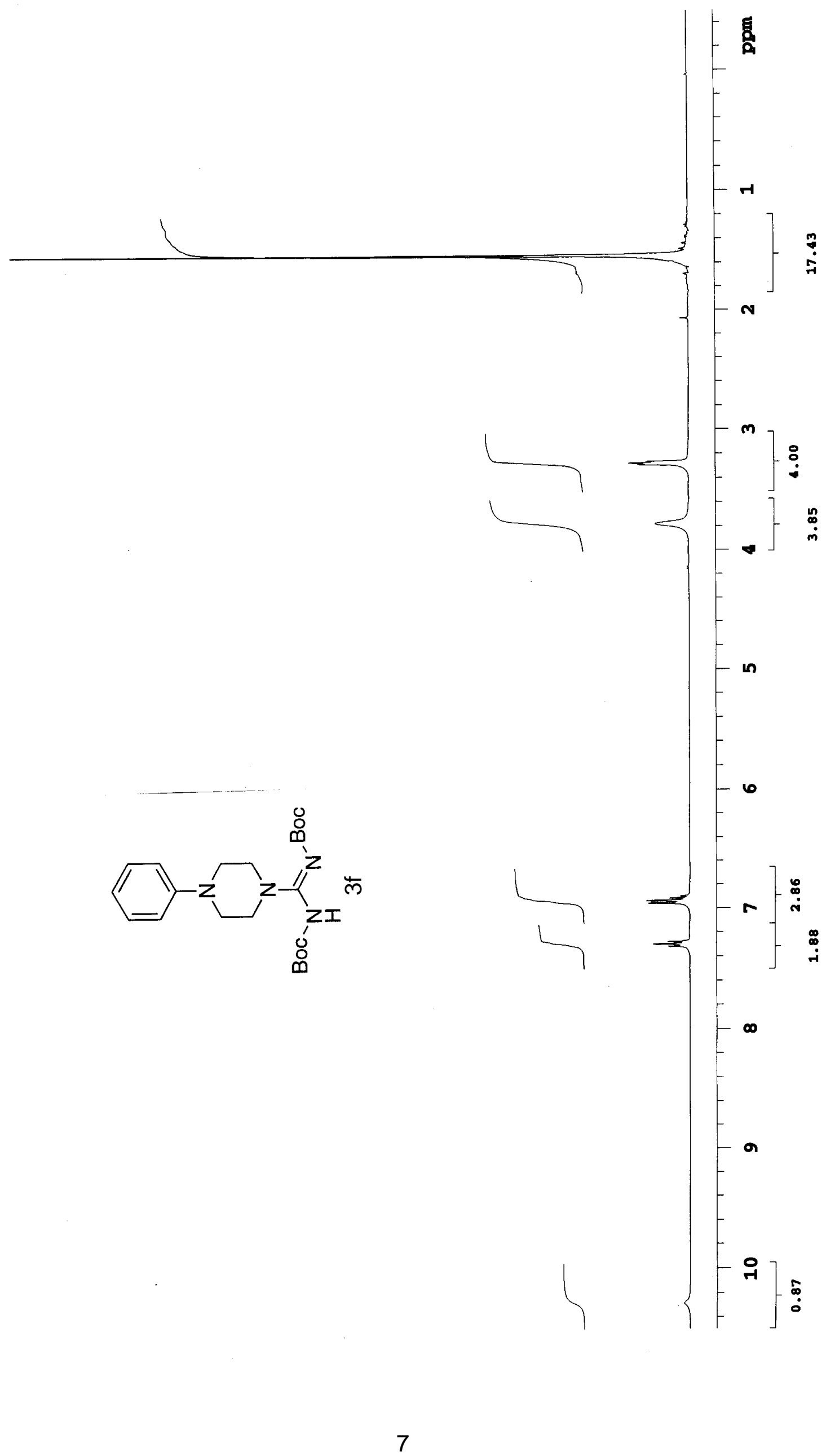




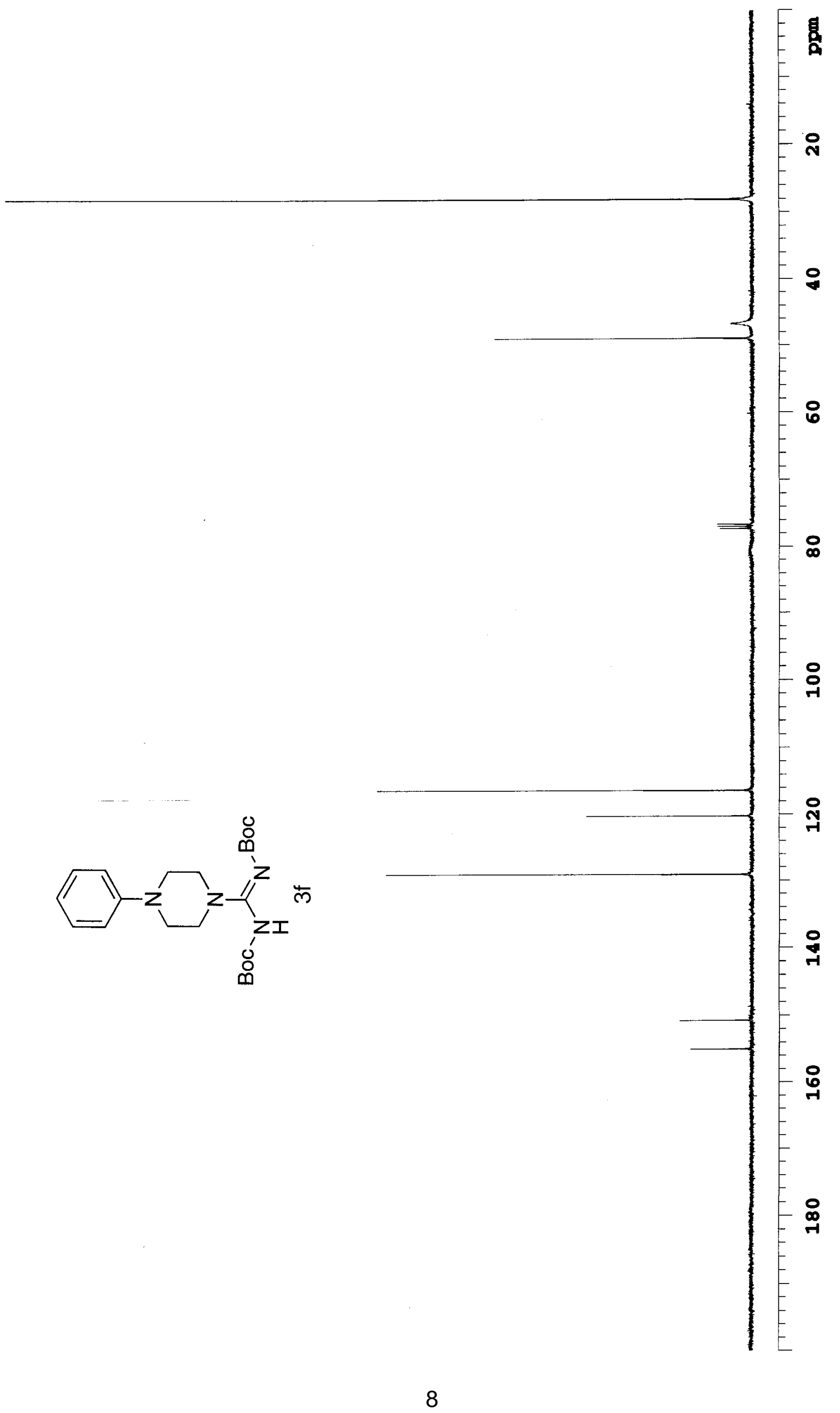




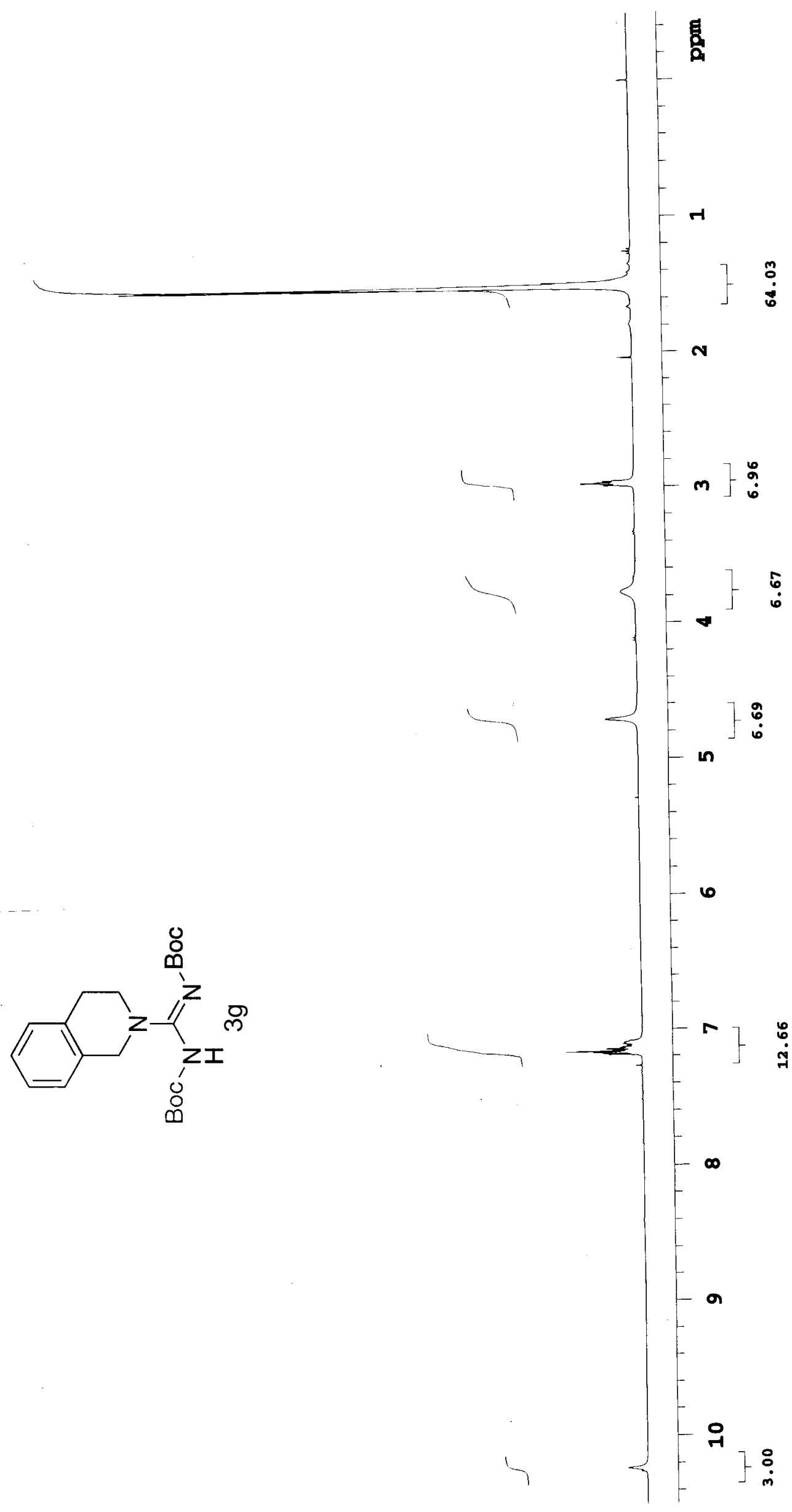




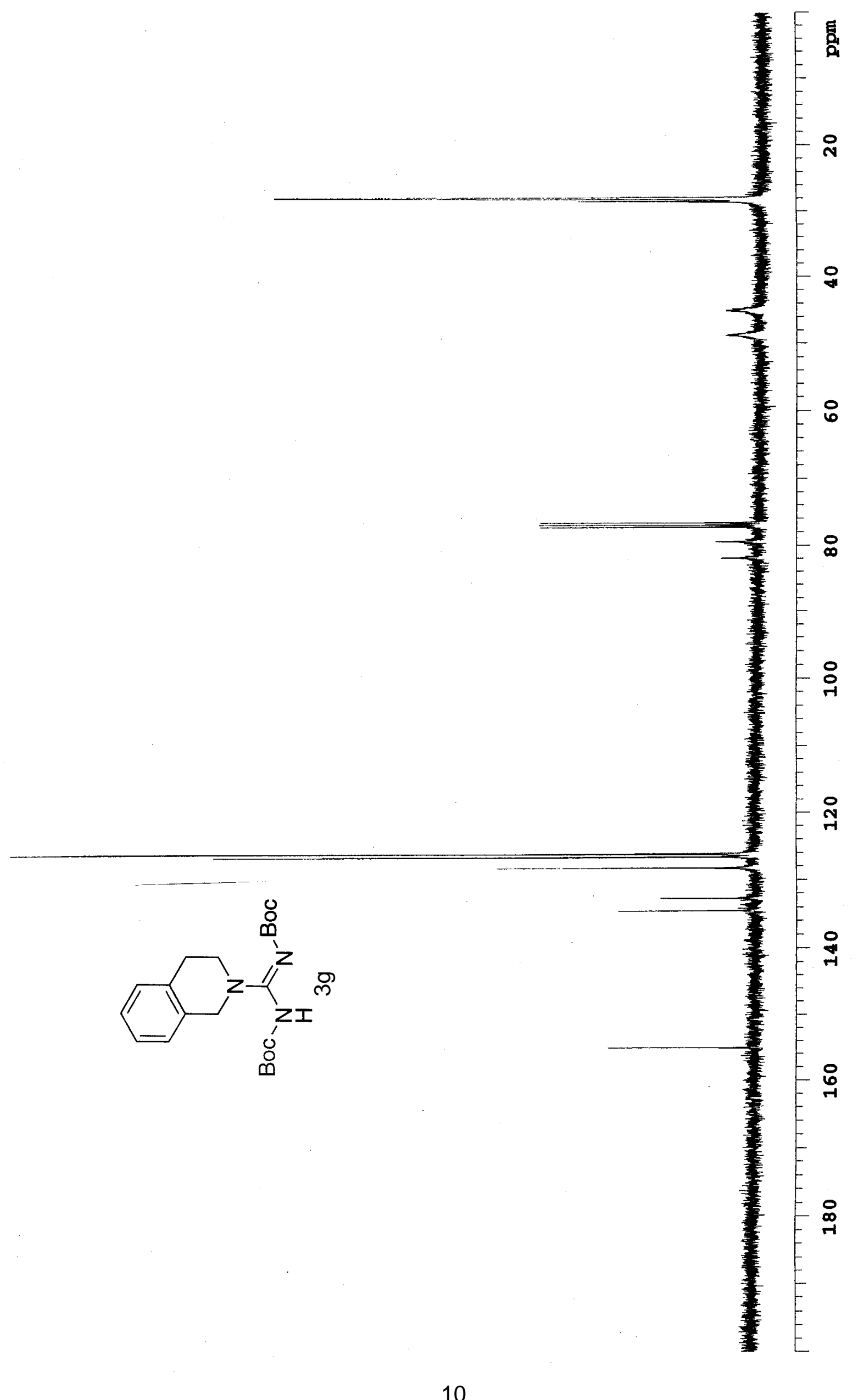




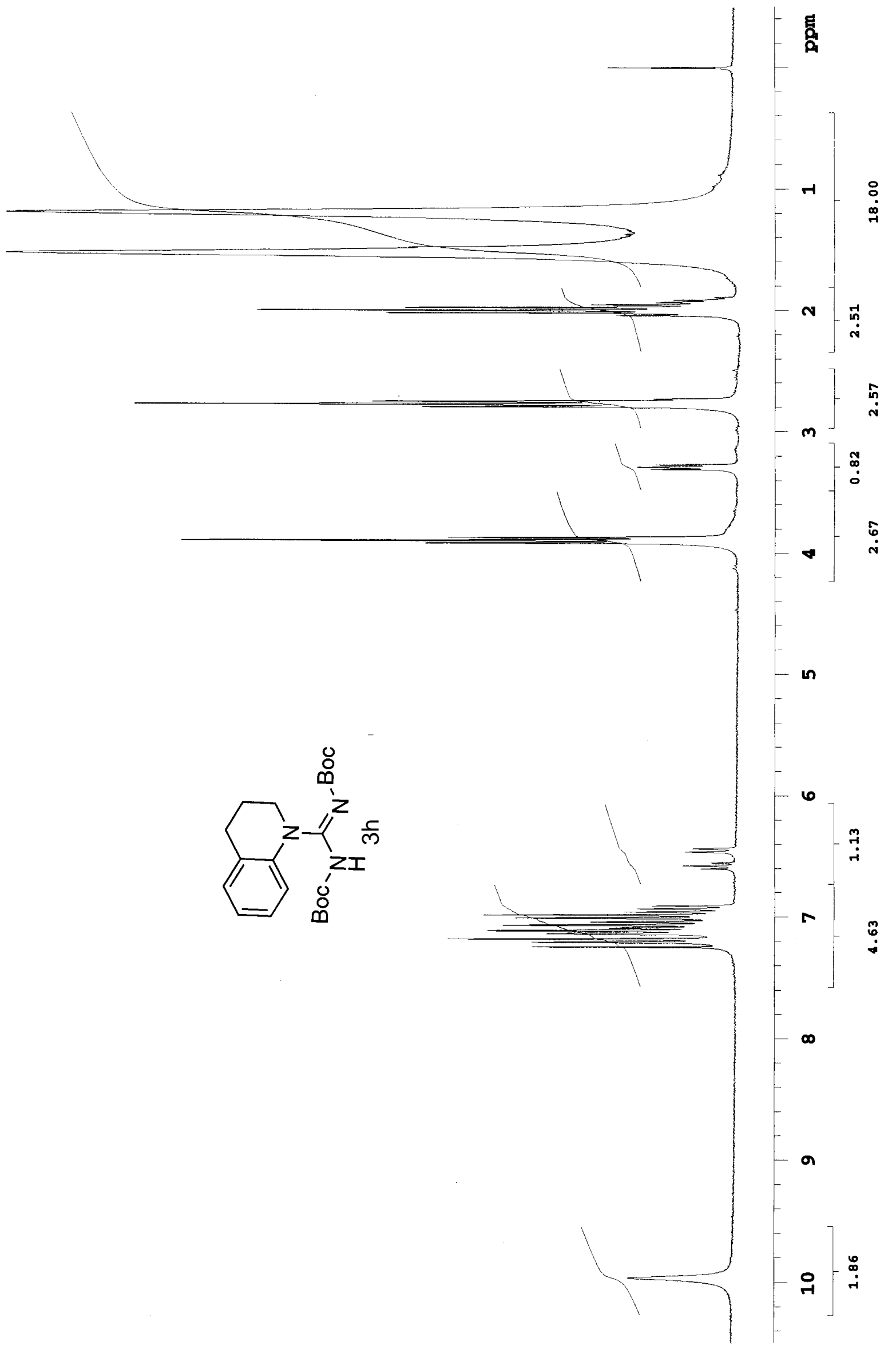




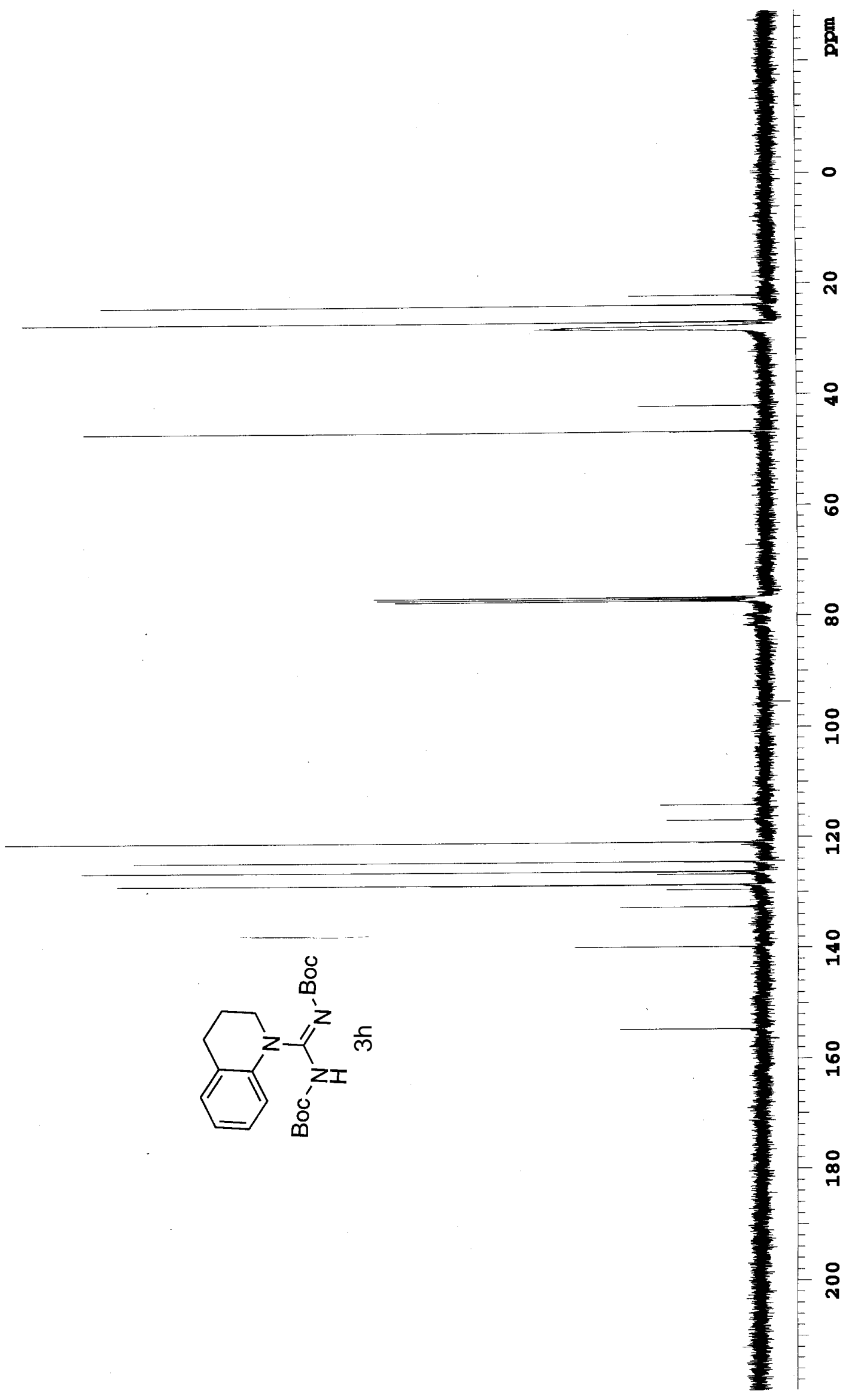




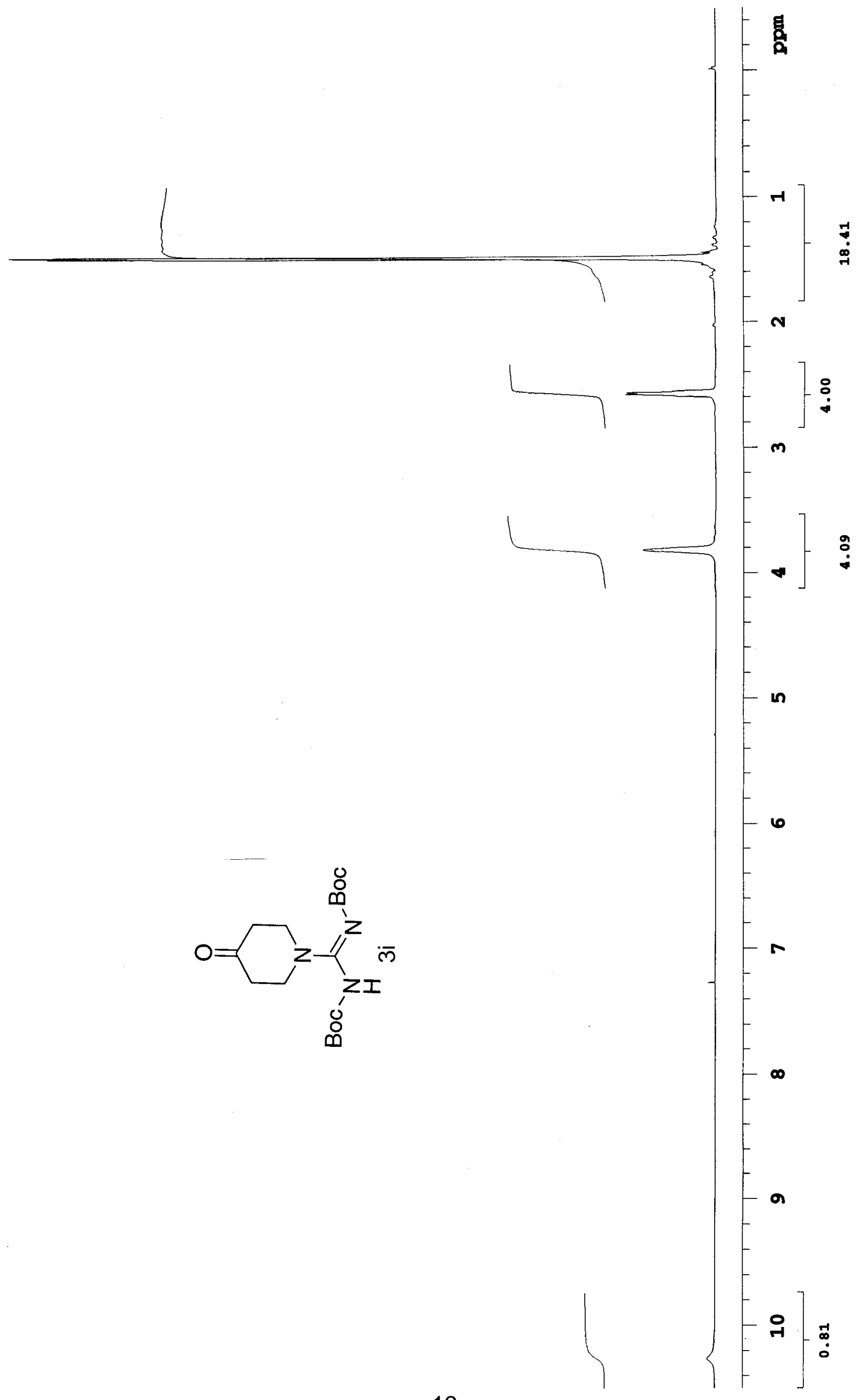




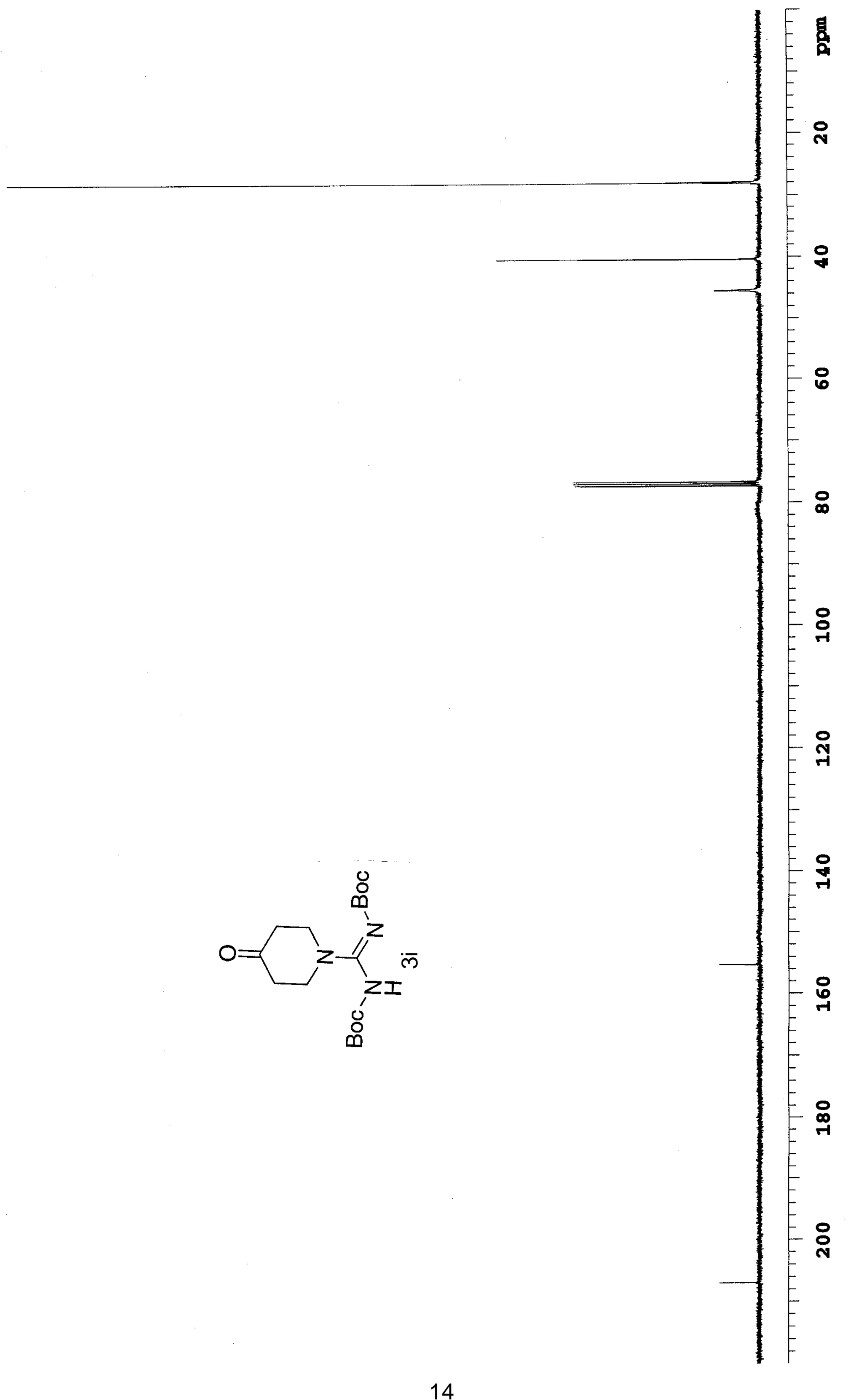




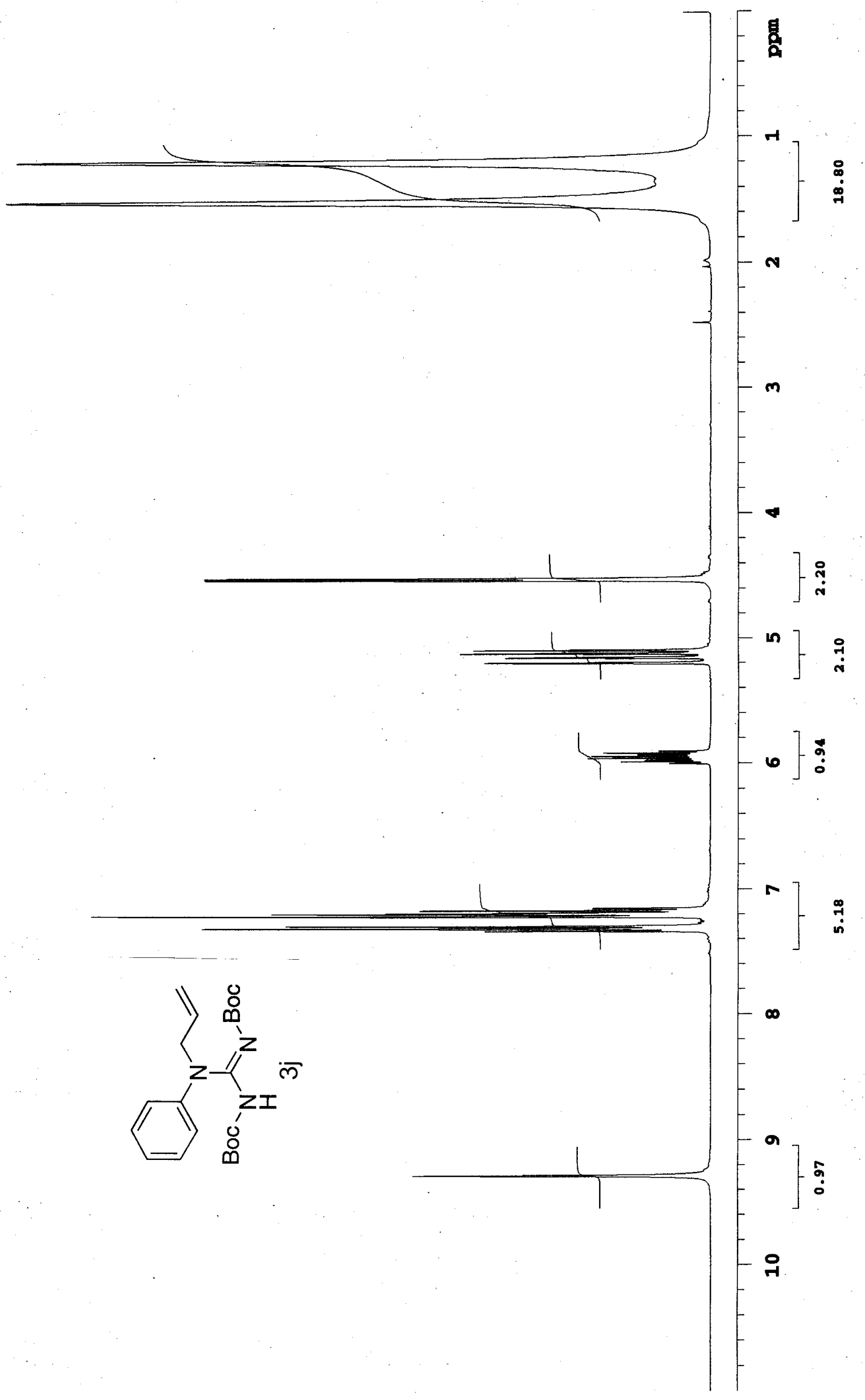




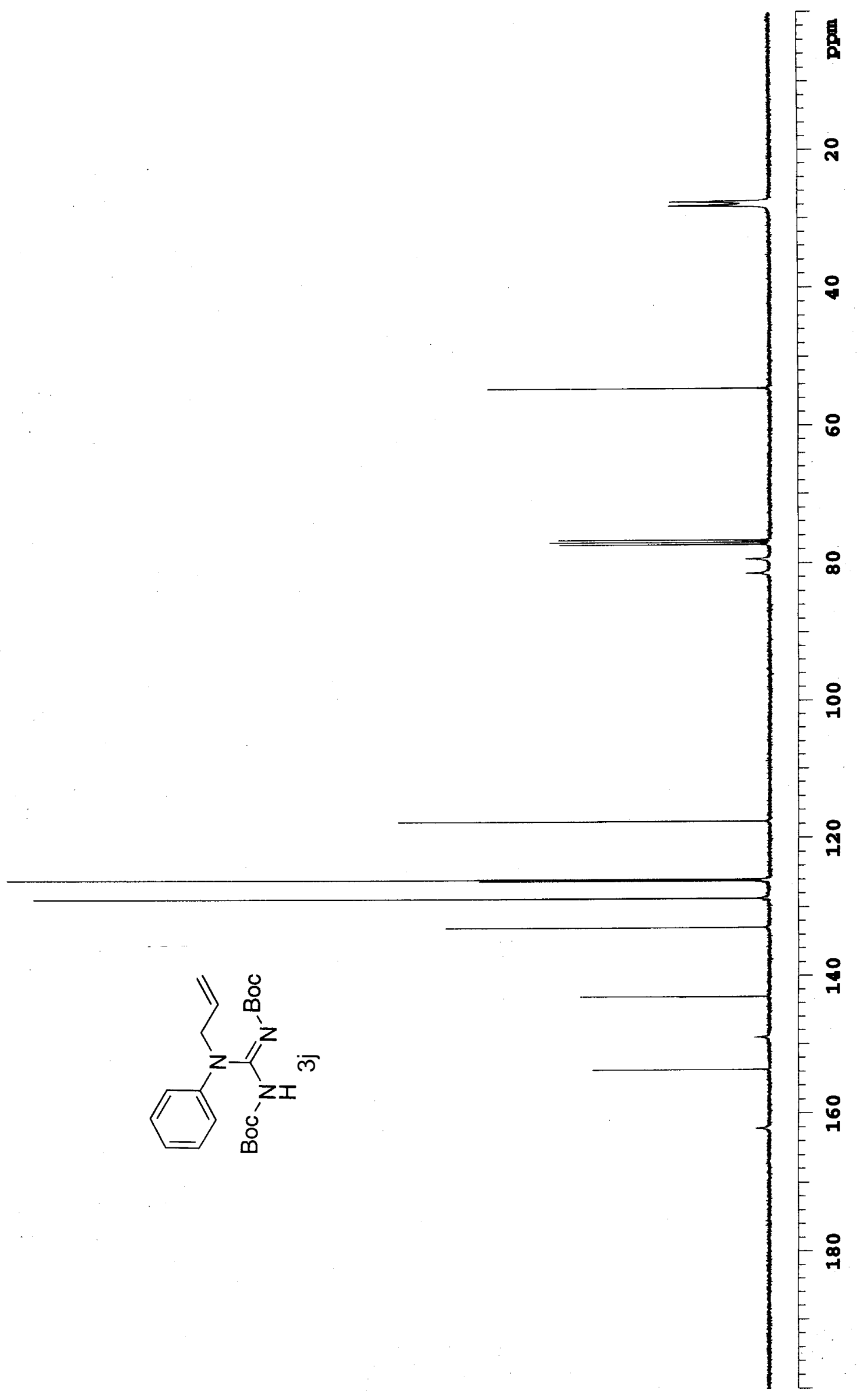




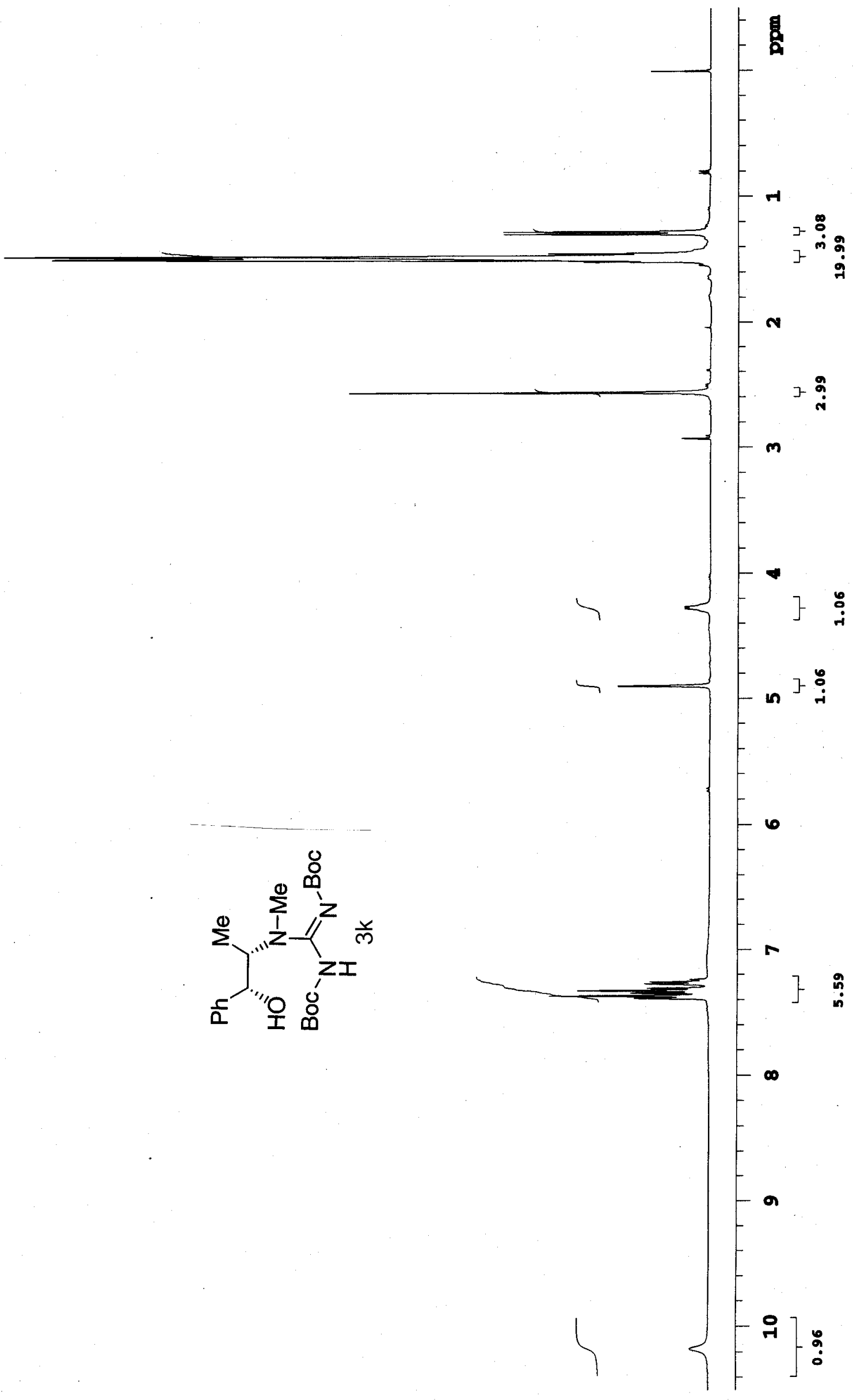




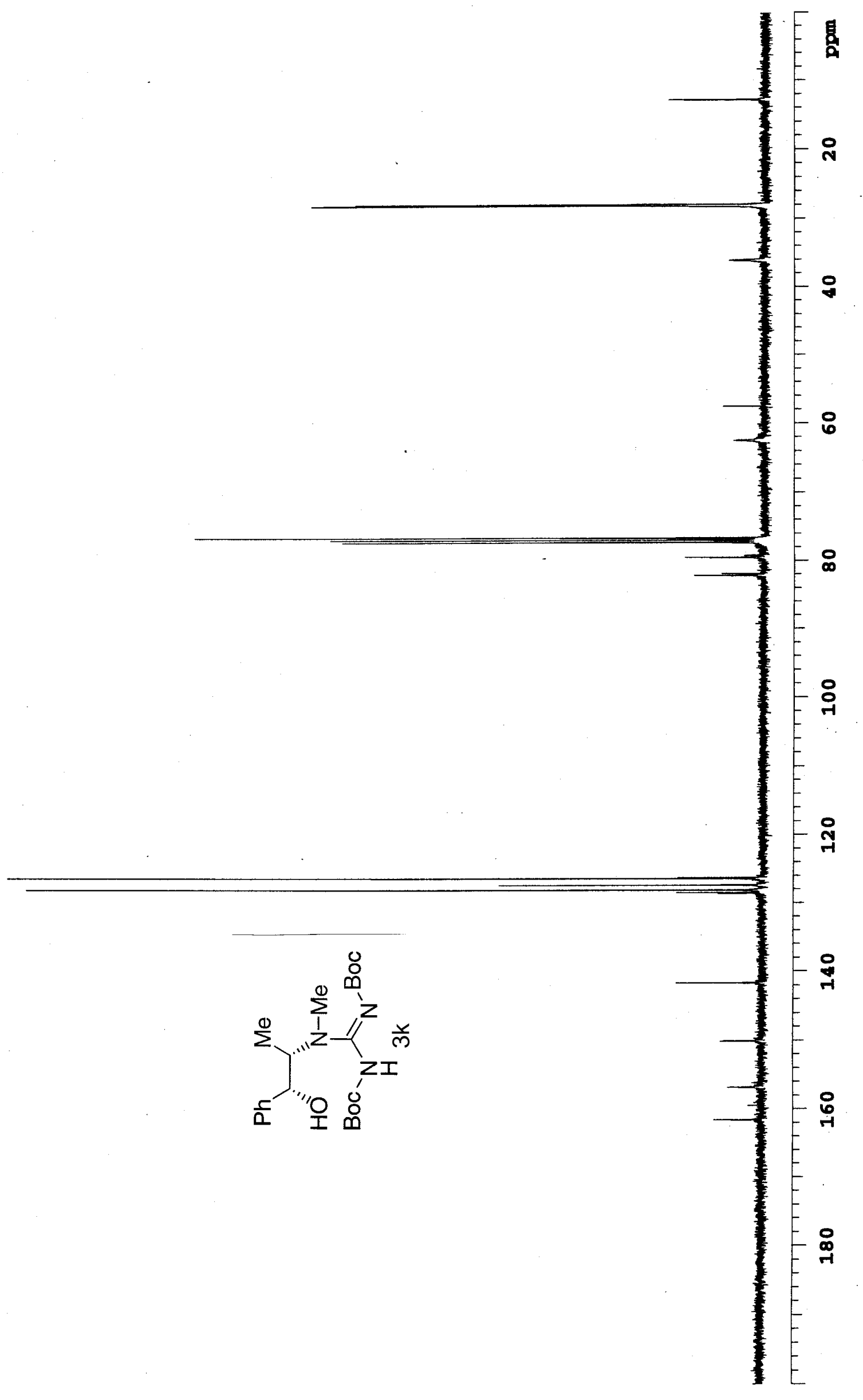




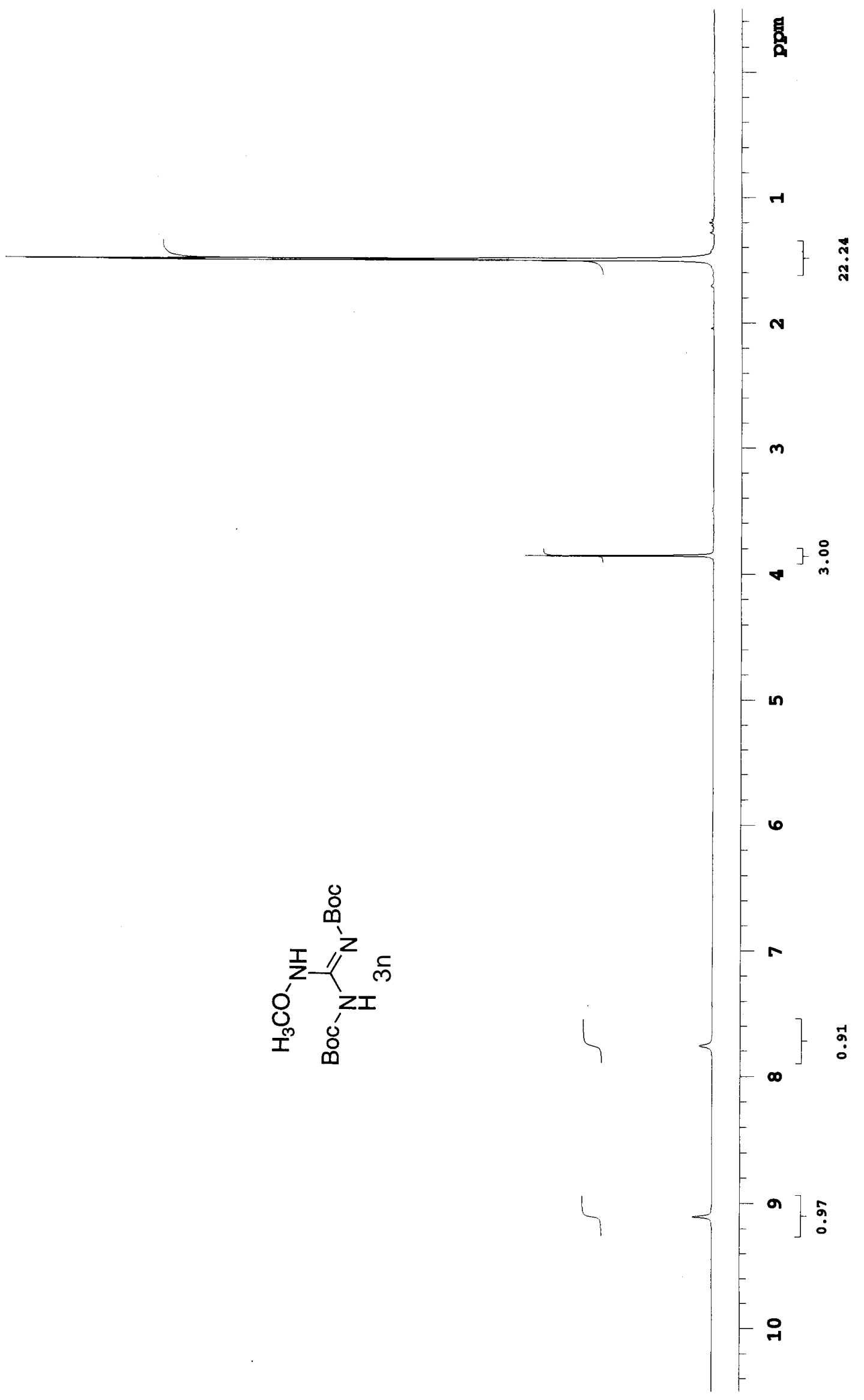




$$
.1
$$




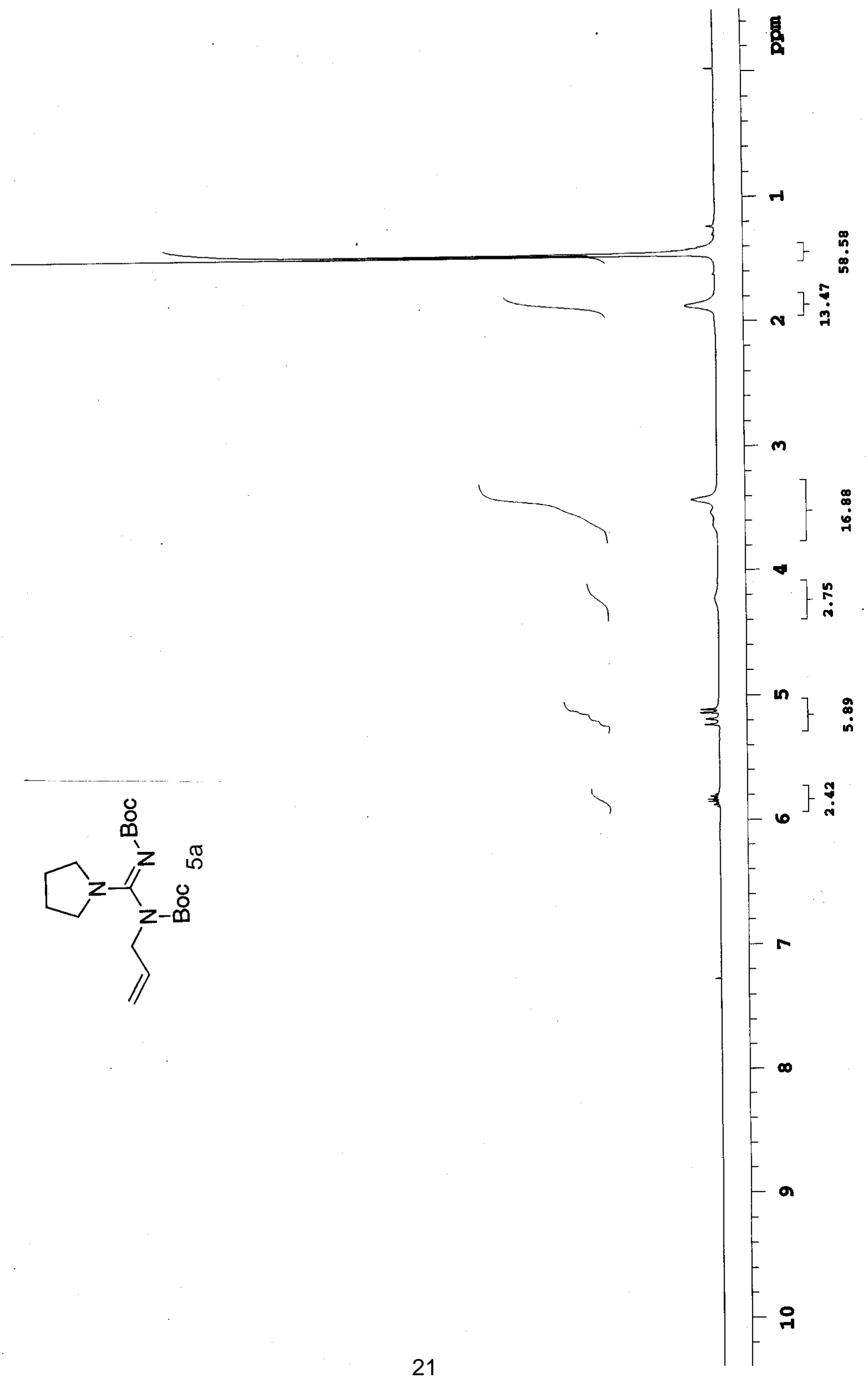




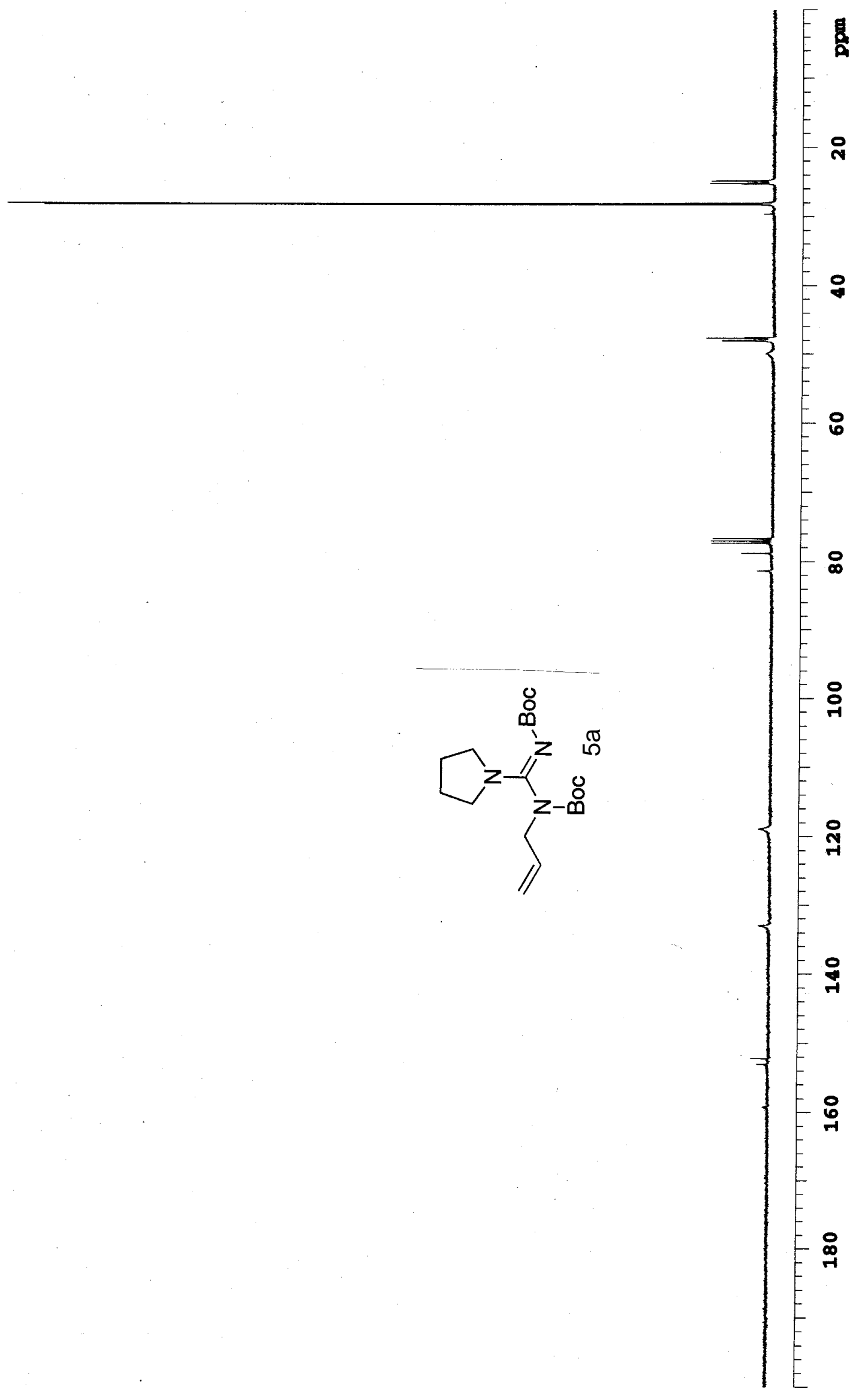




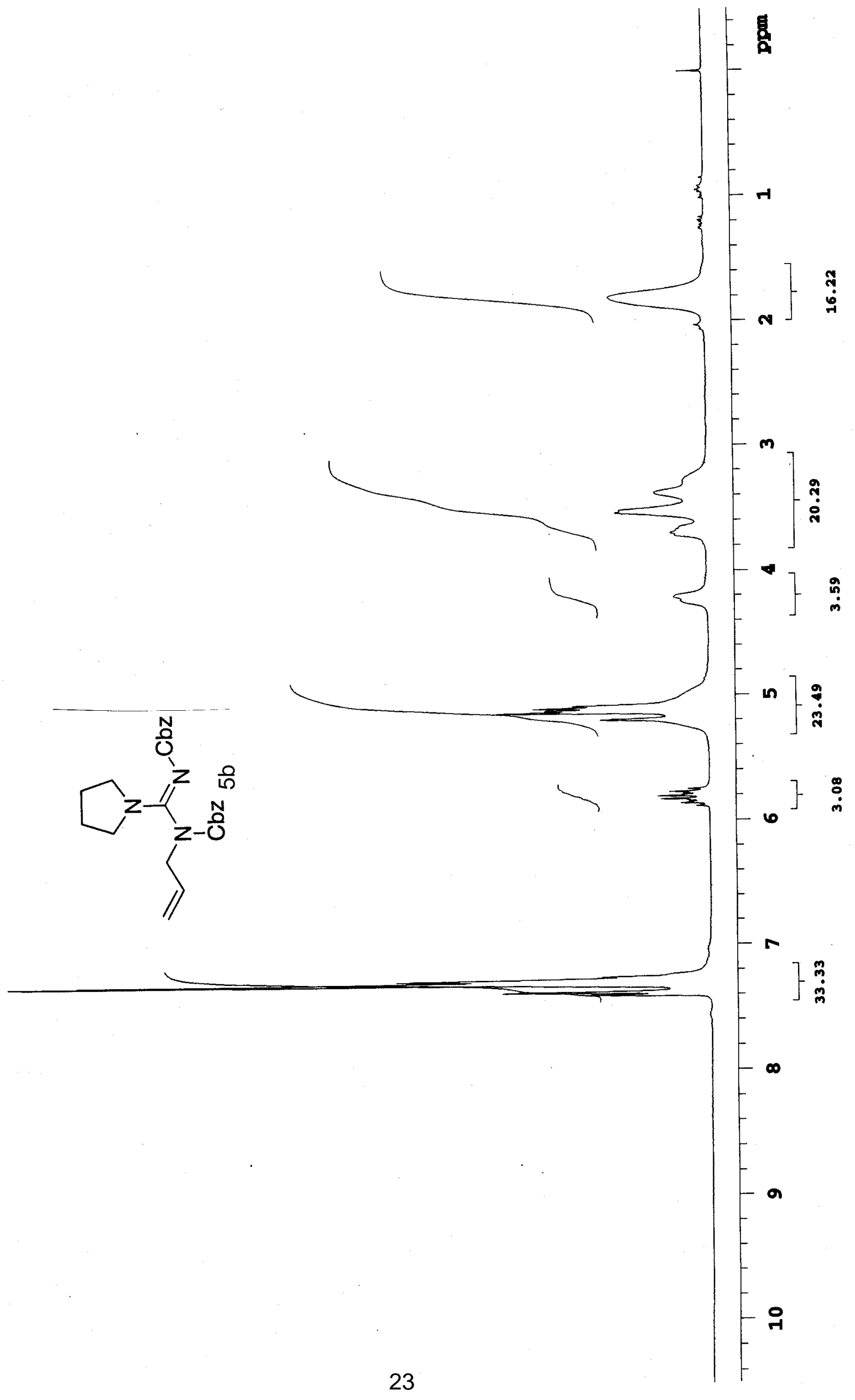




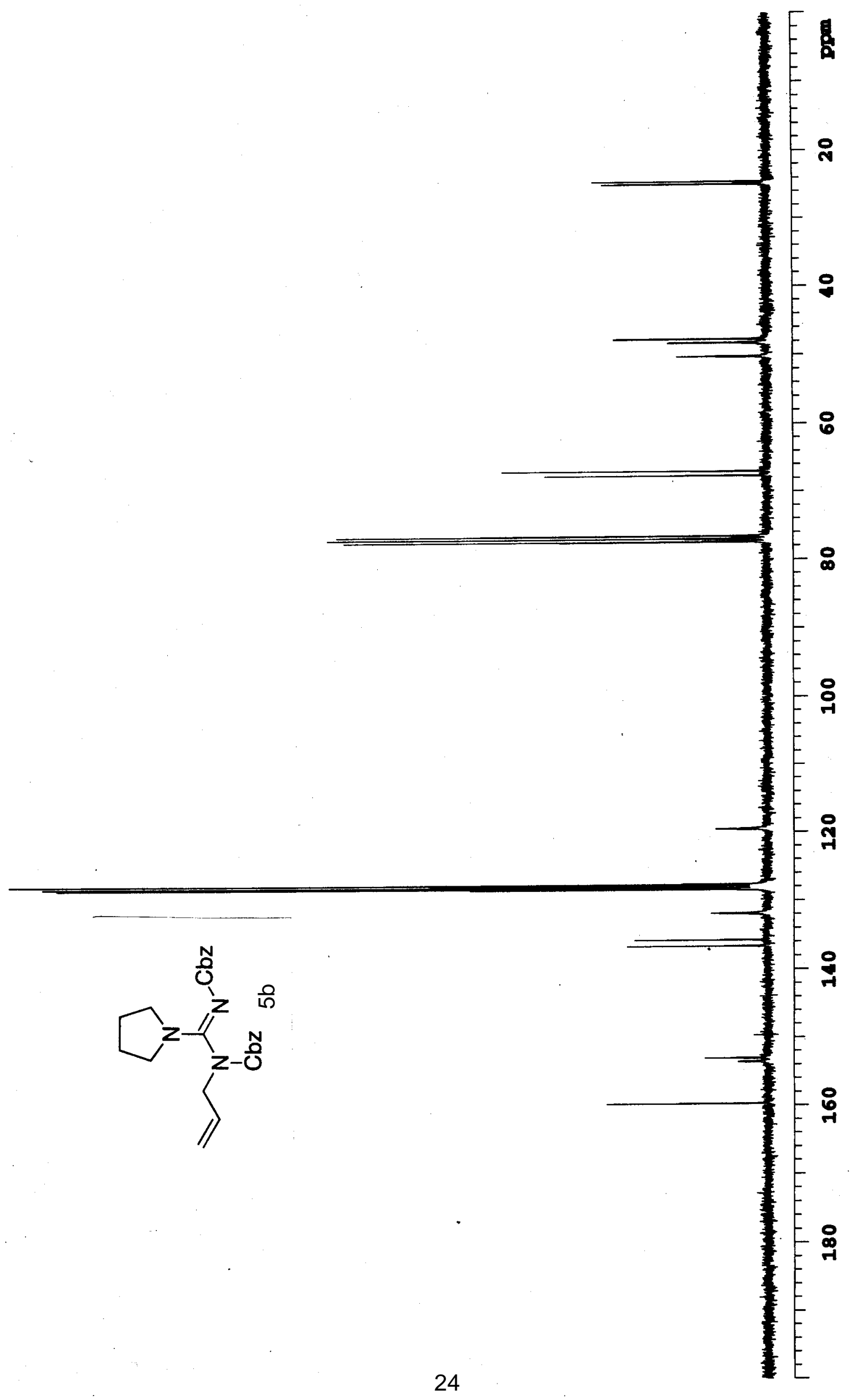




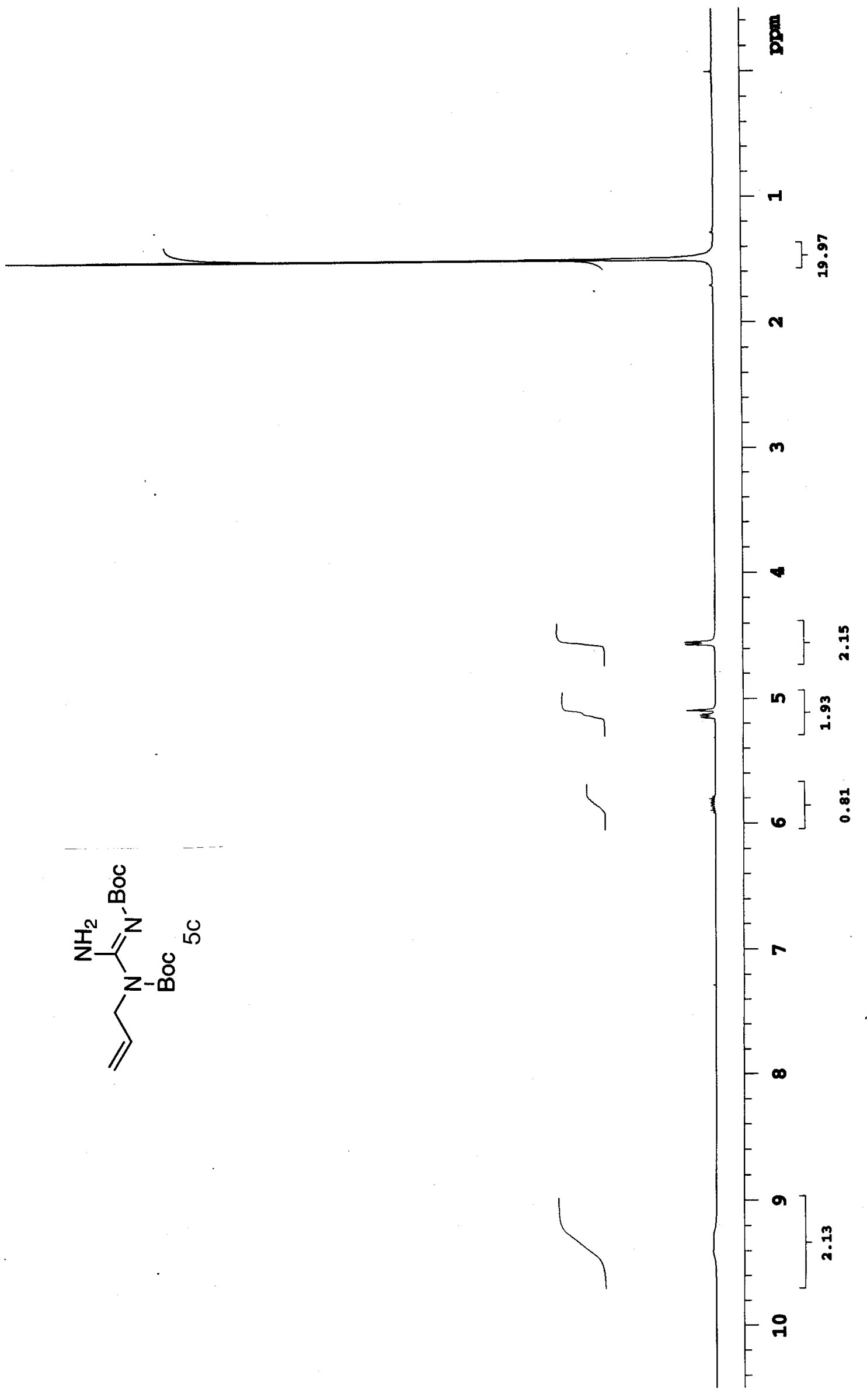




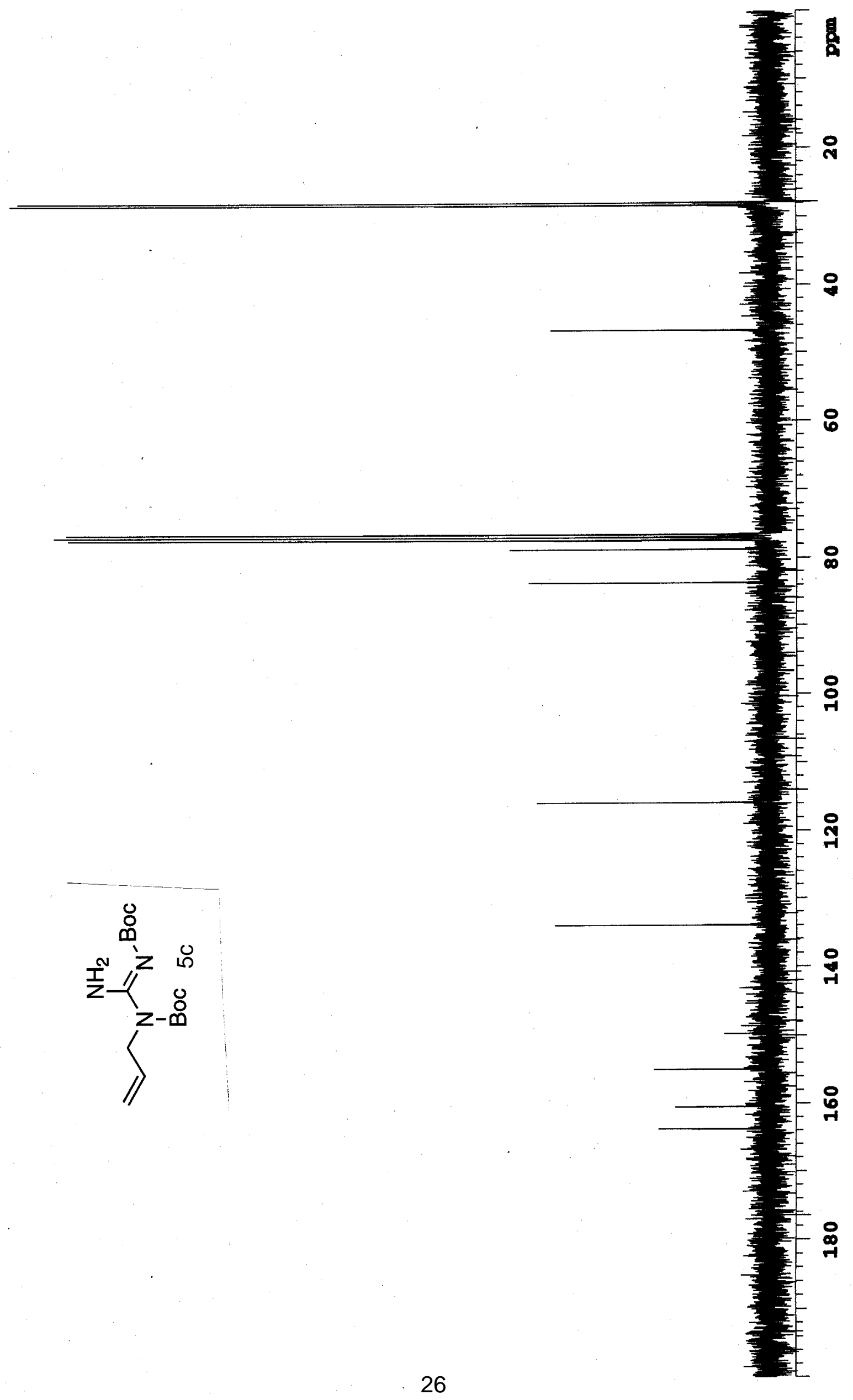




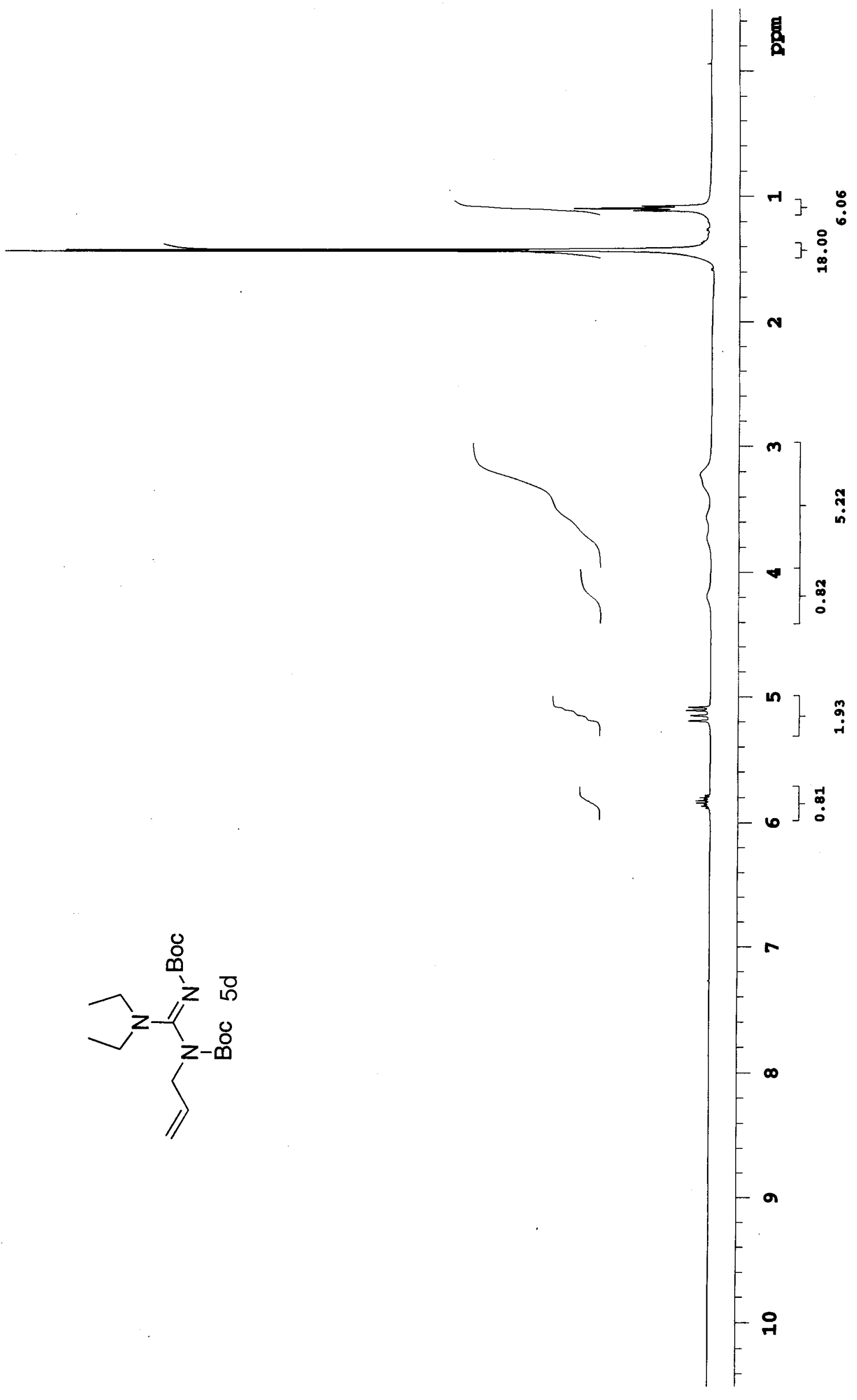




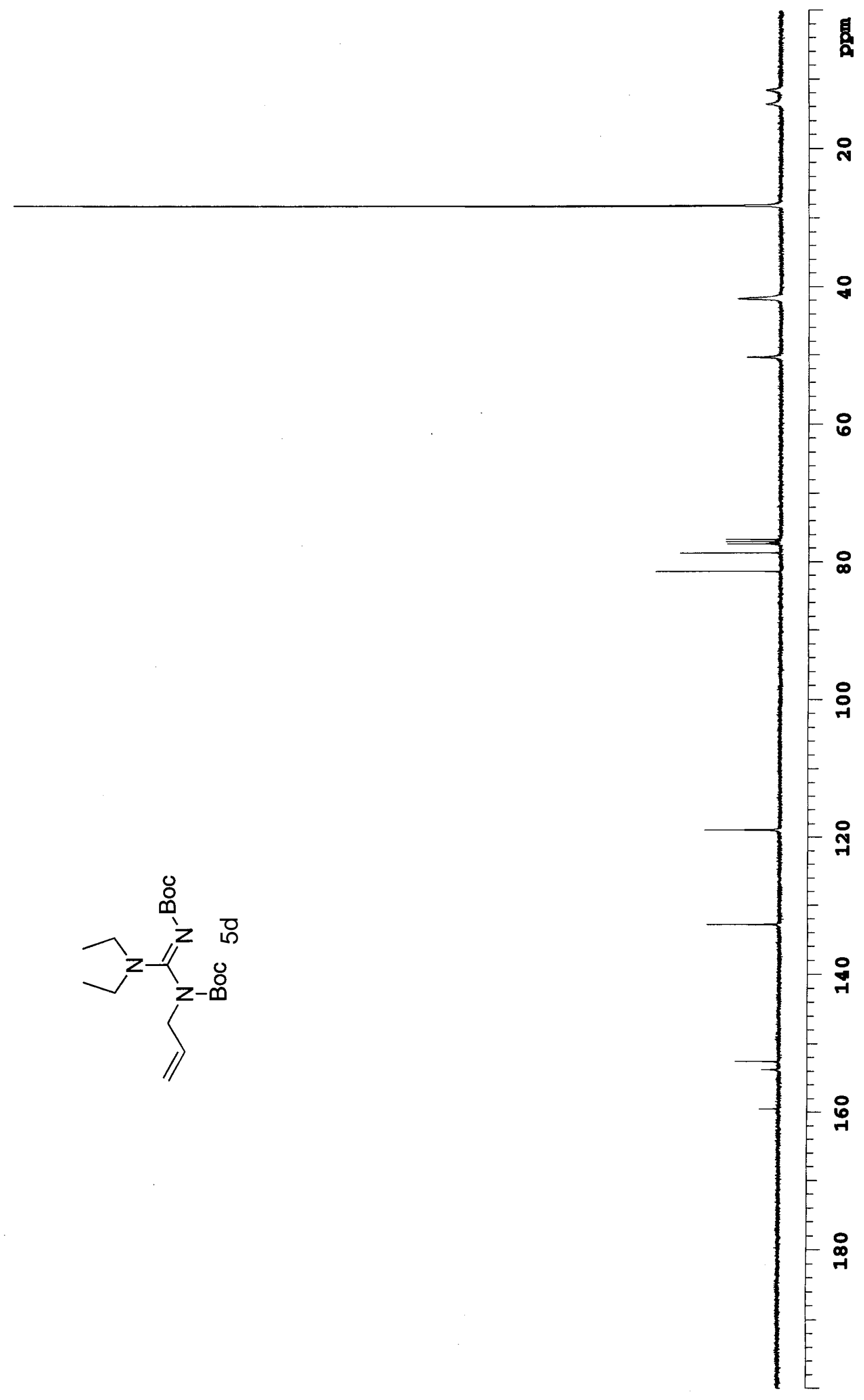




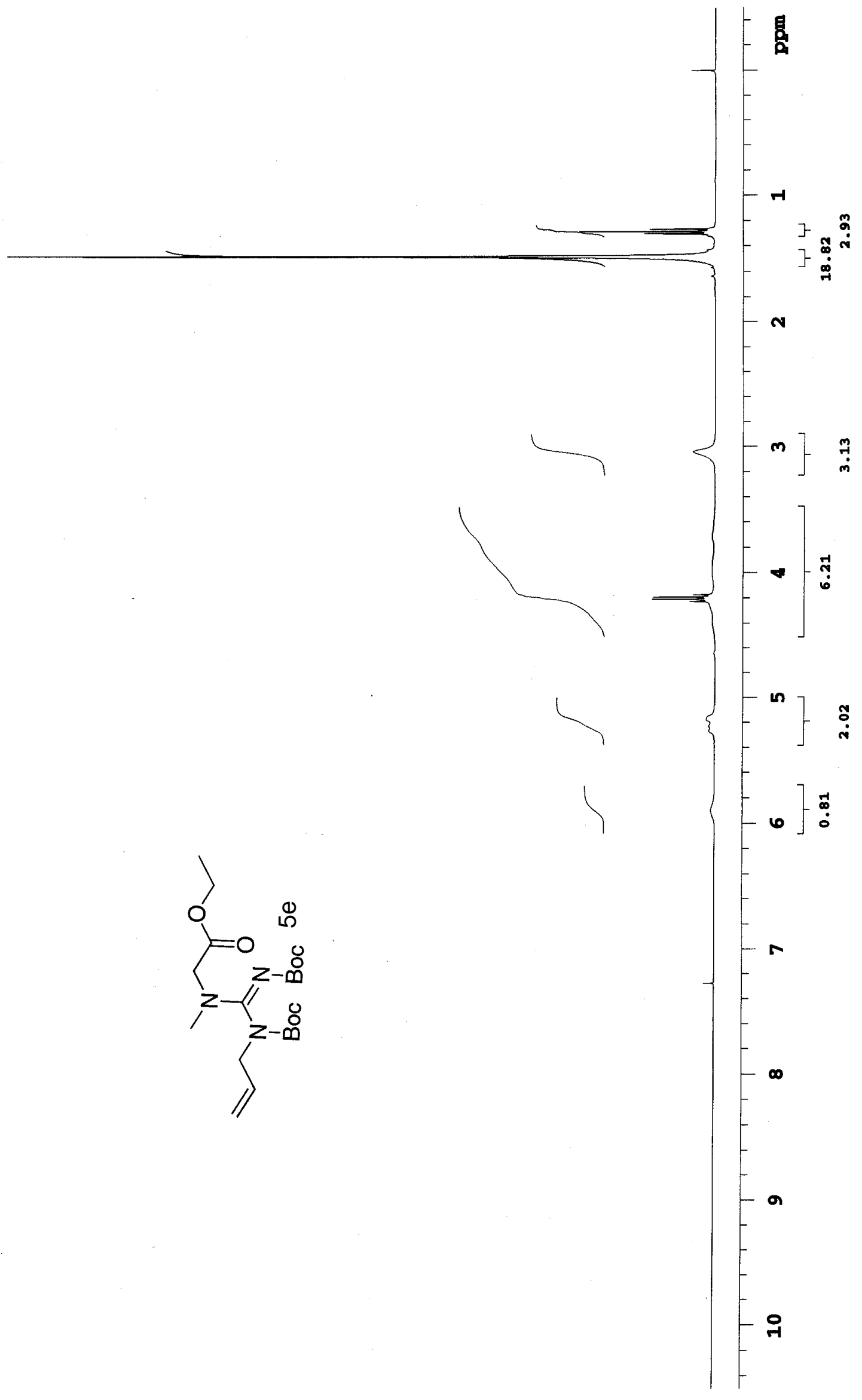




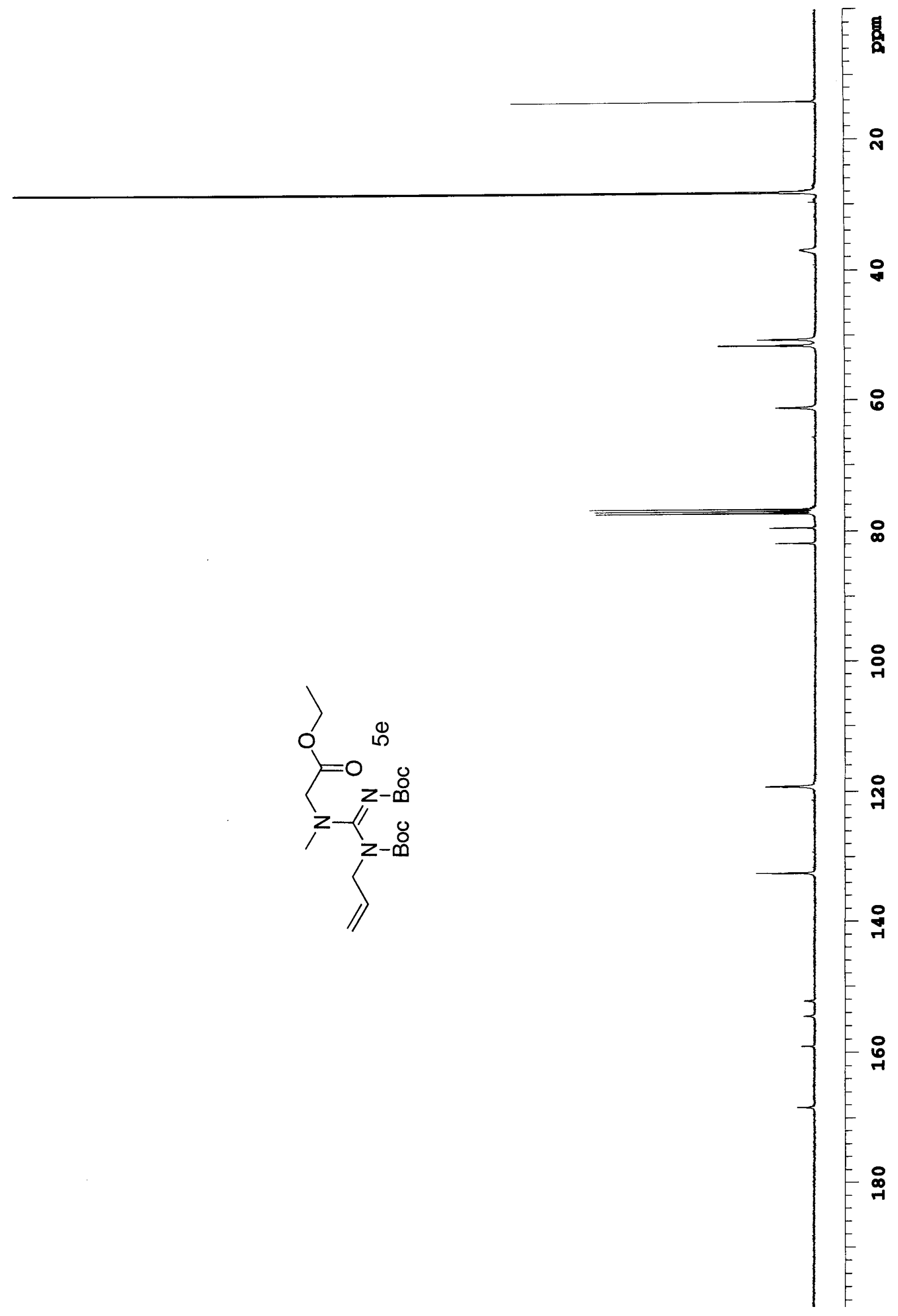




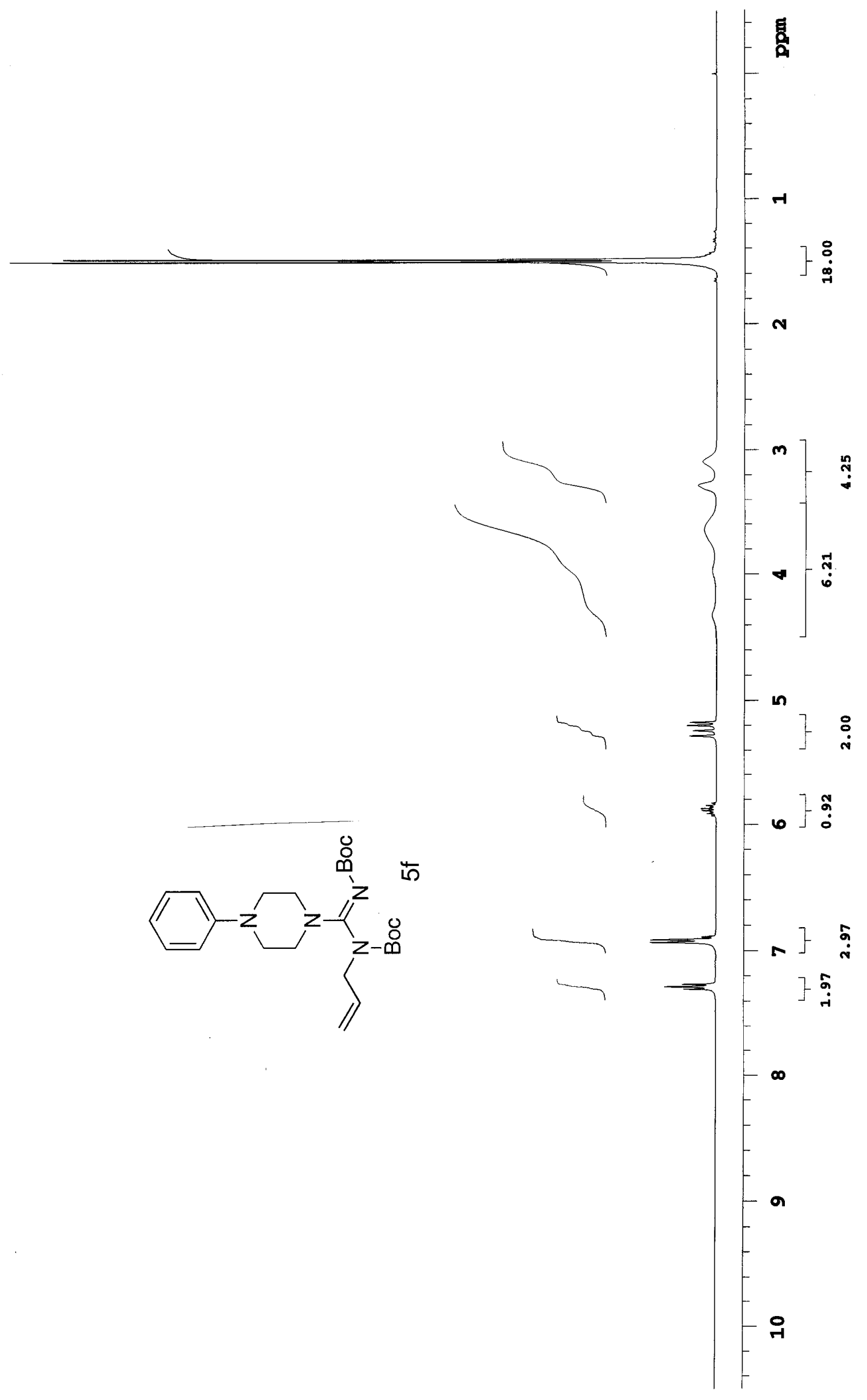




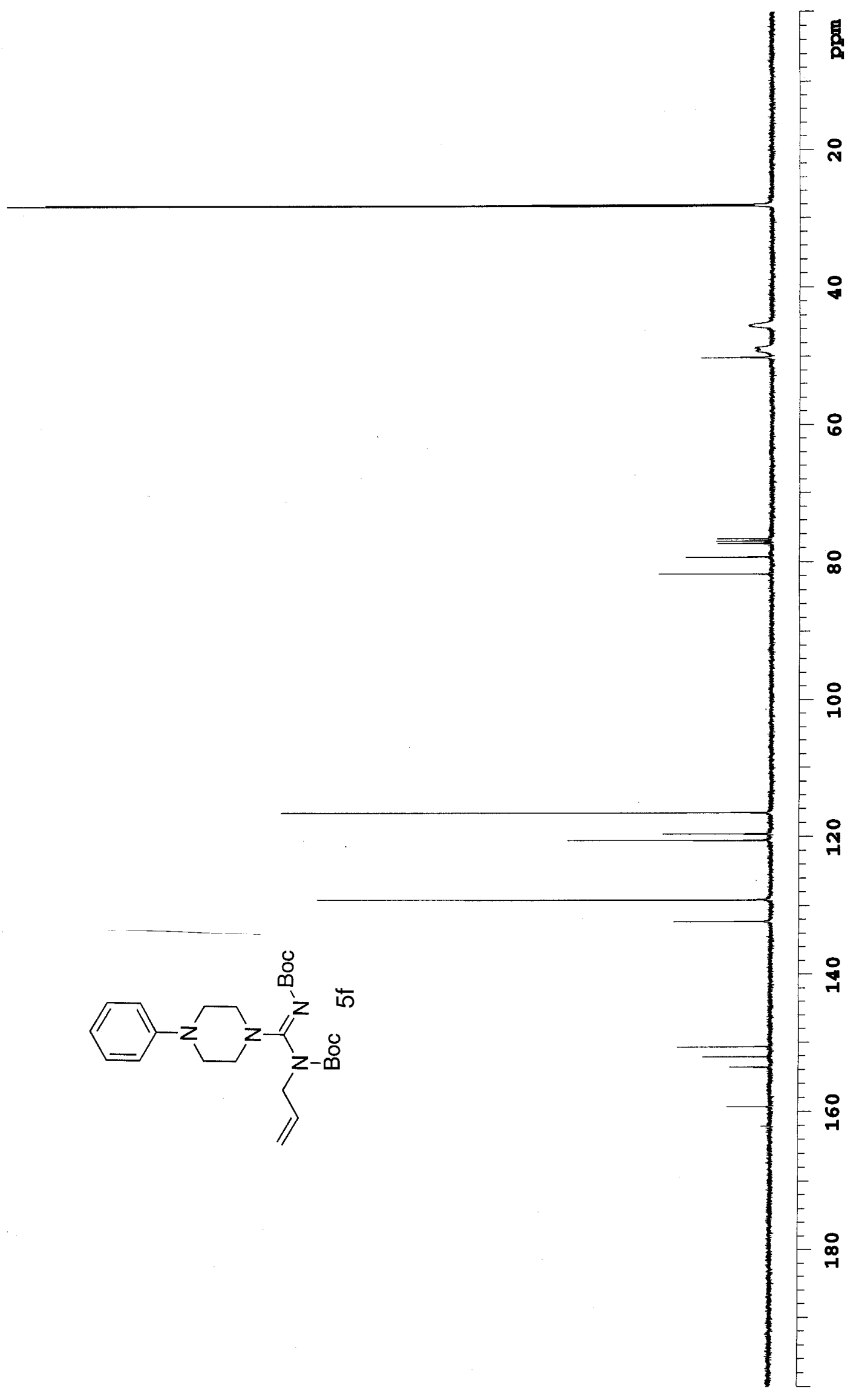




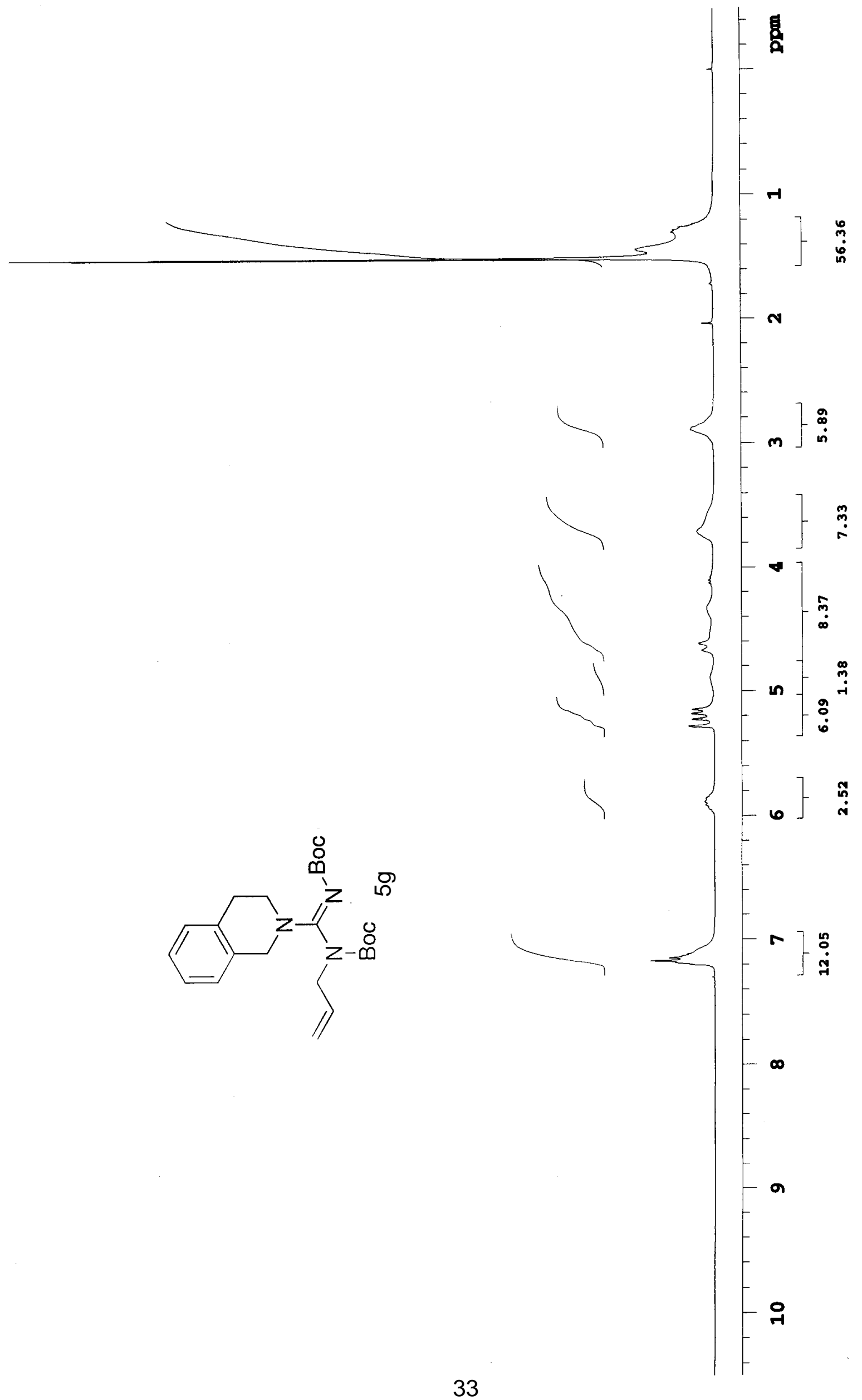




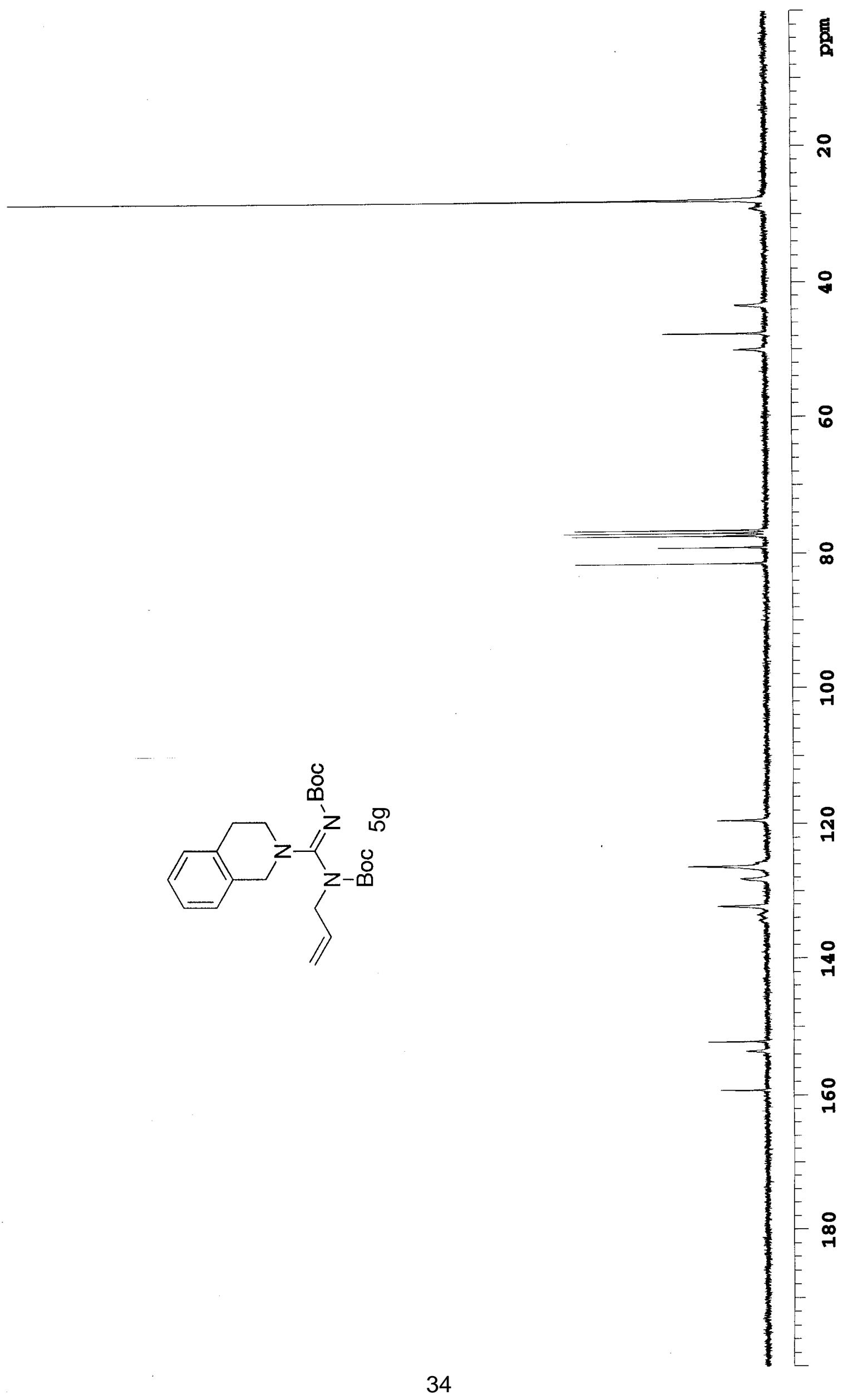




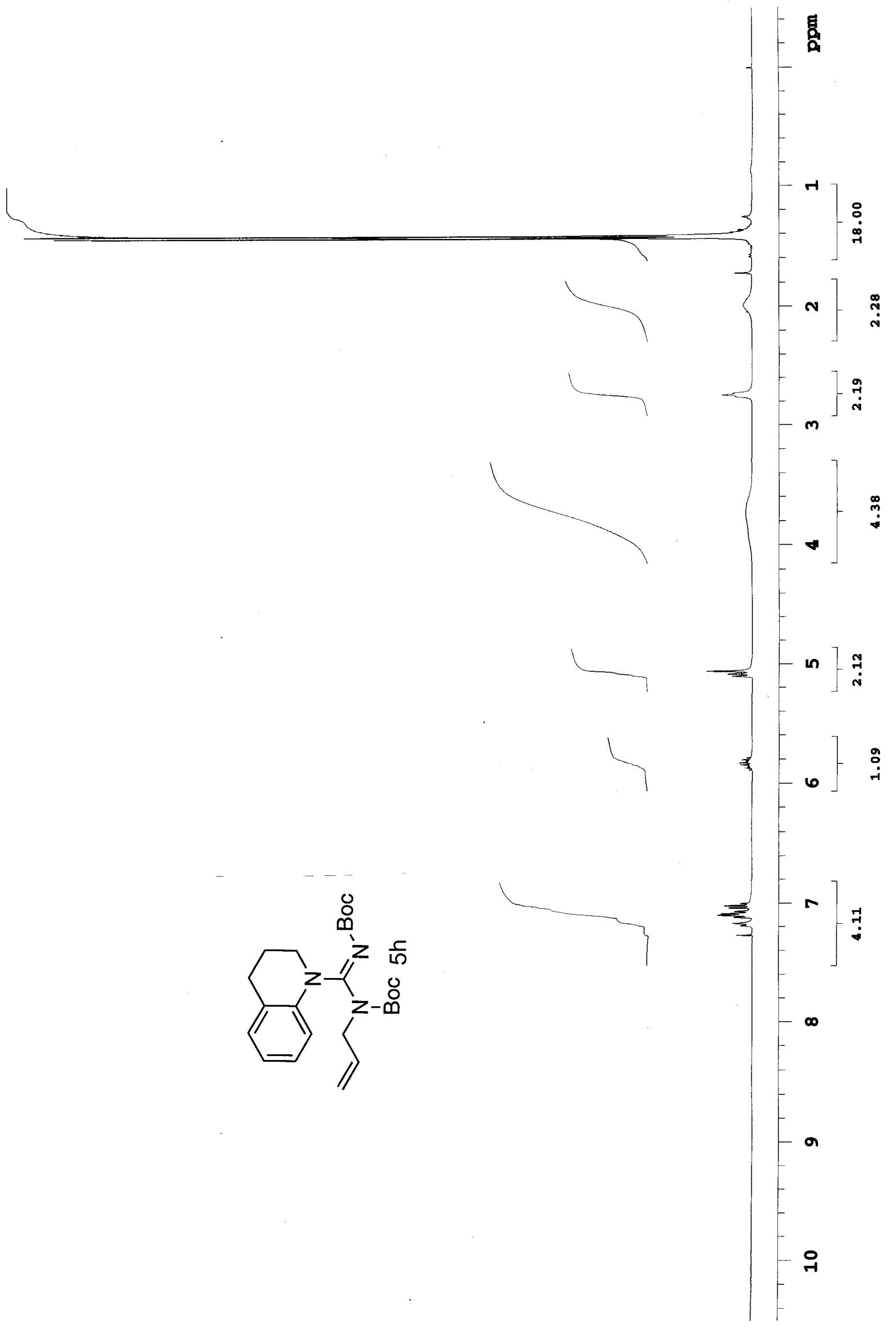




$$
1
$$




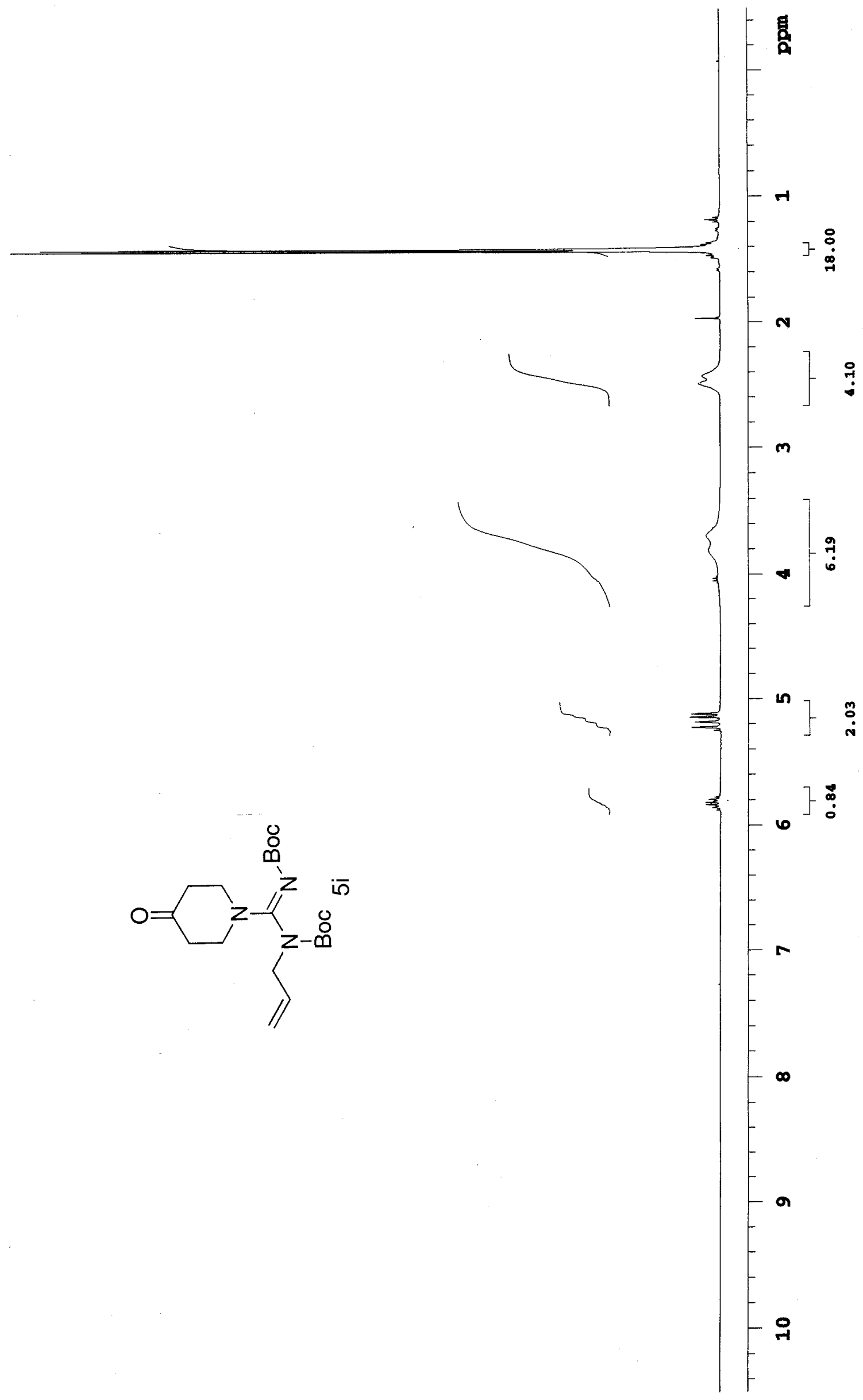




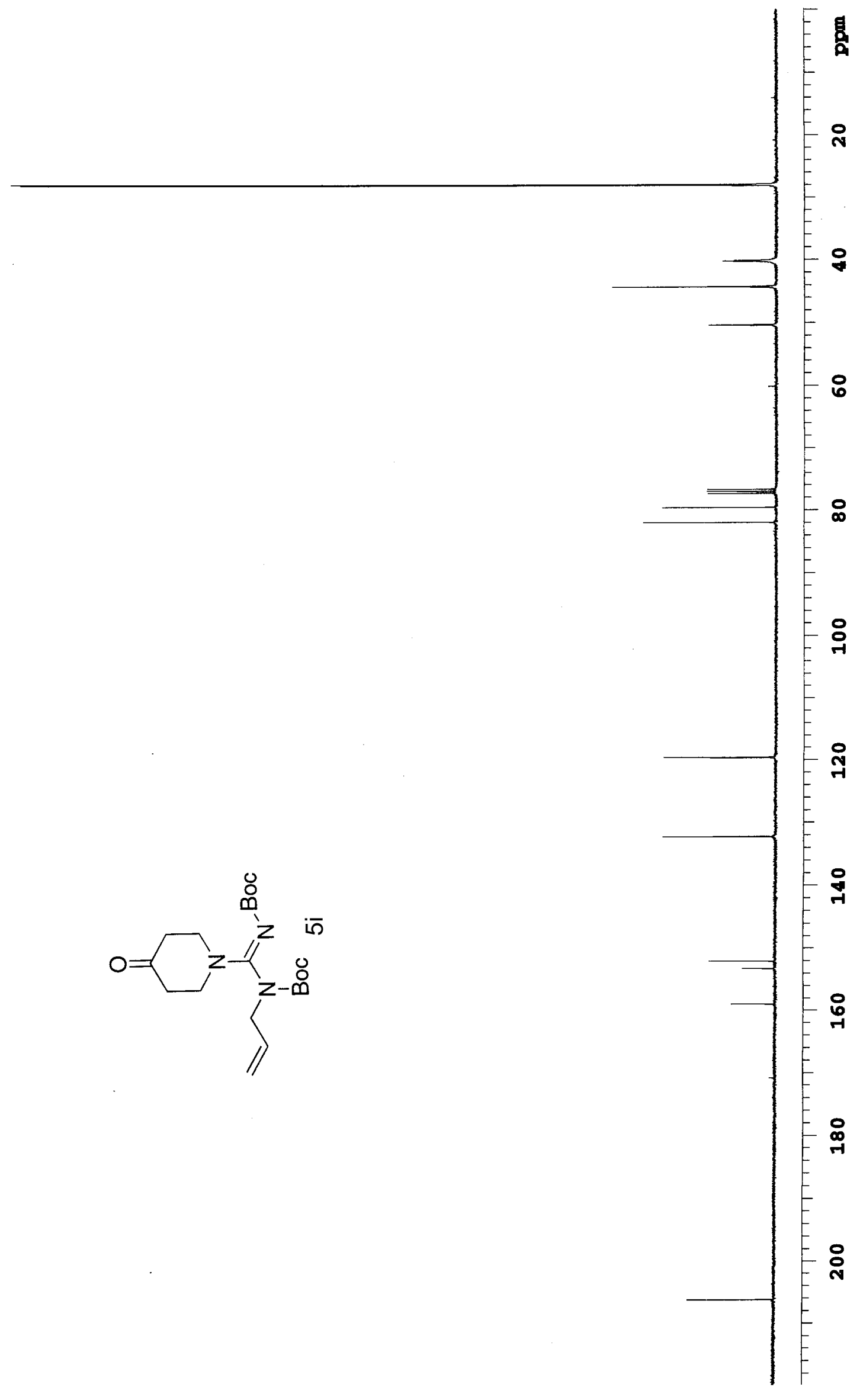




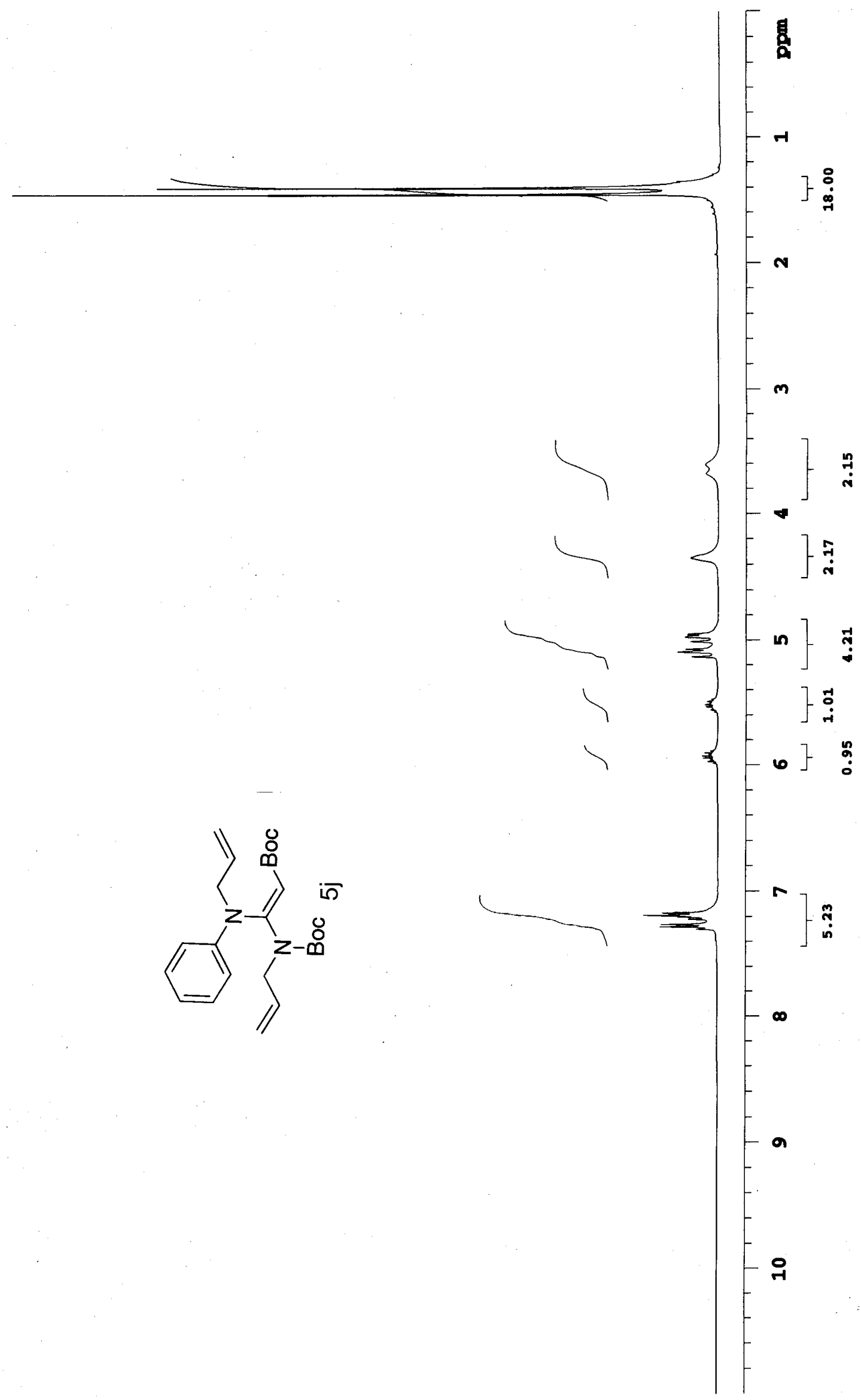




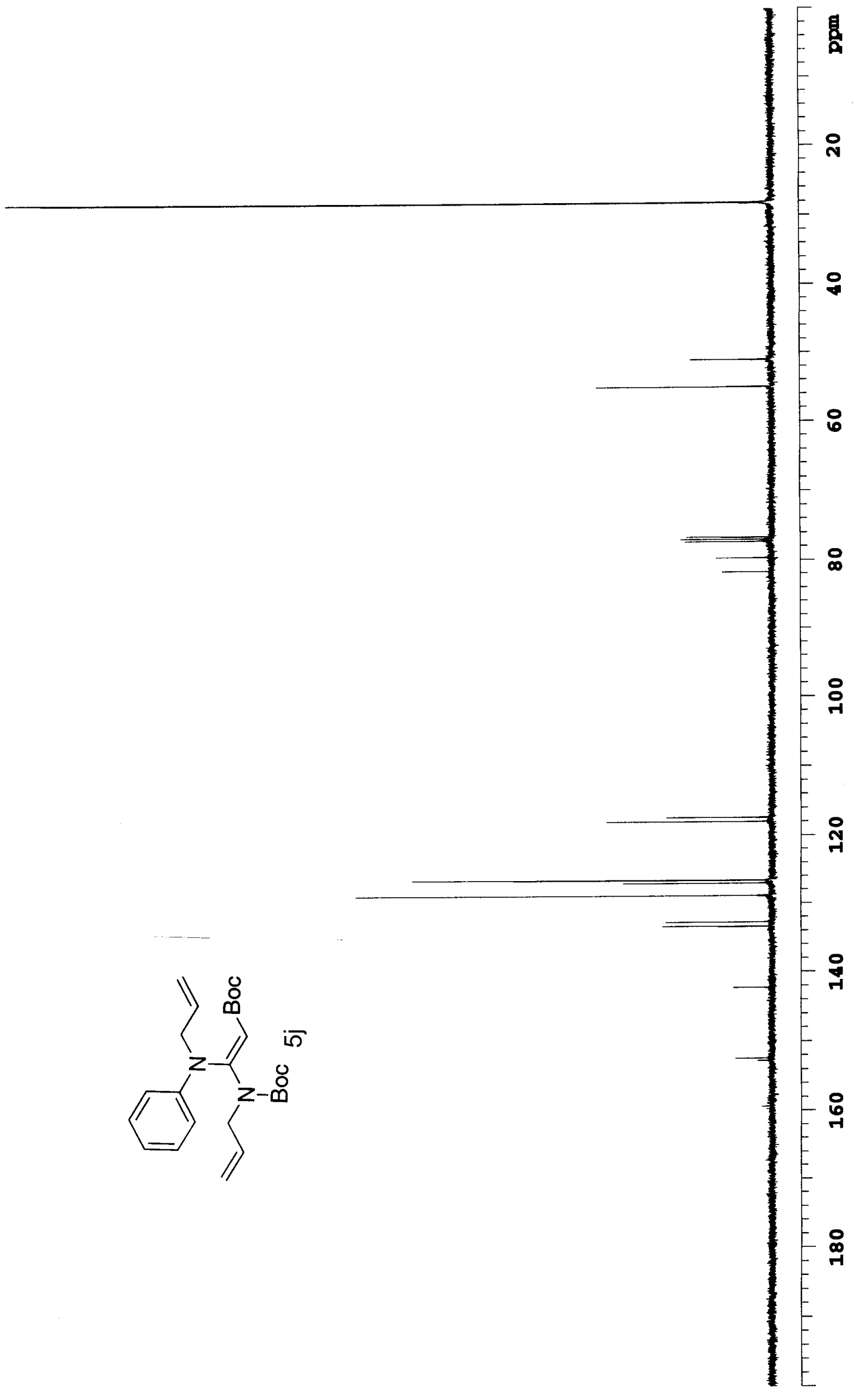




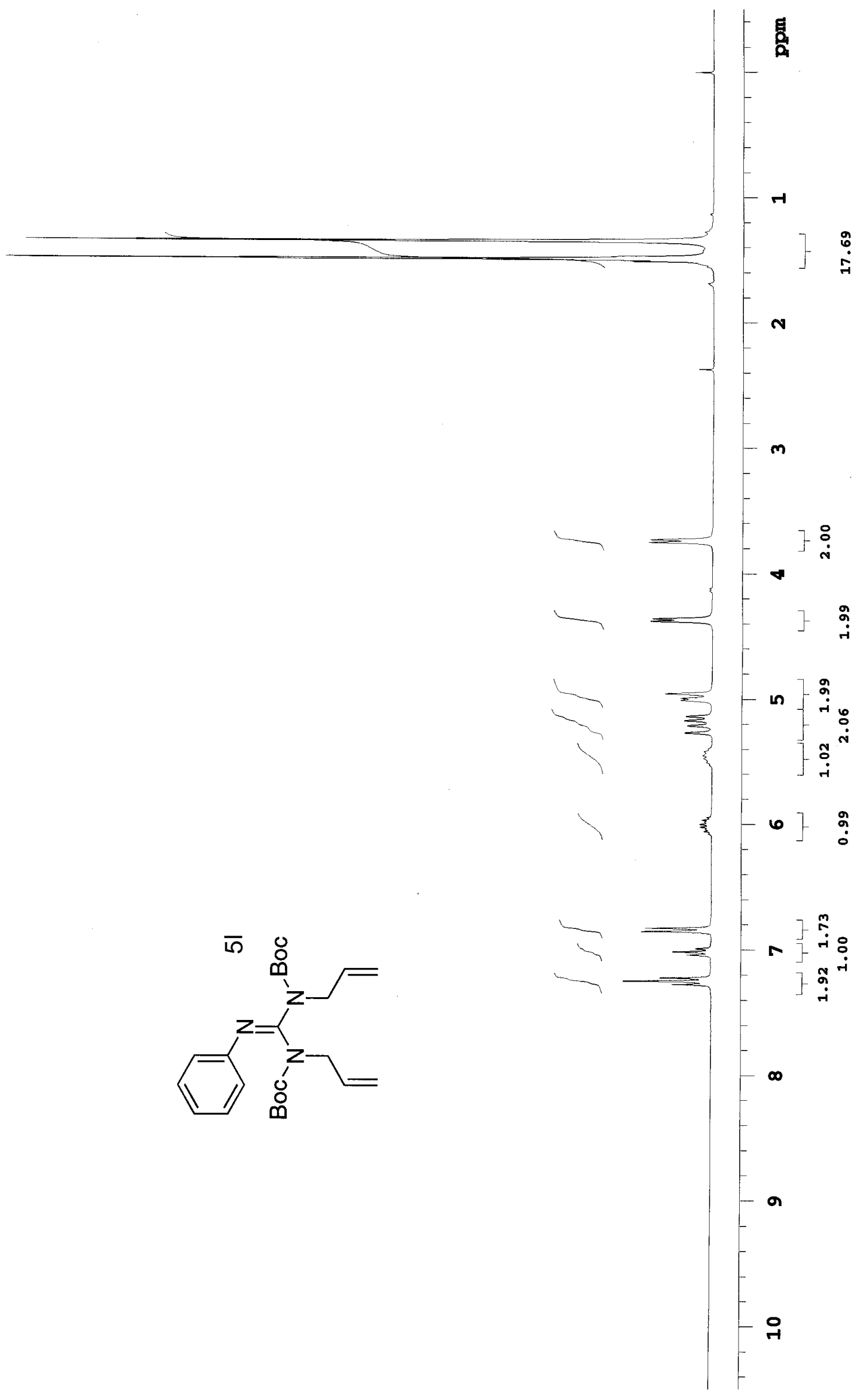




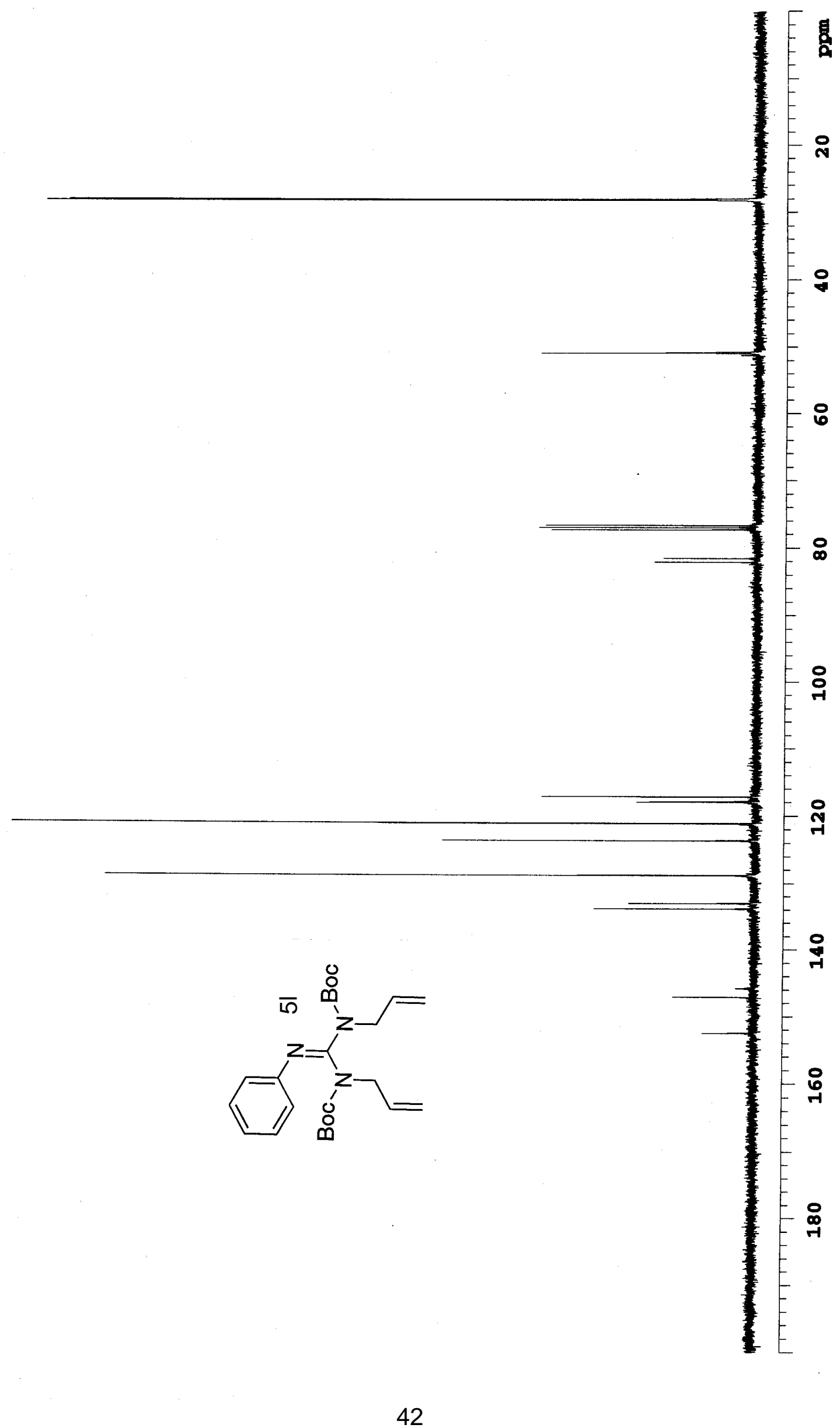




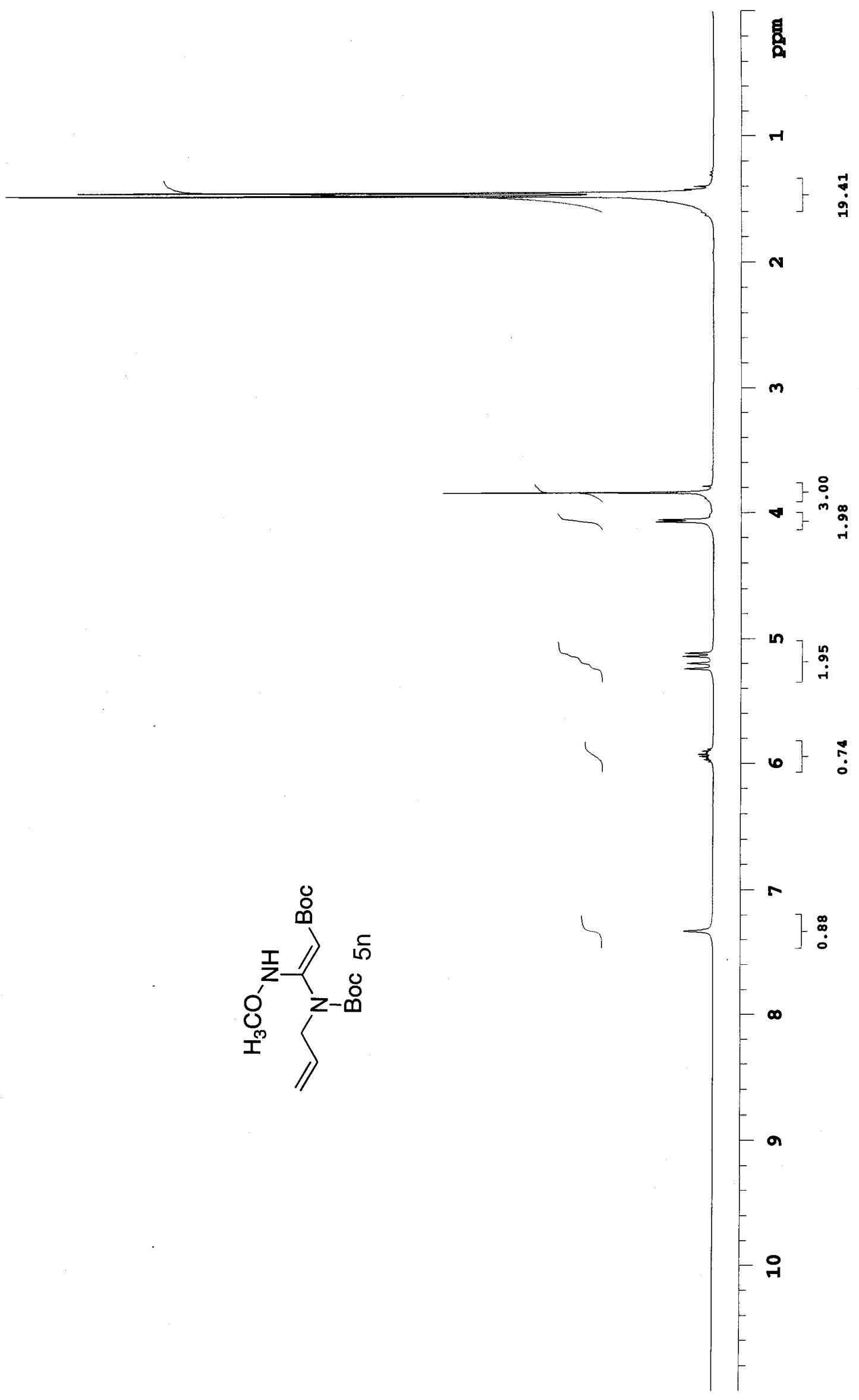




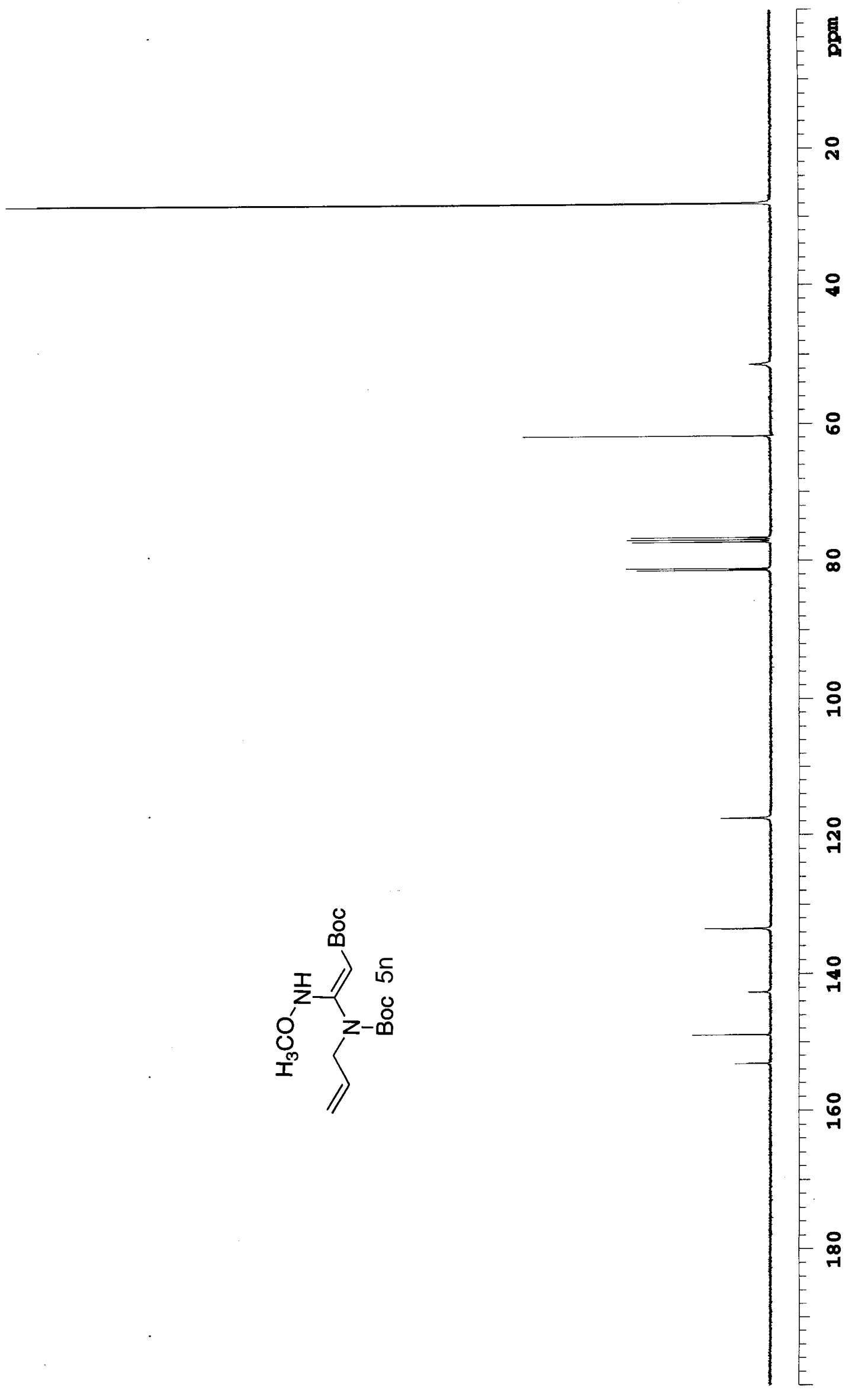




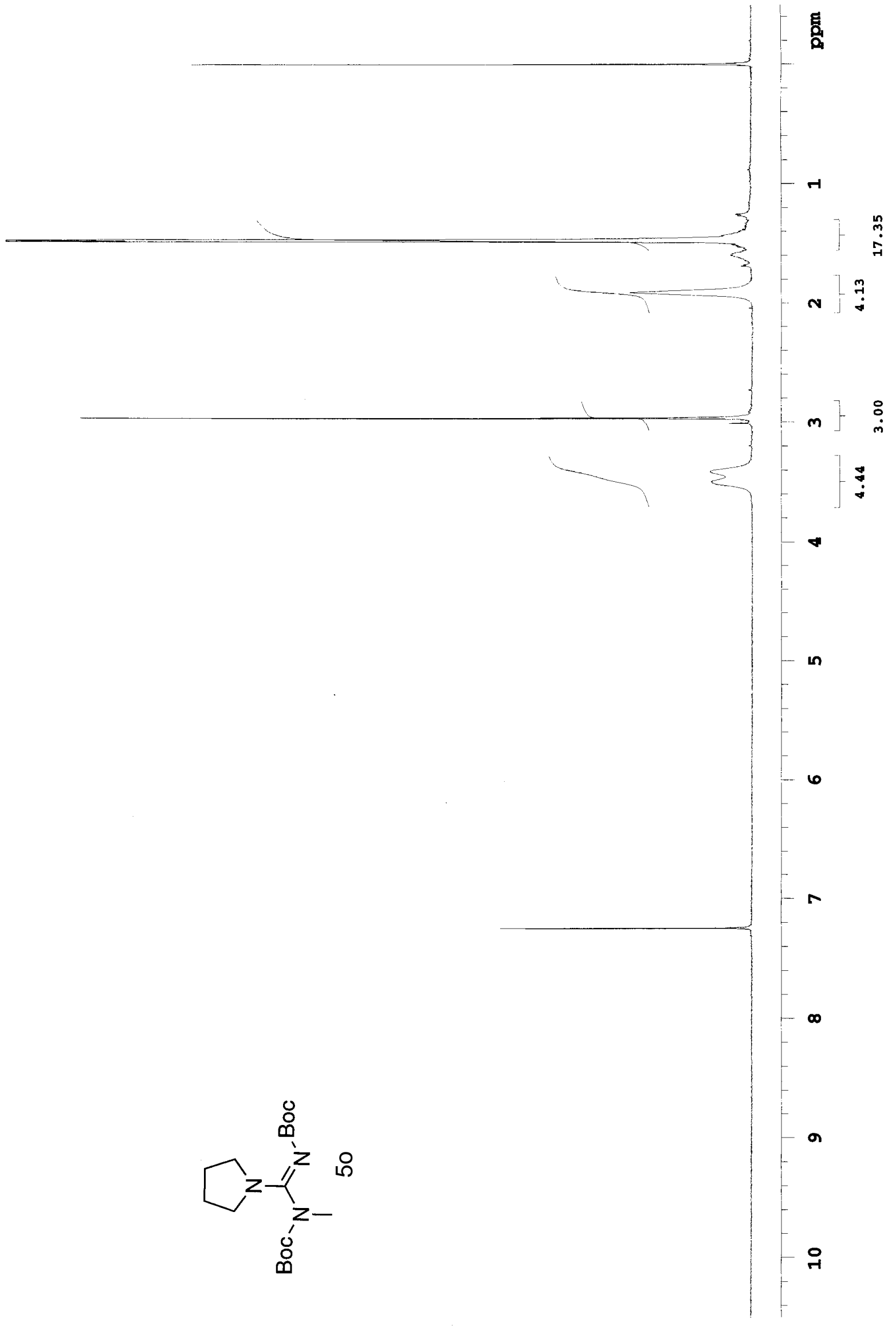




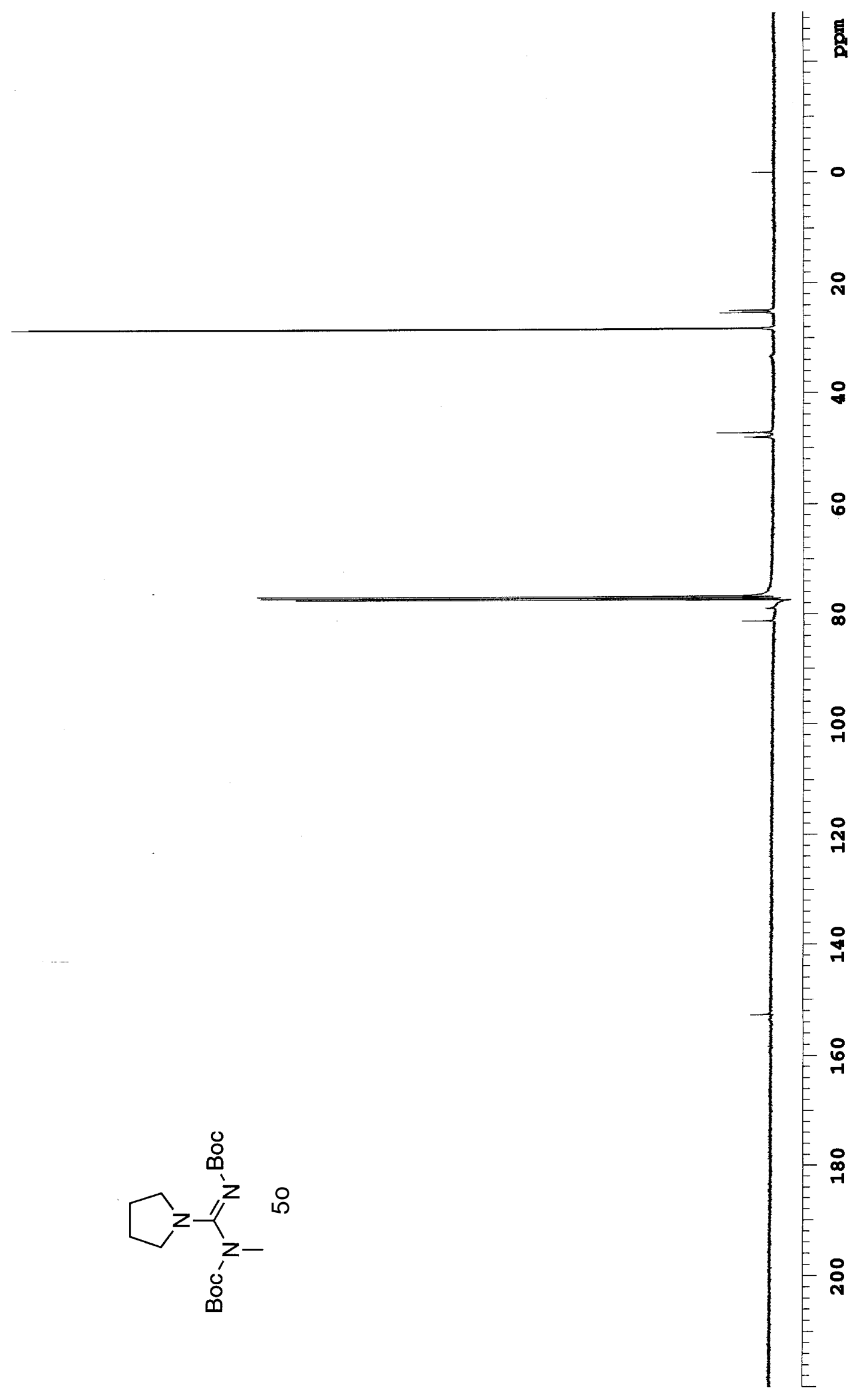




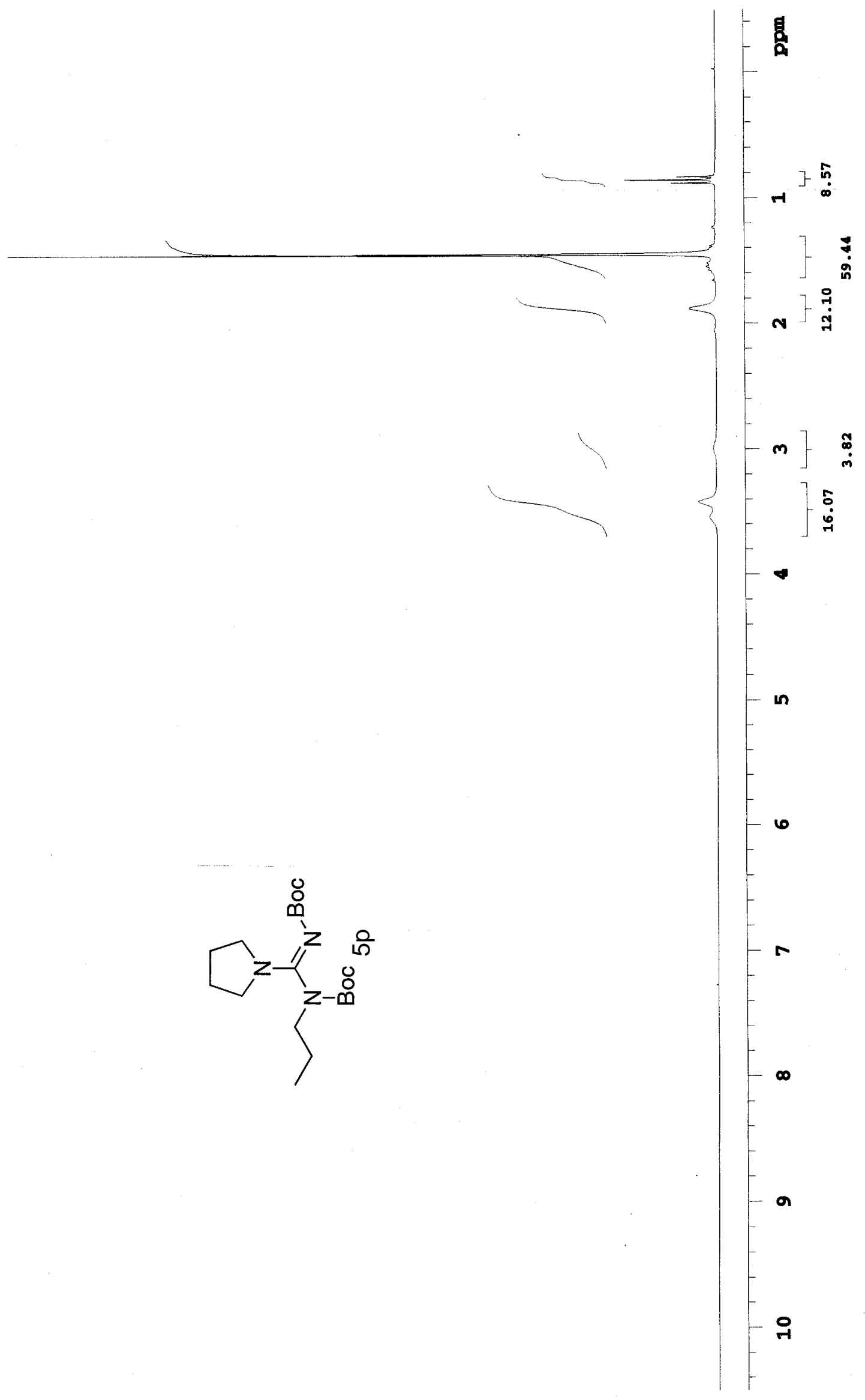




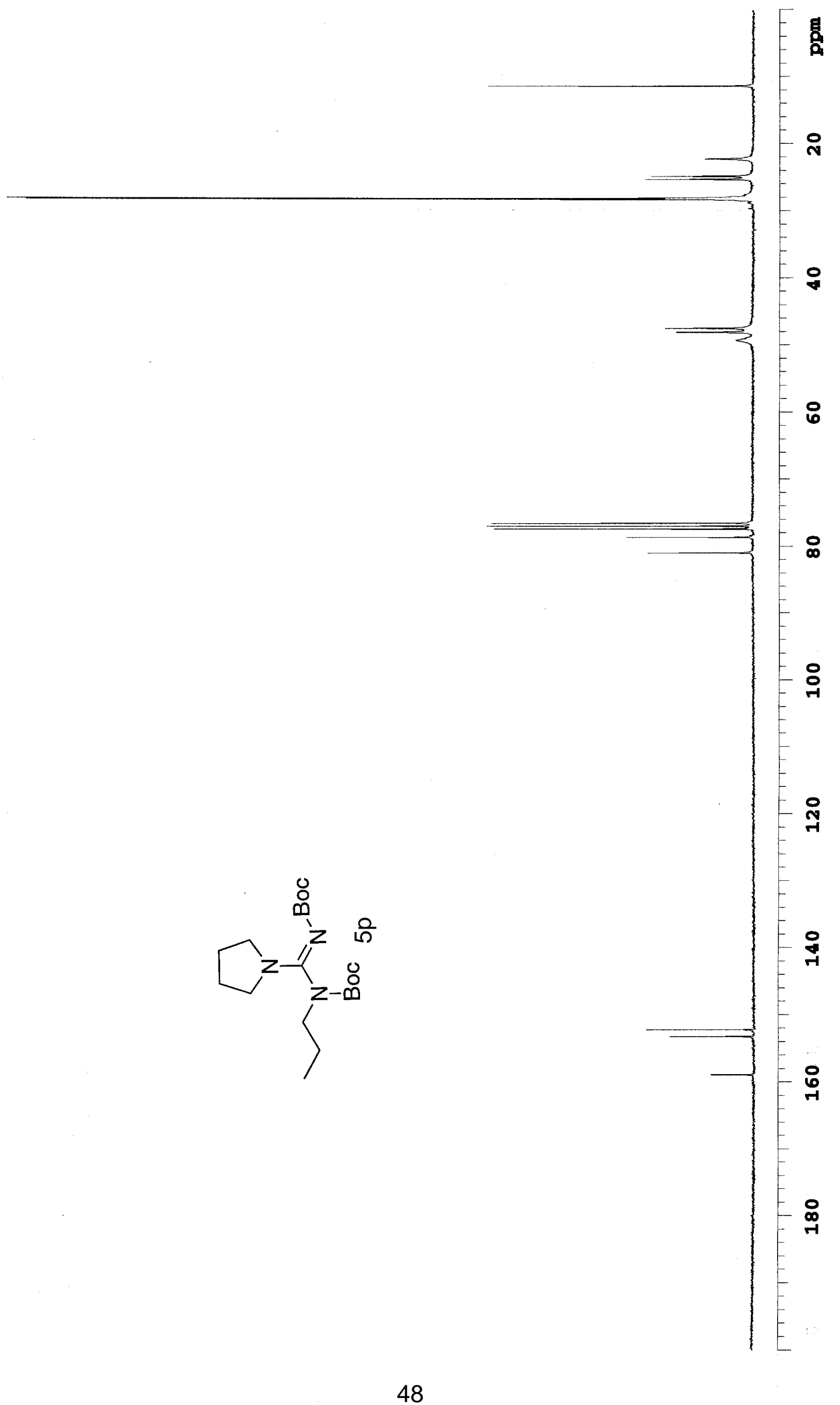




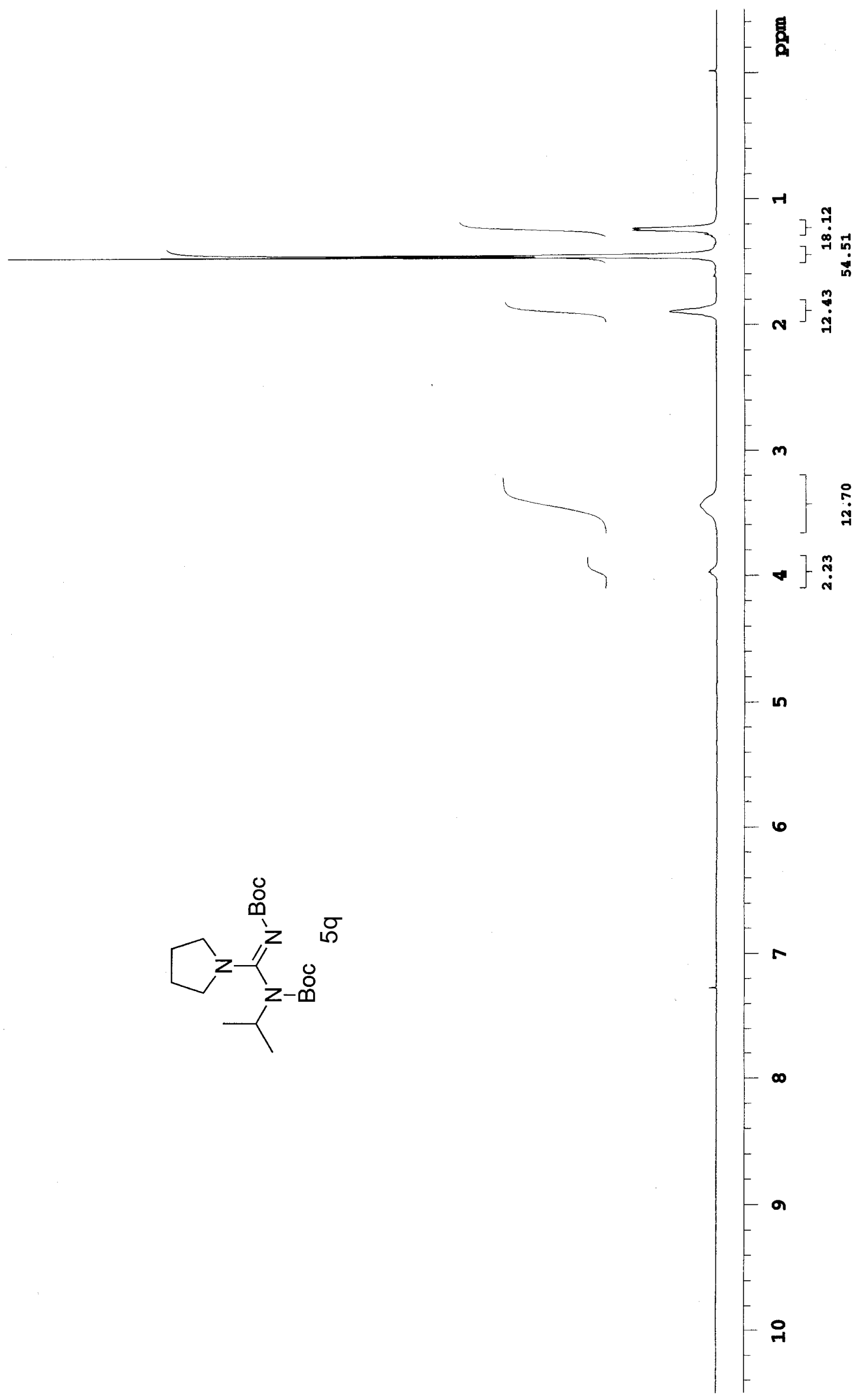




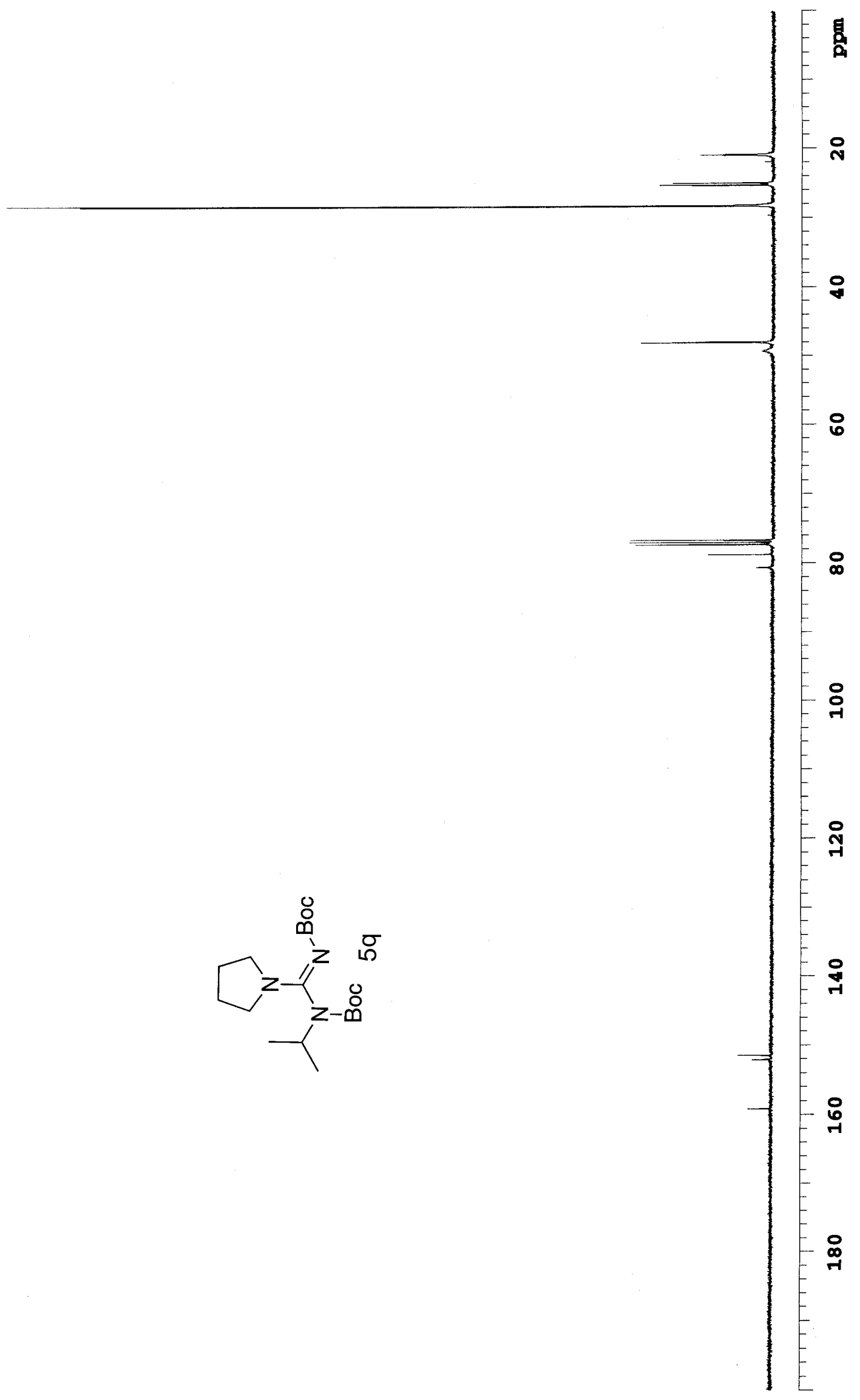




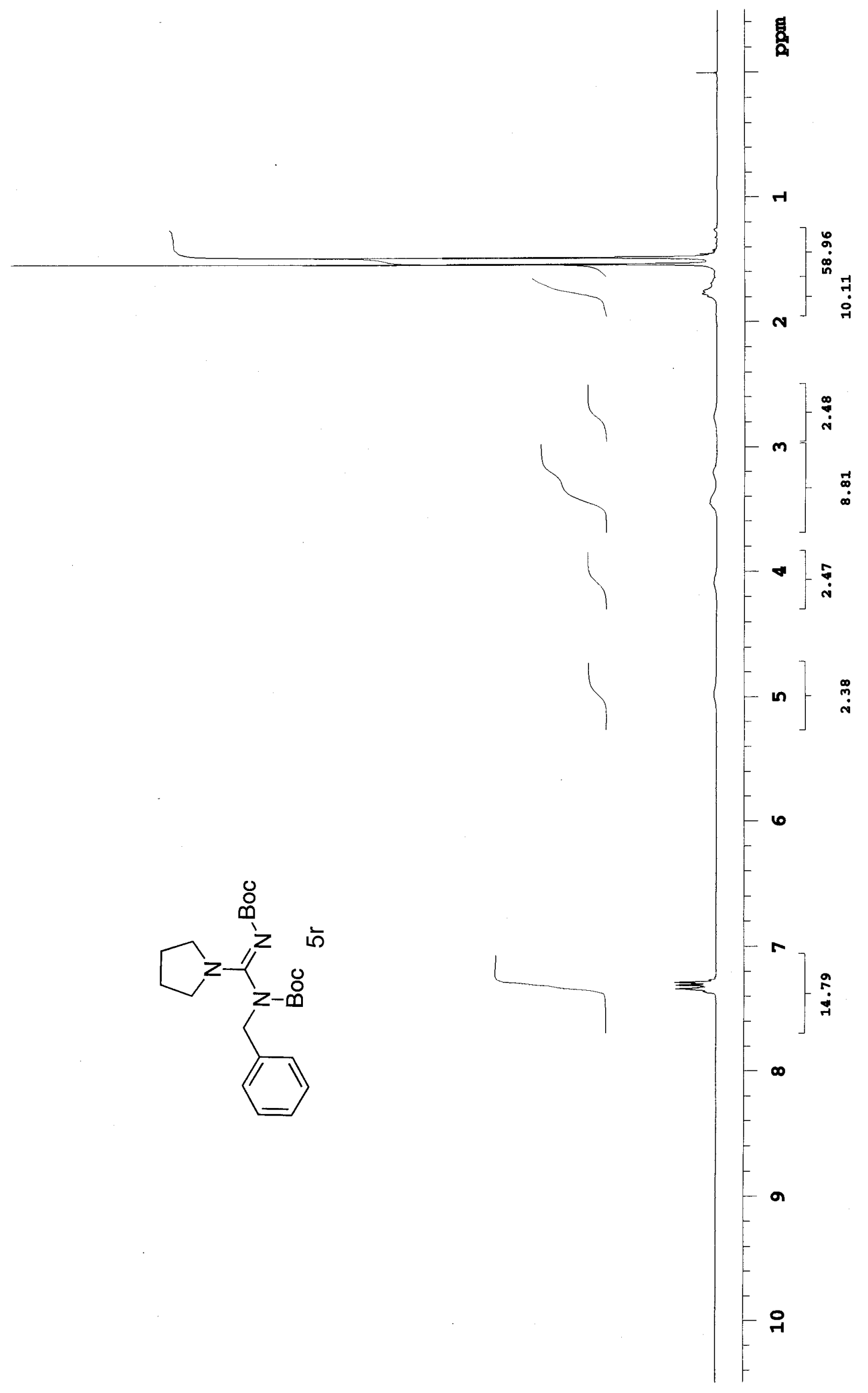




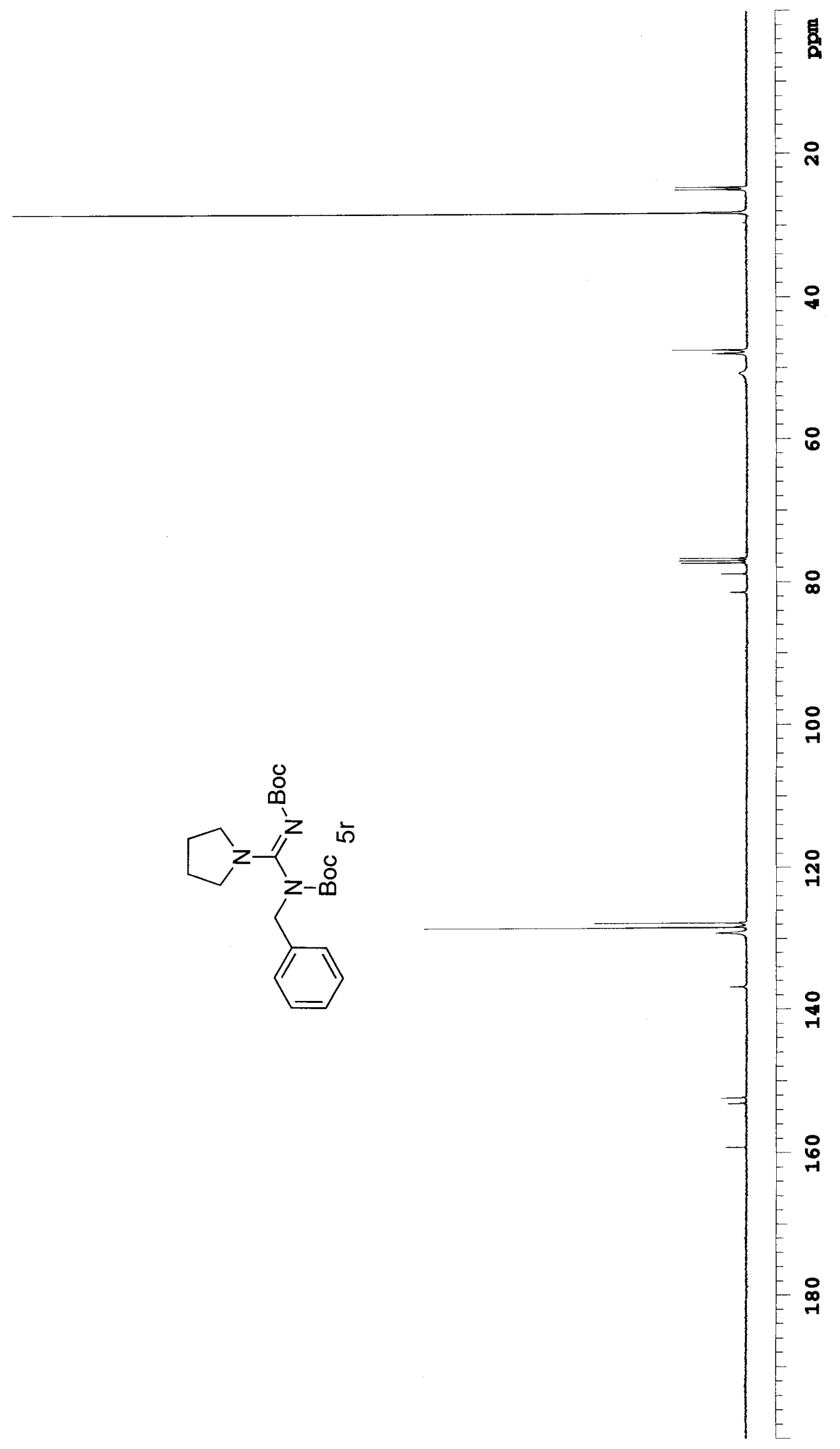




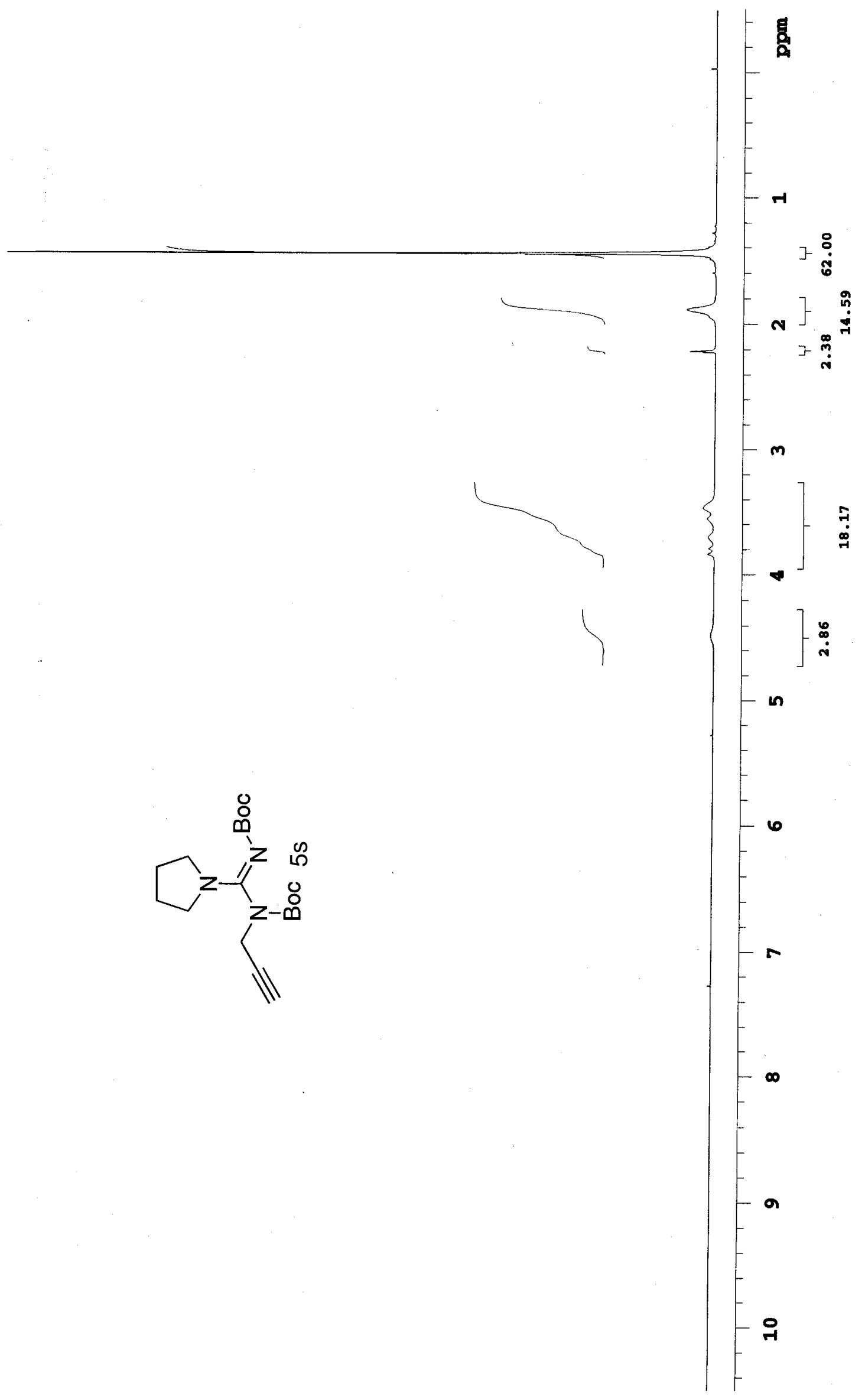




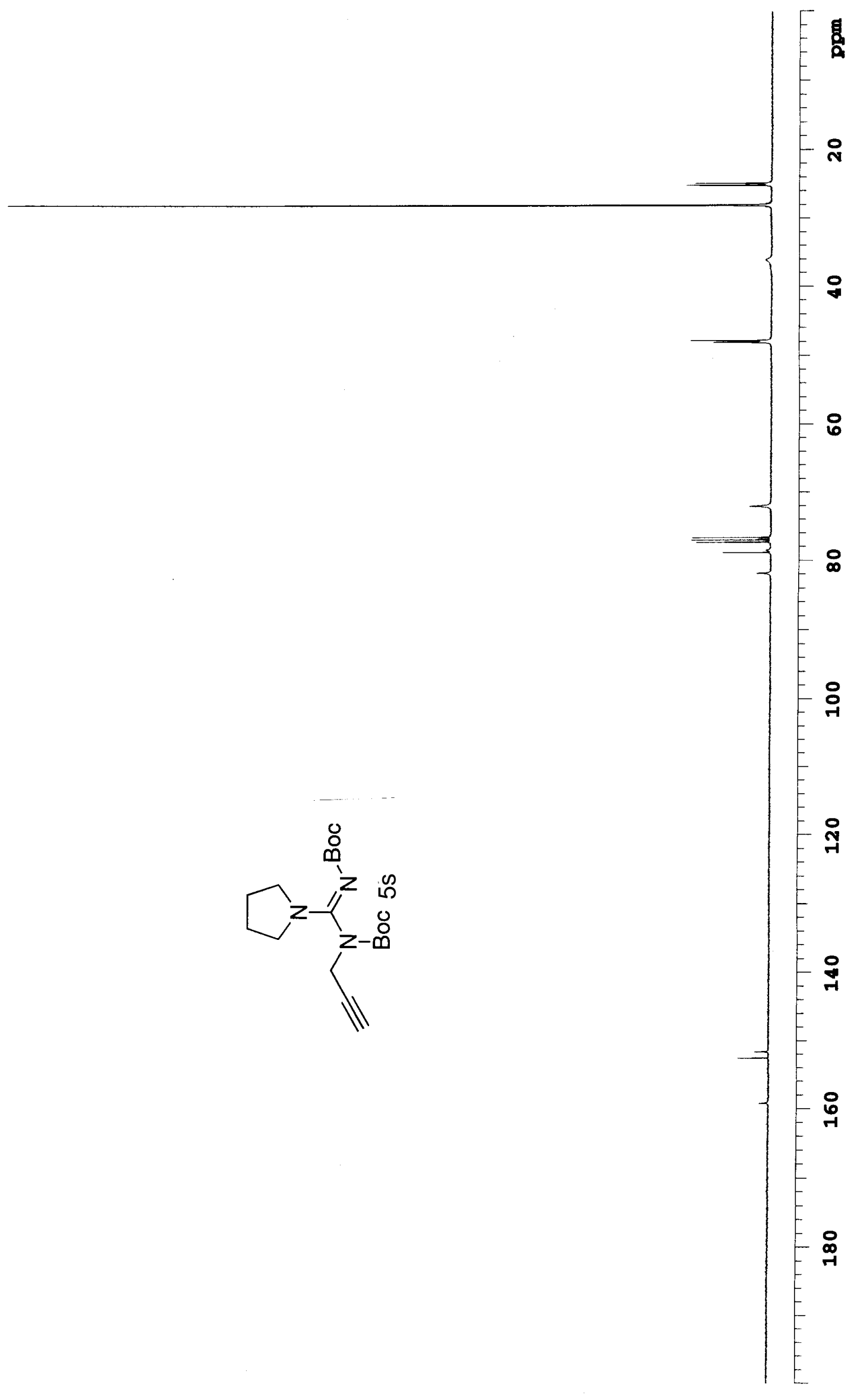




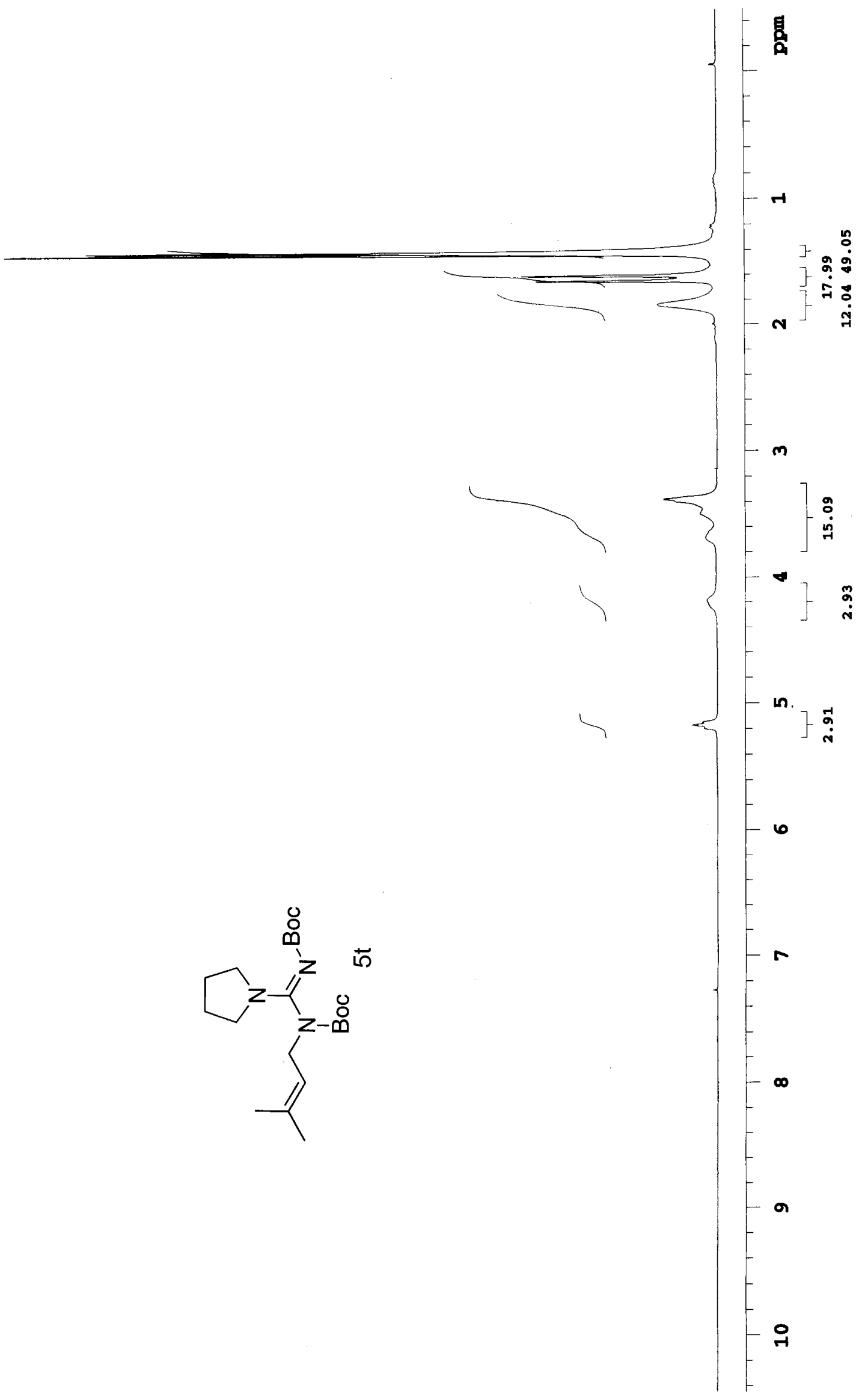




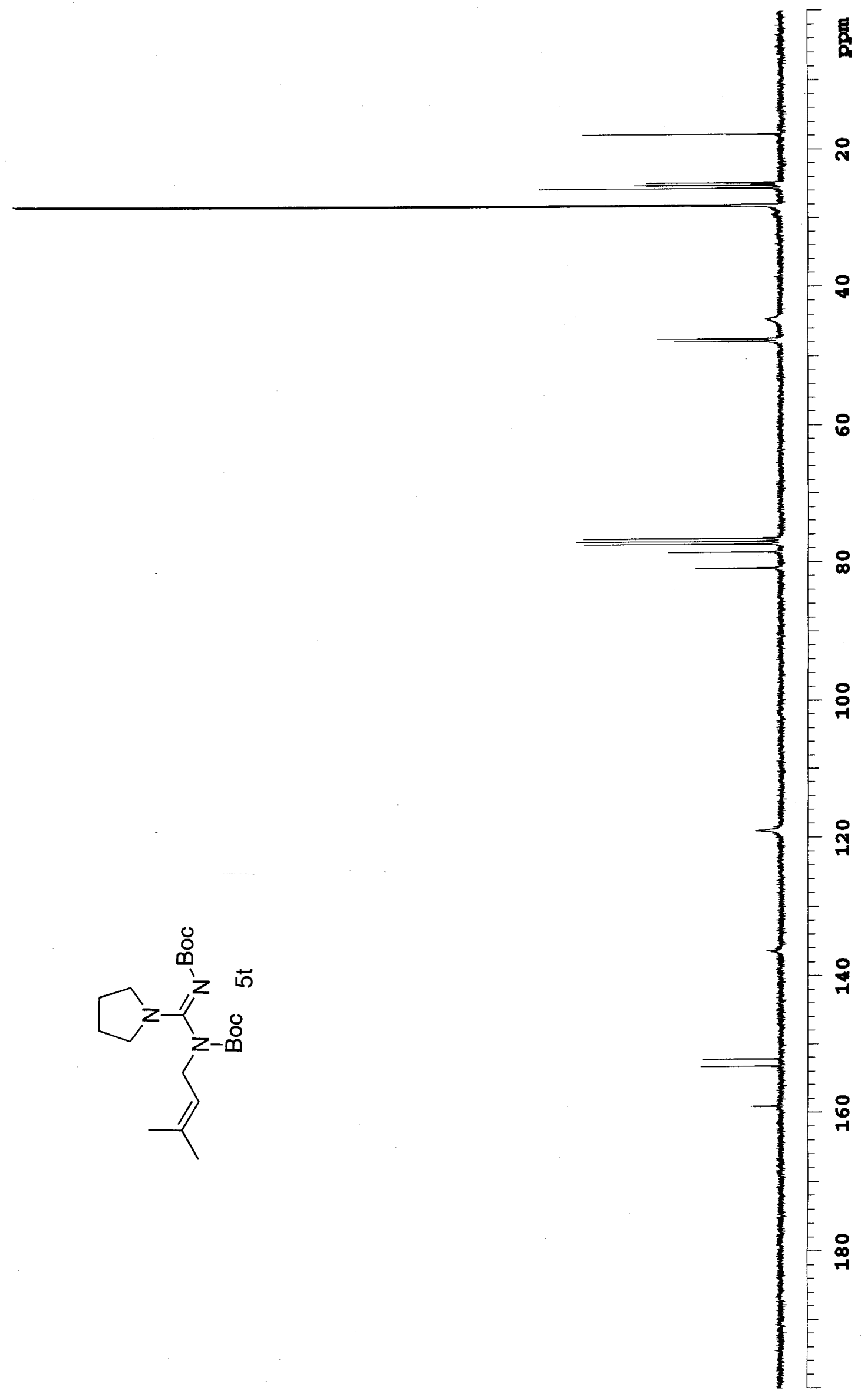




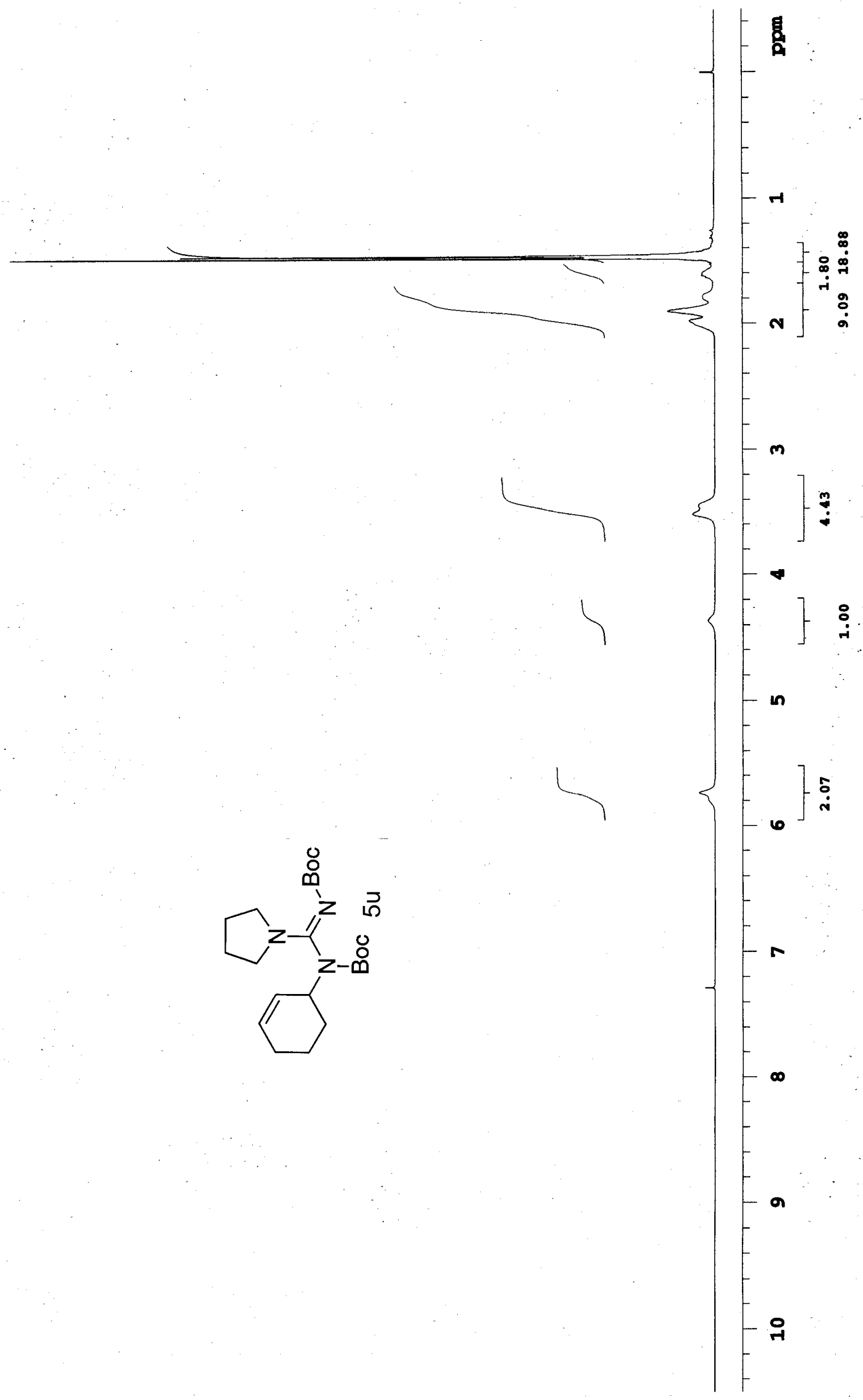




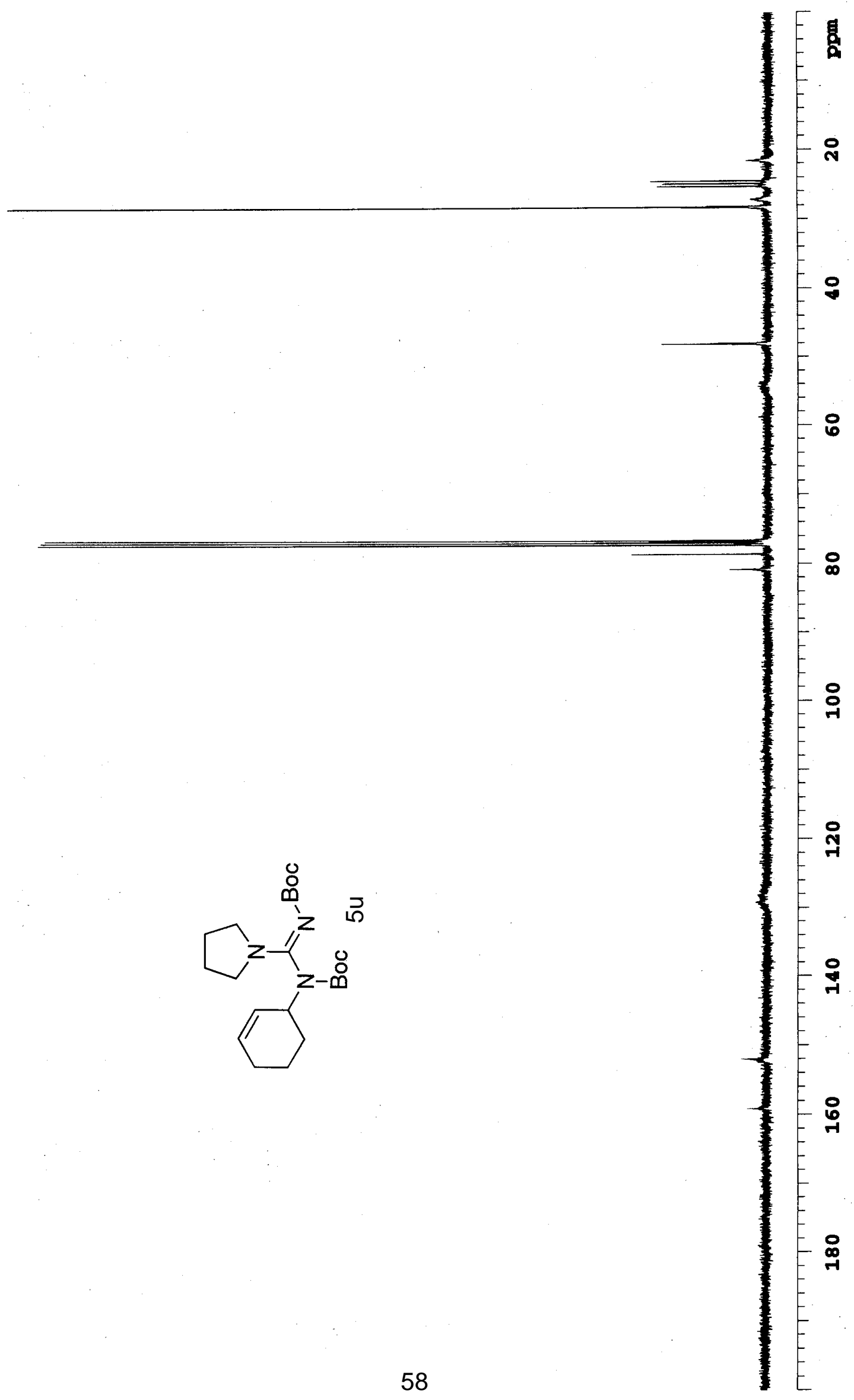




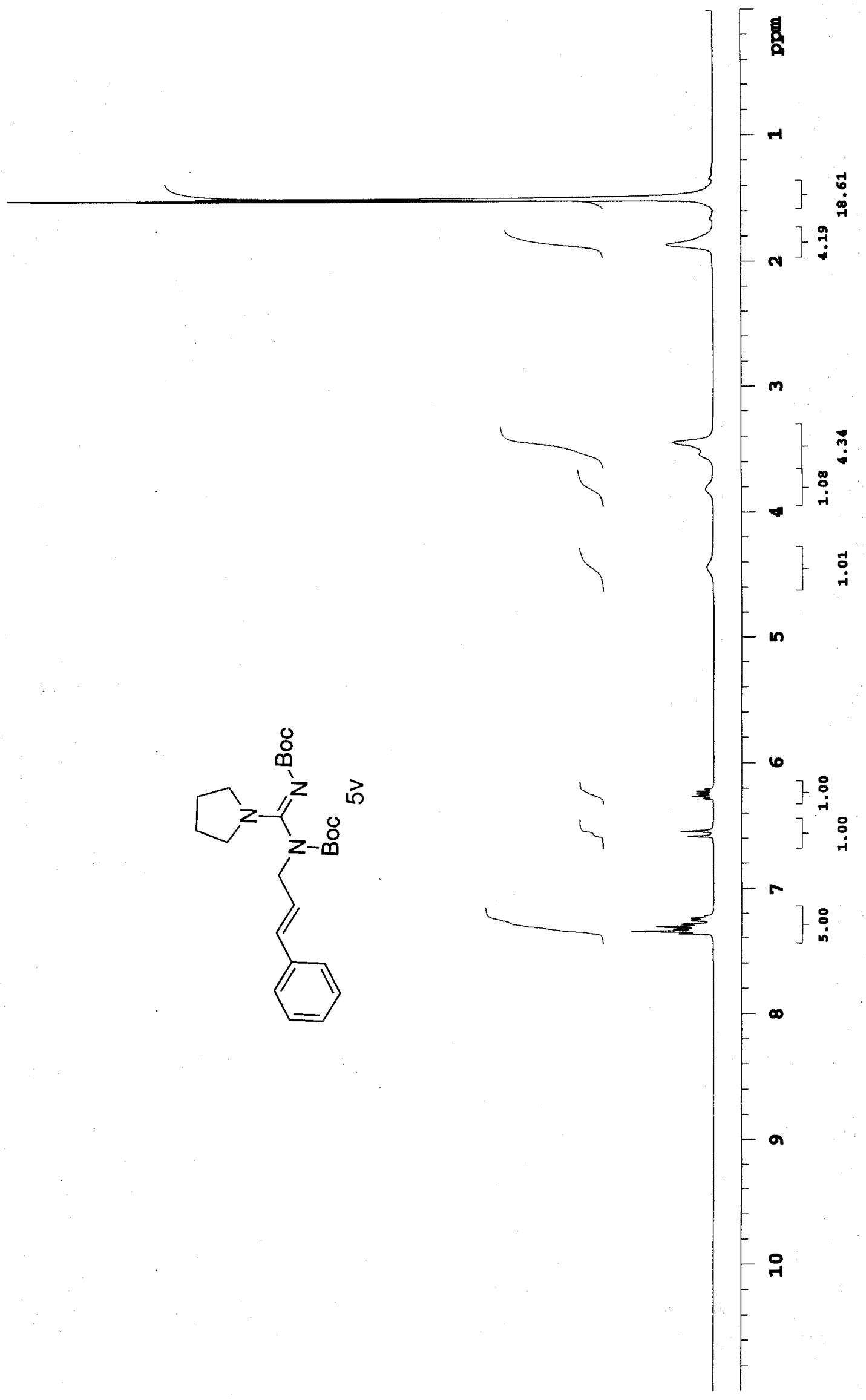




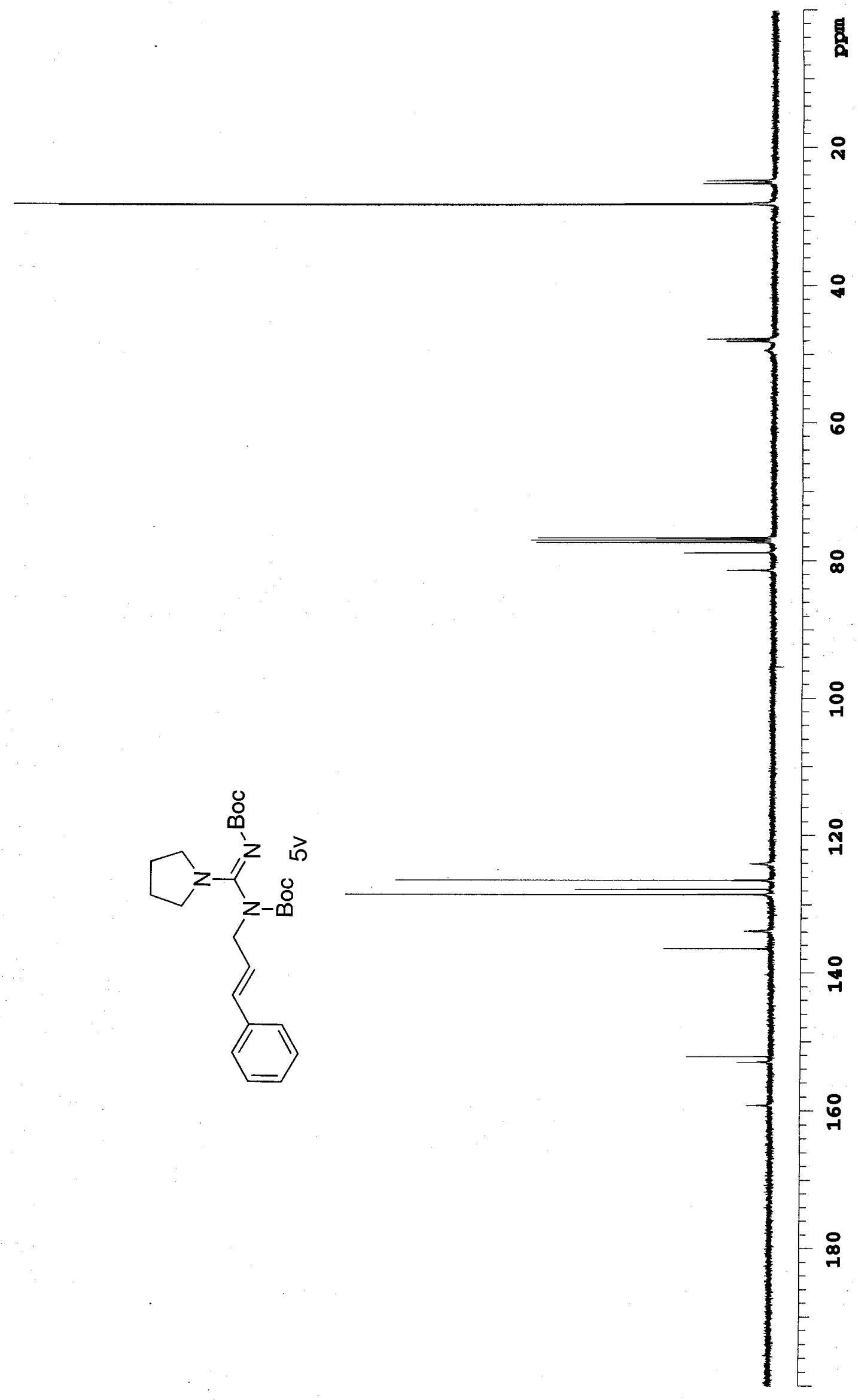




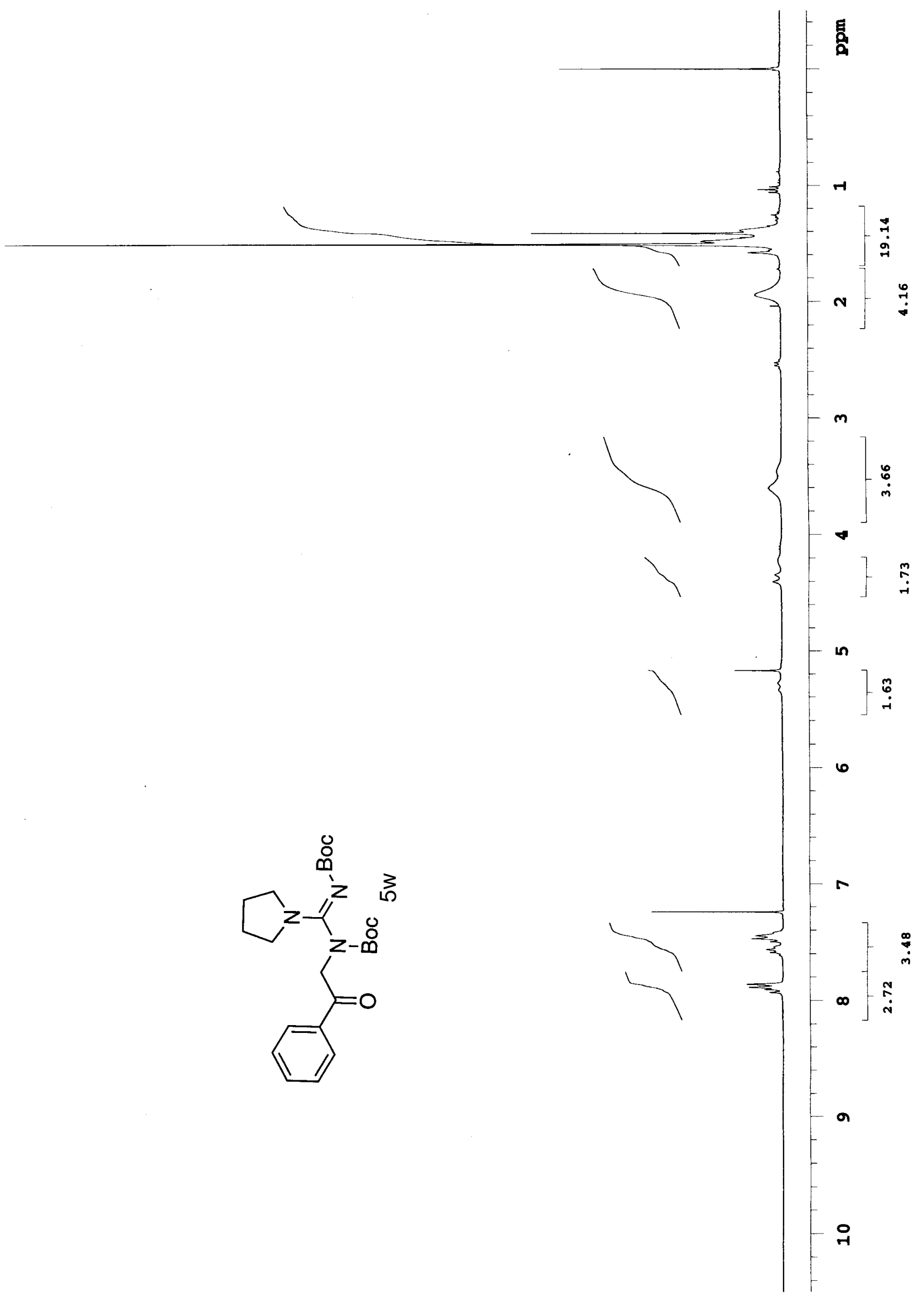




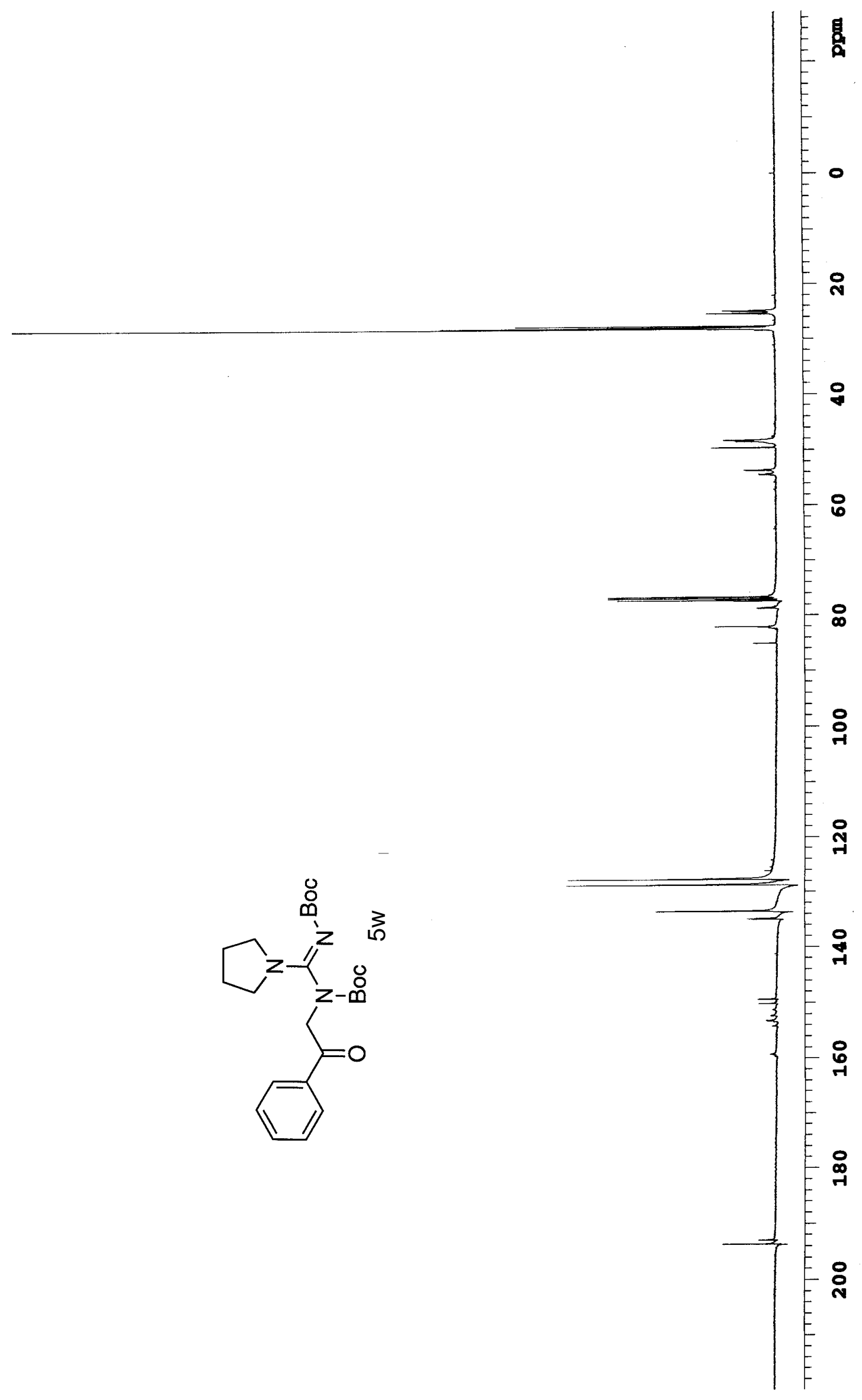




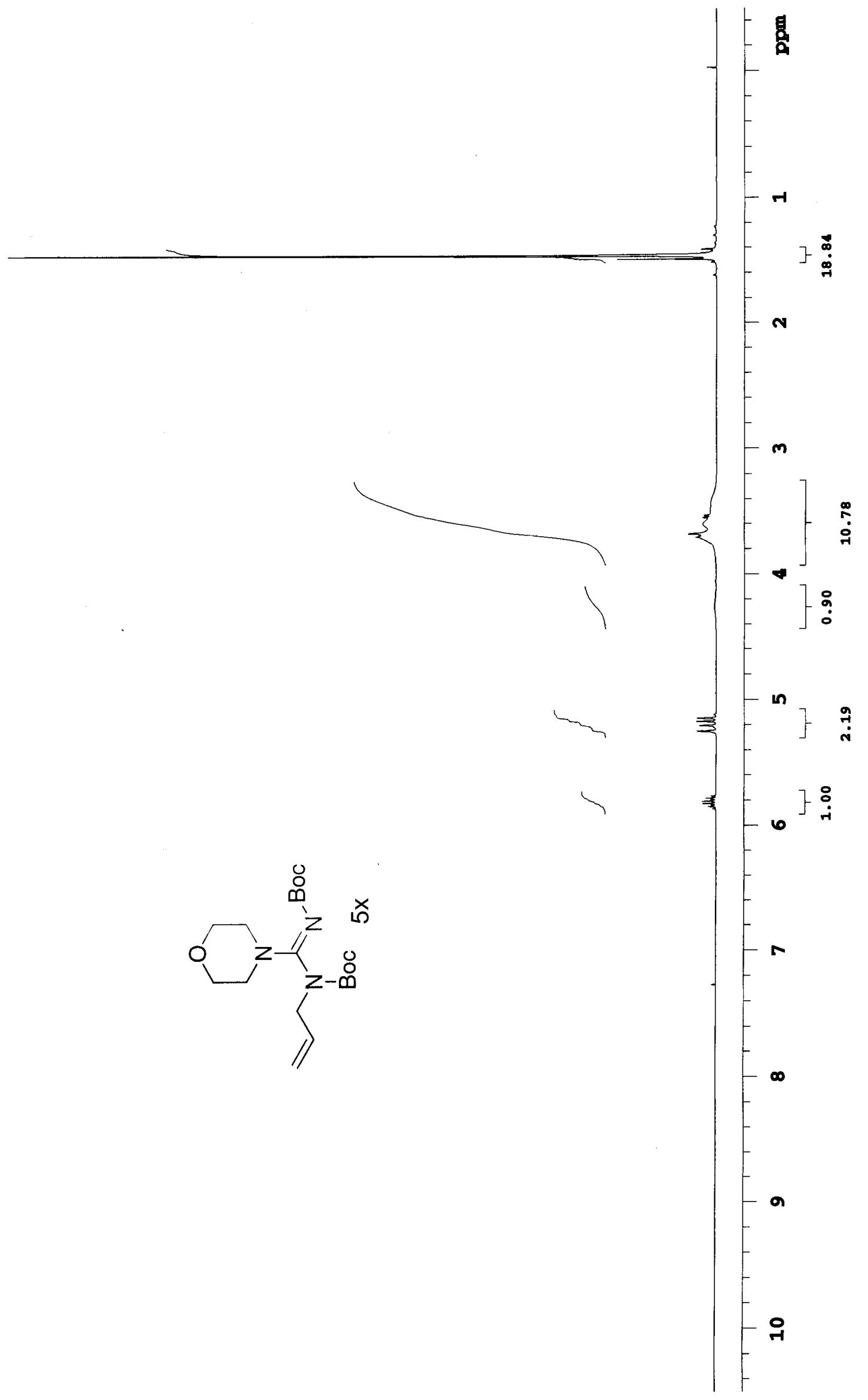




$$
4
$$




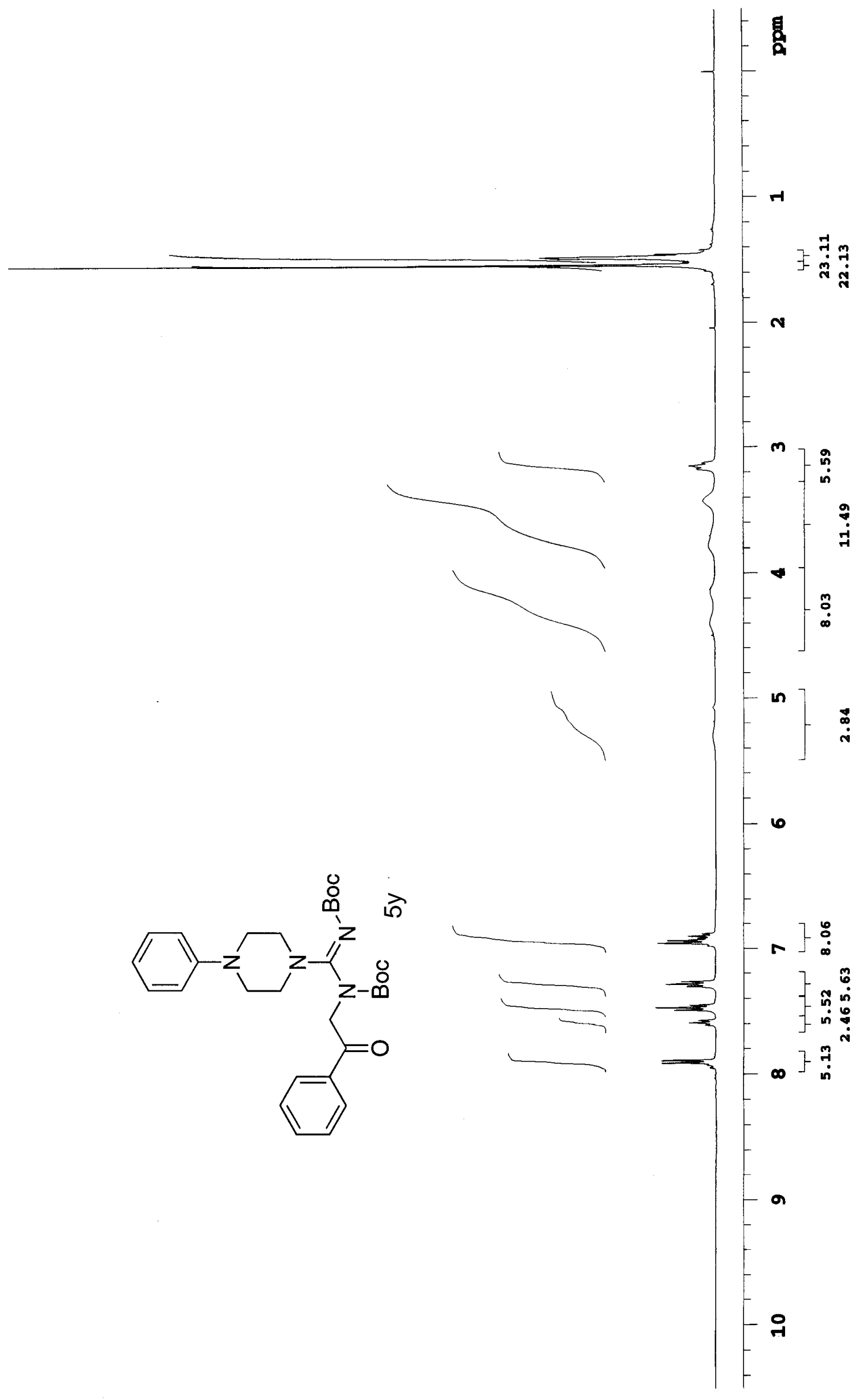




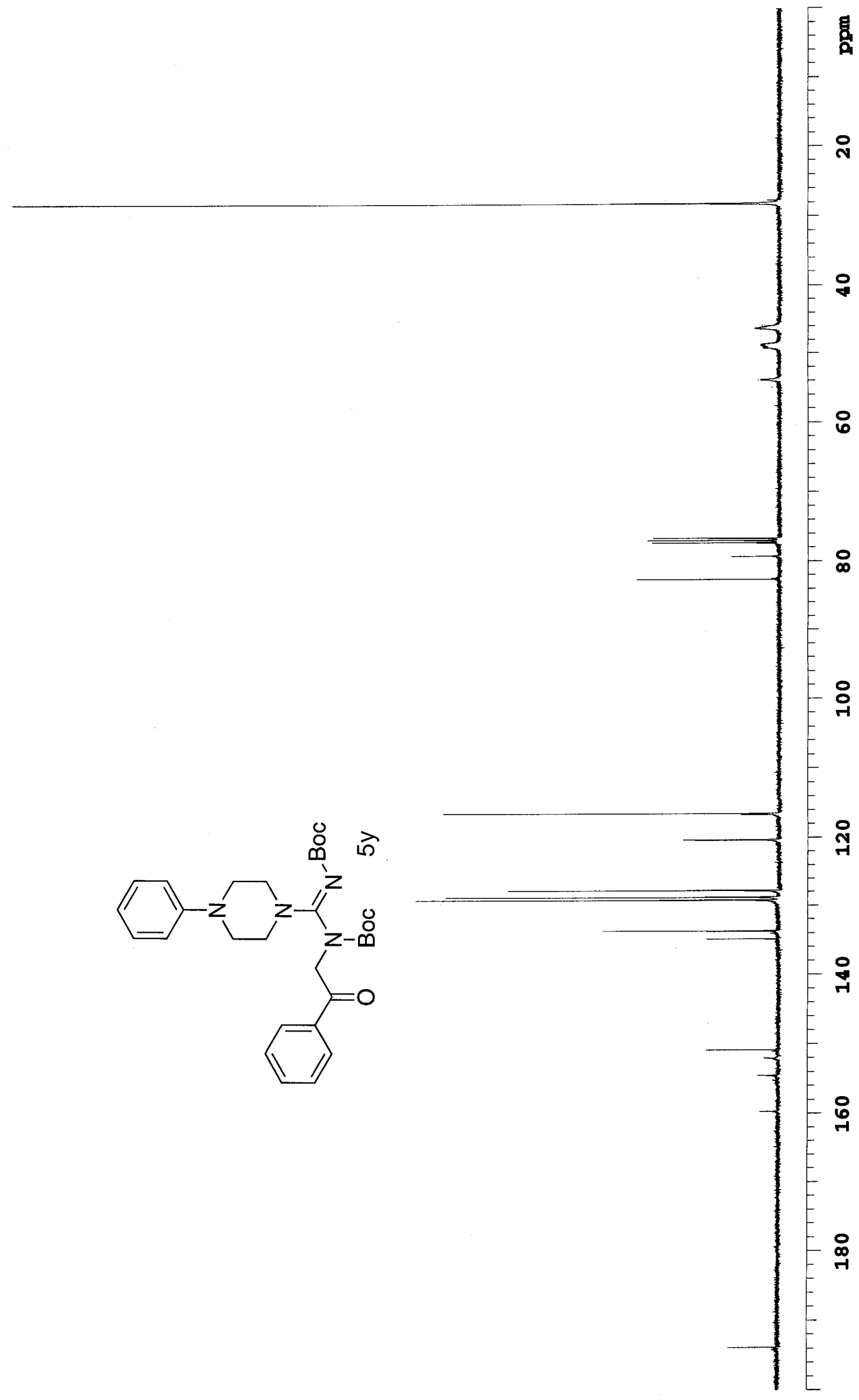




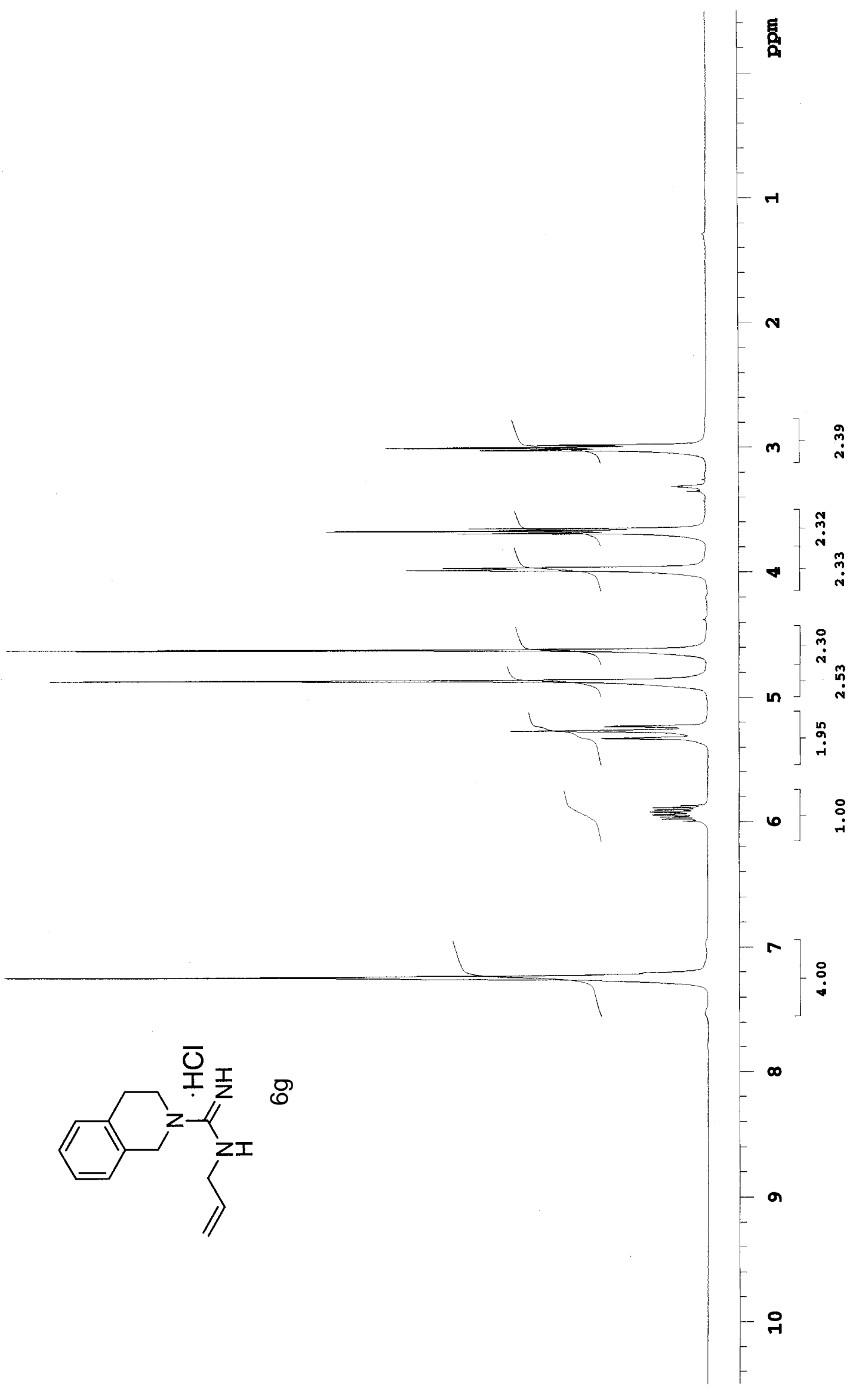




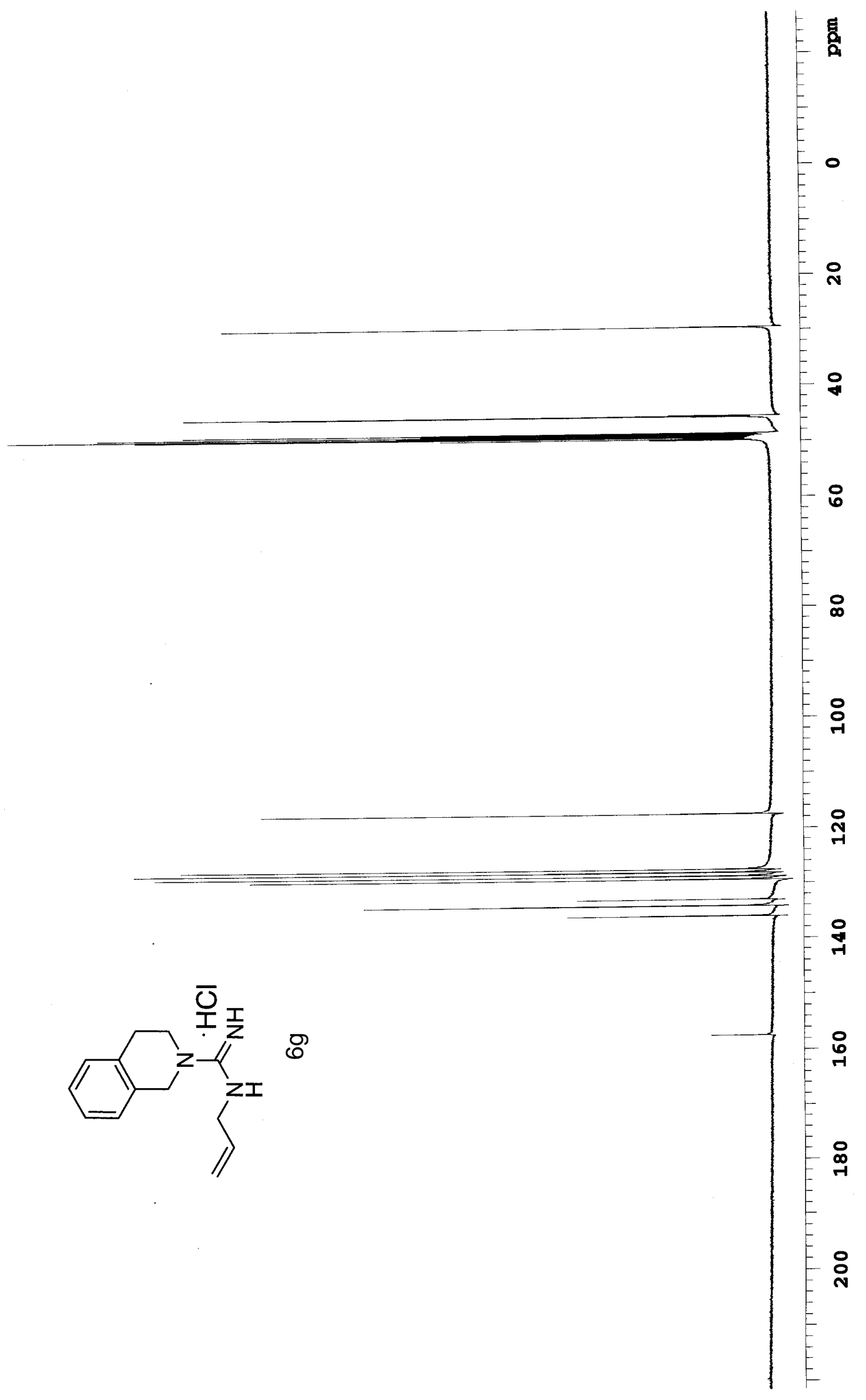




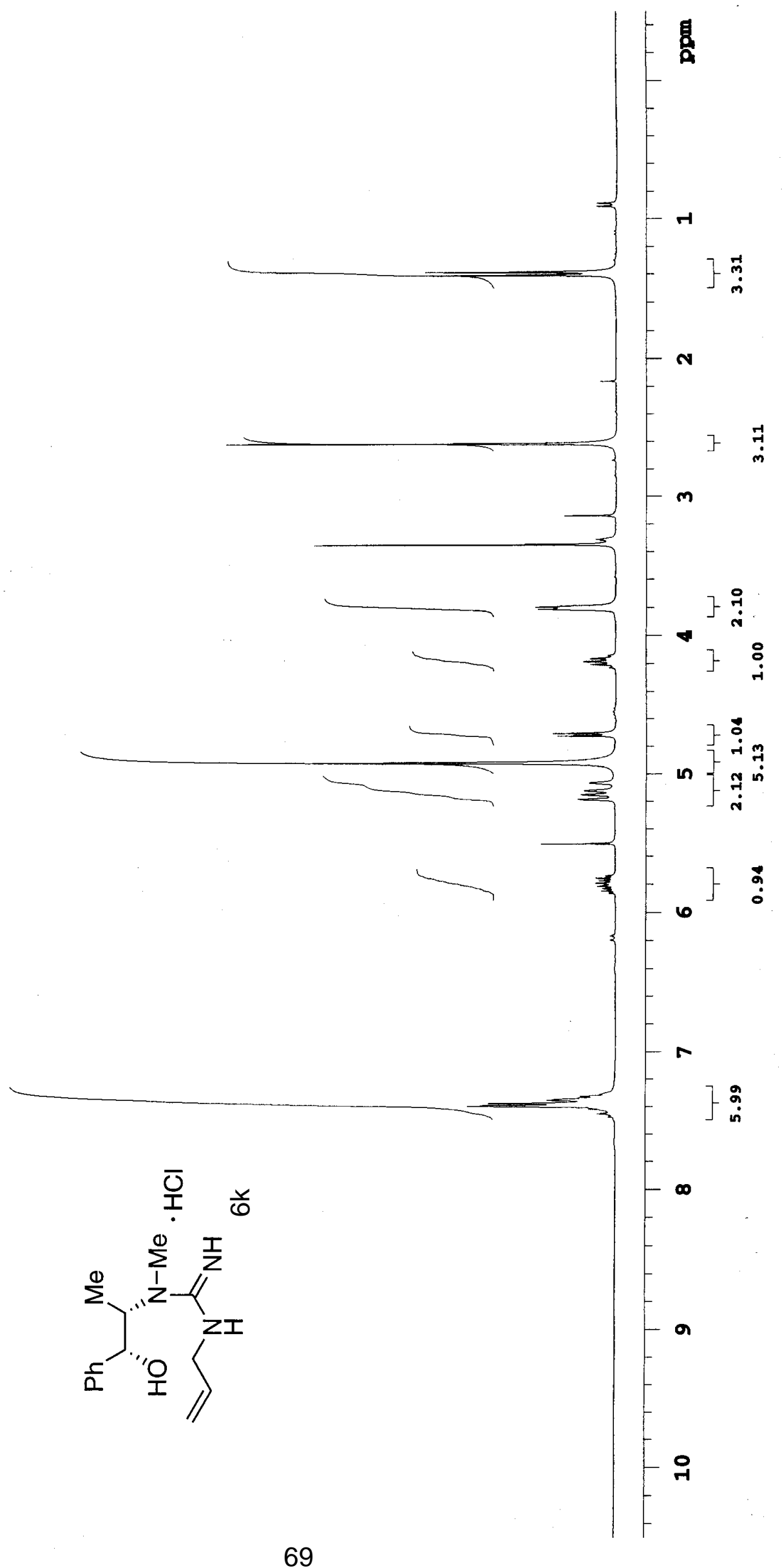




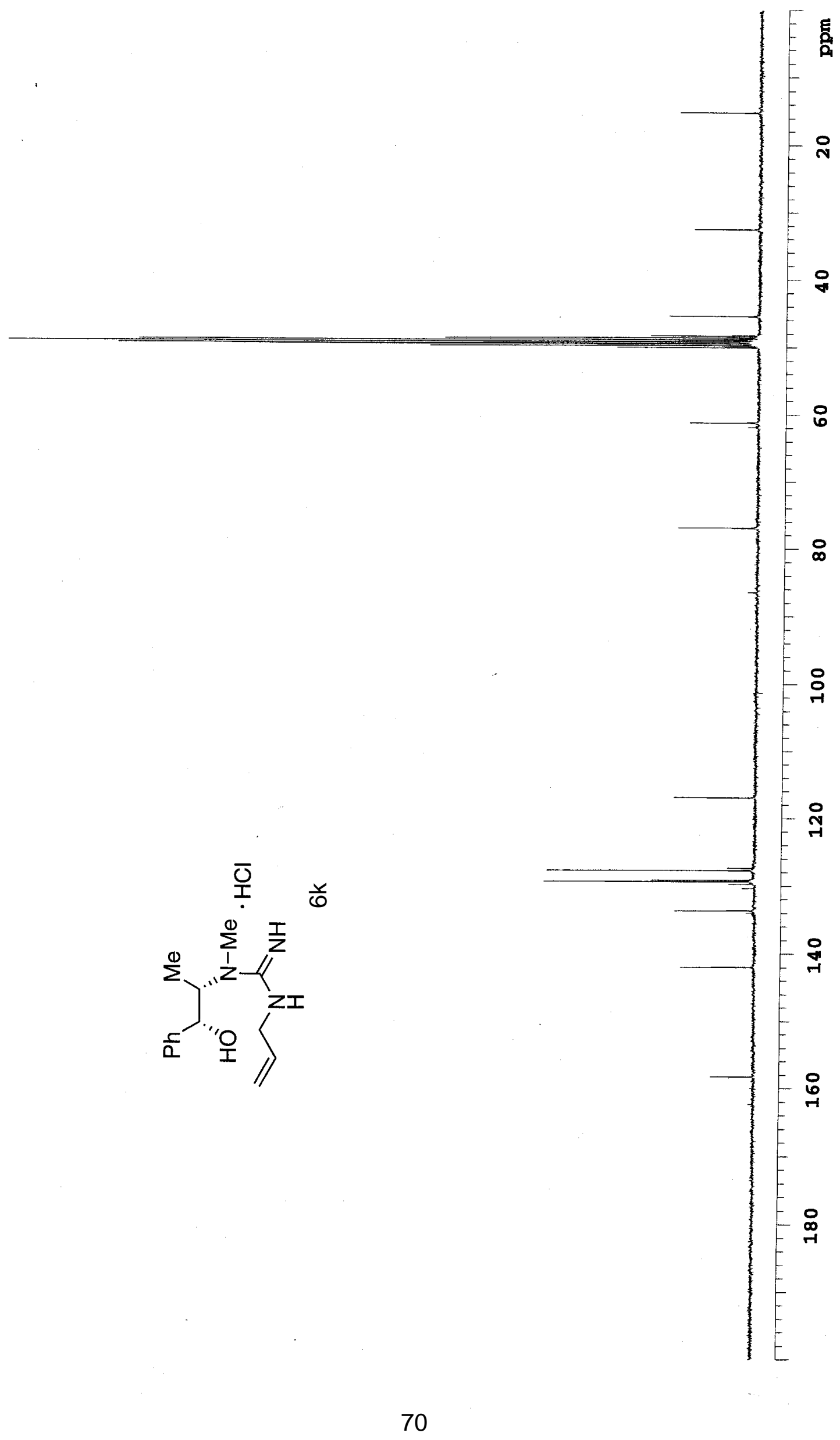




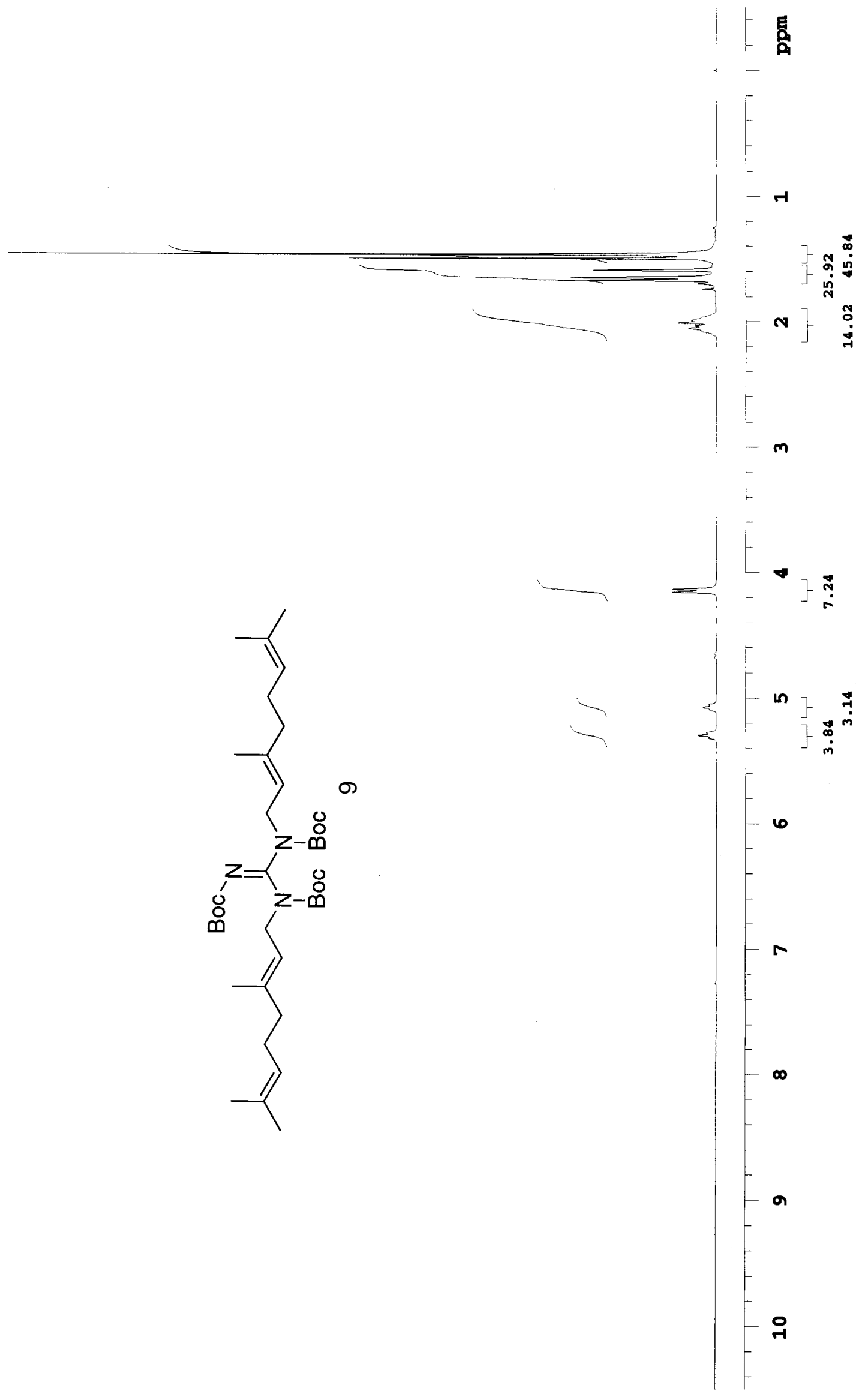




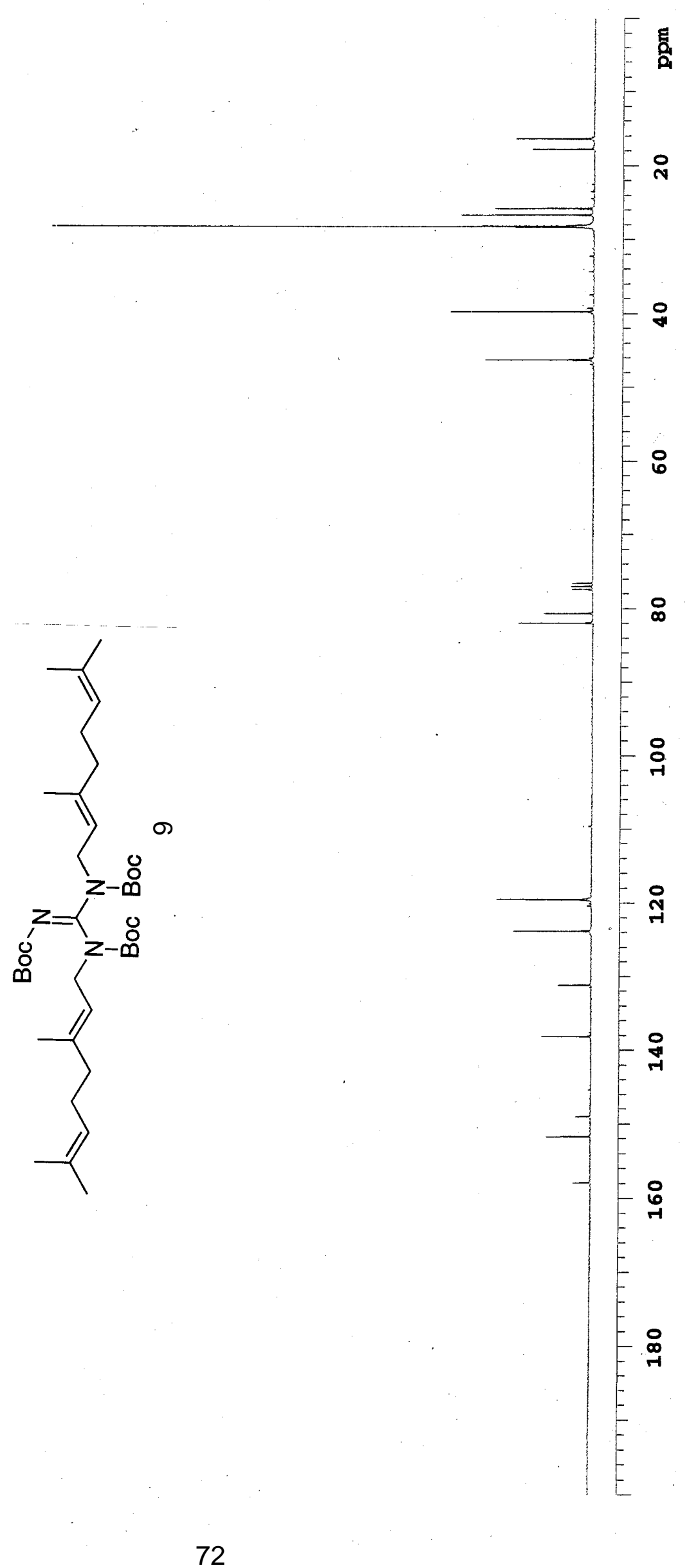




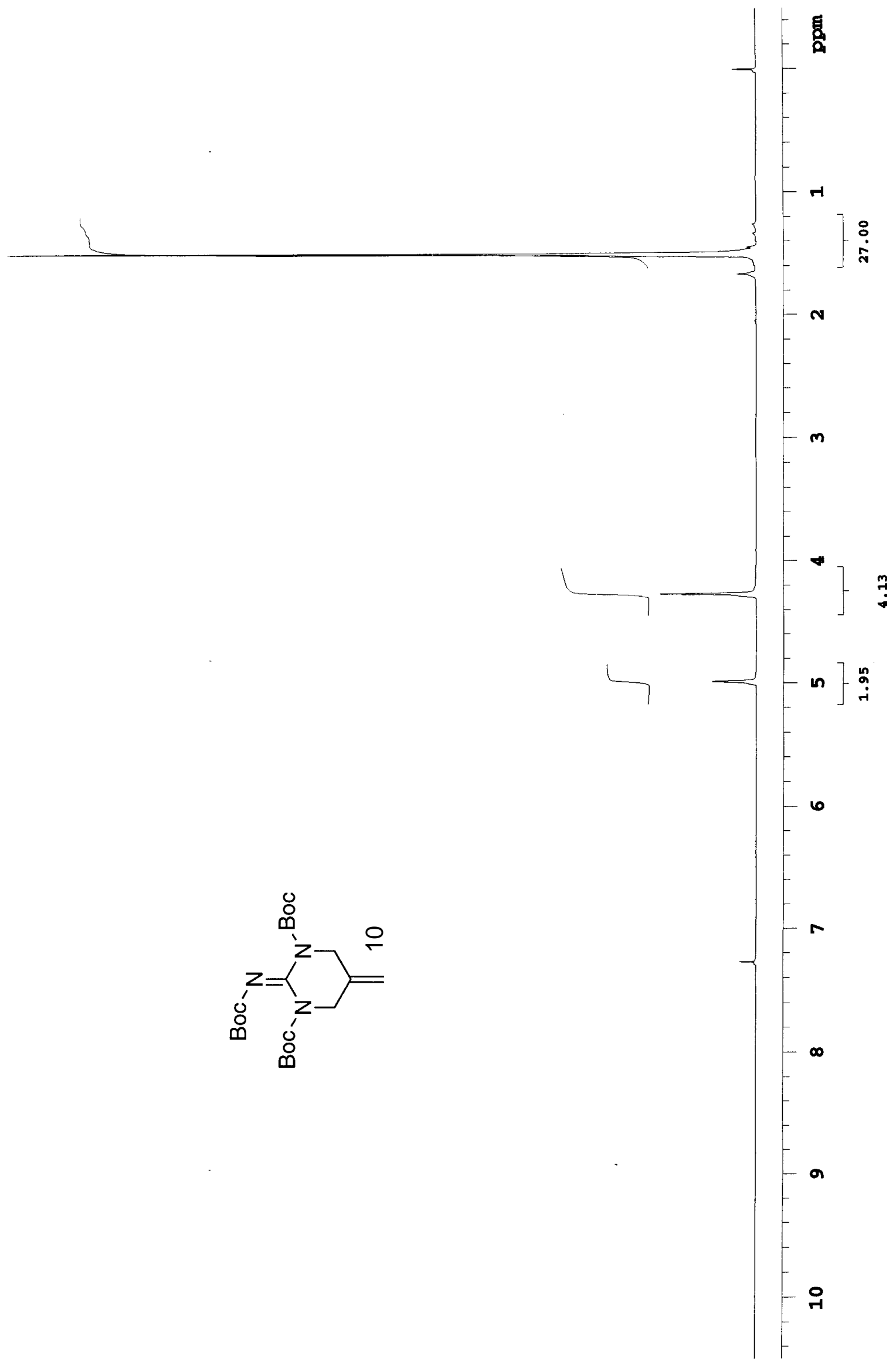




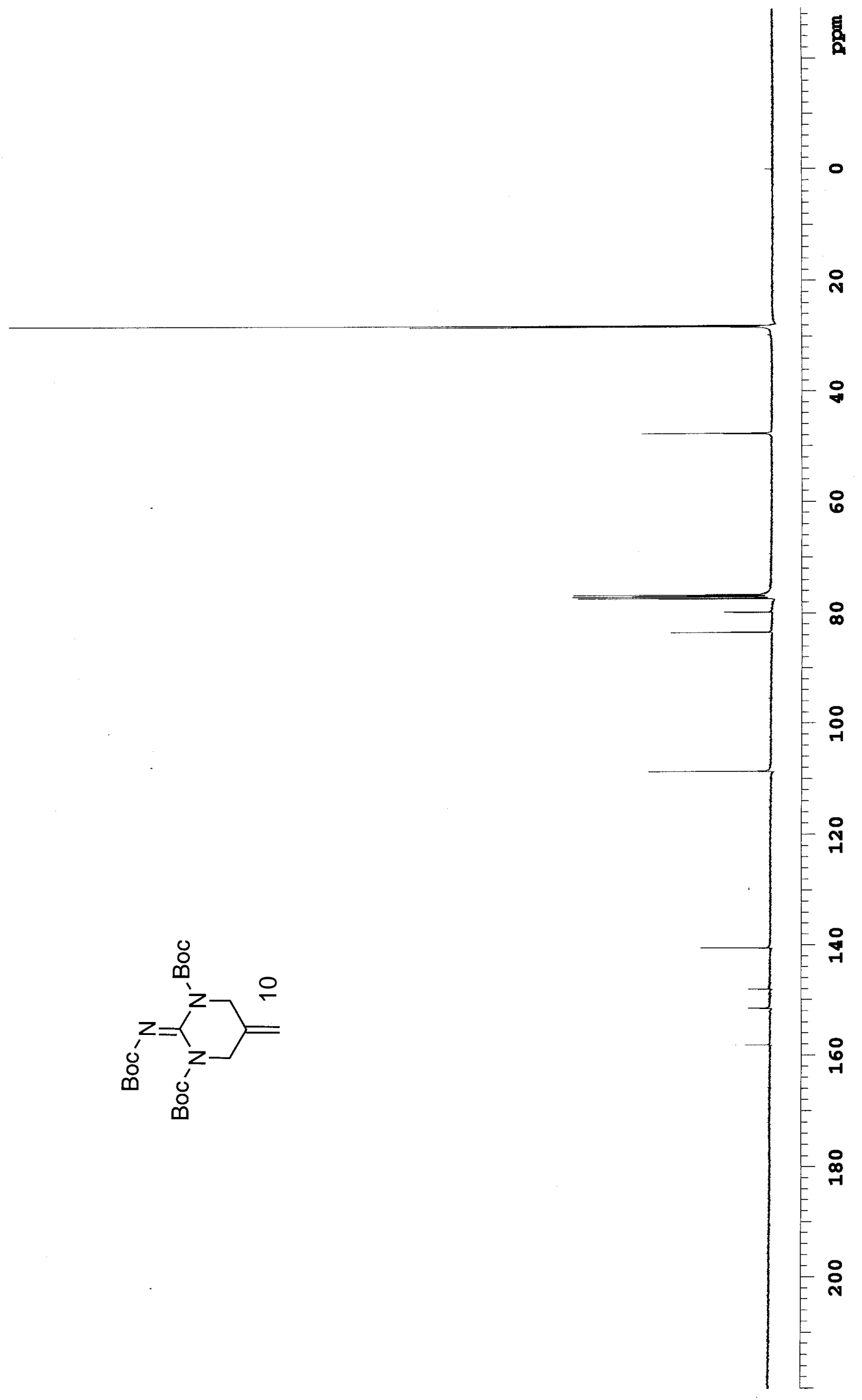




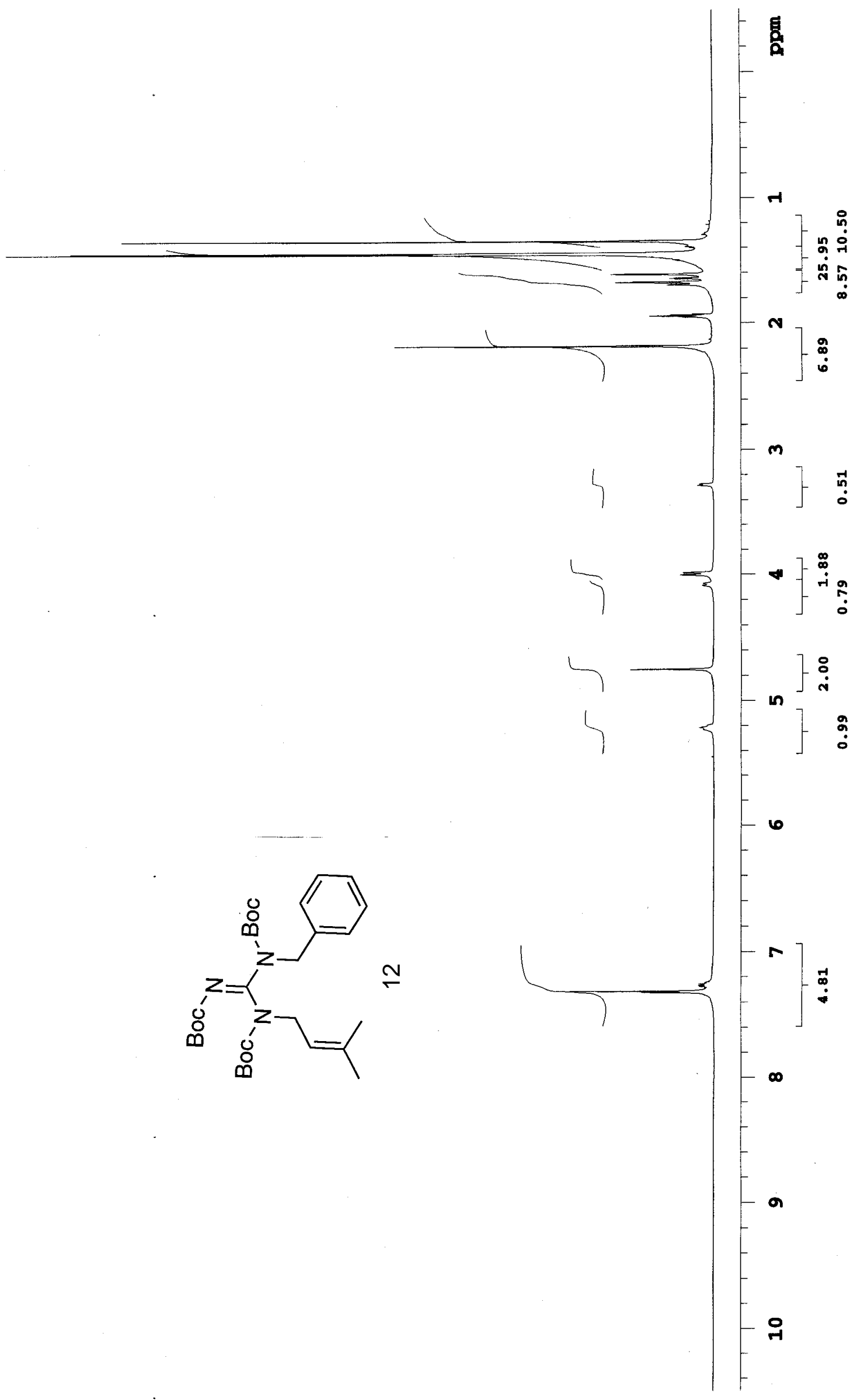




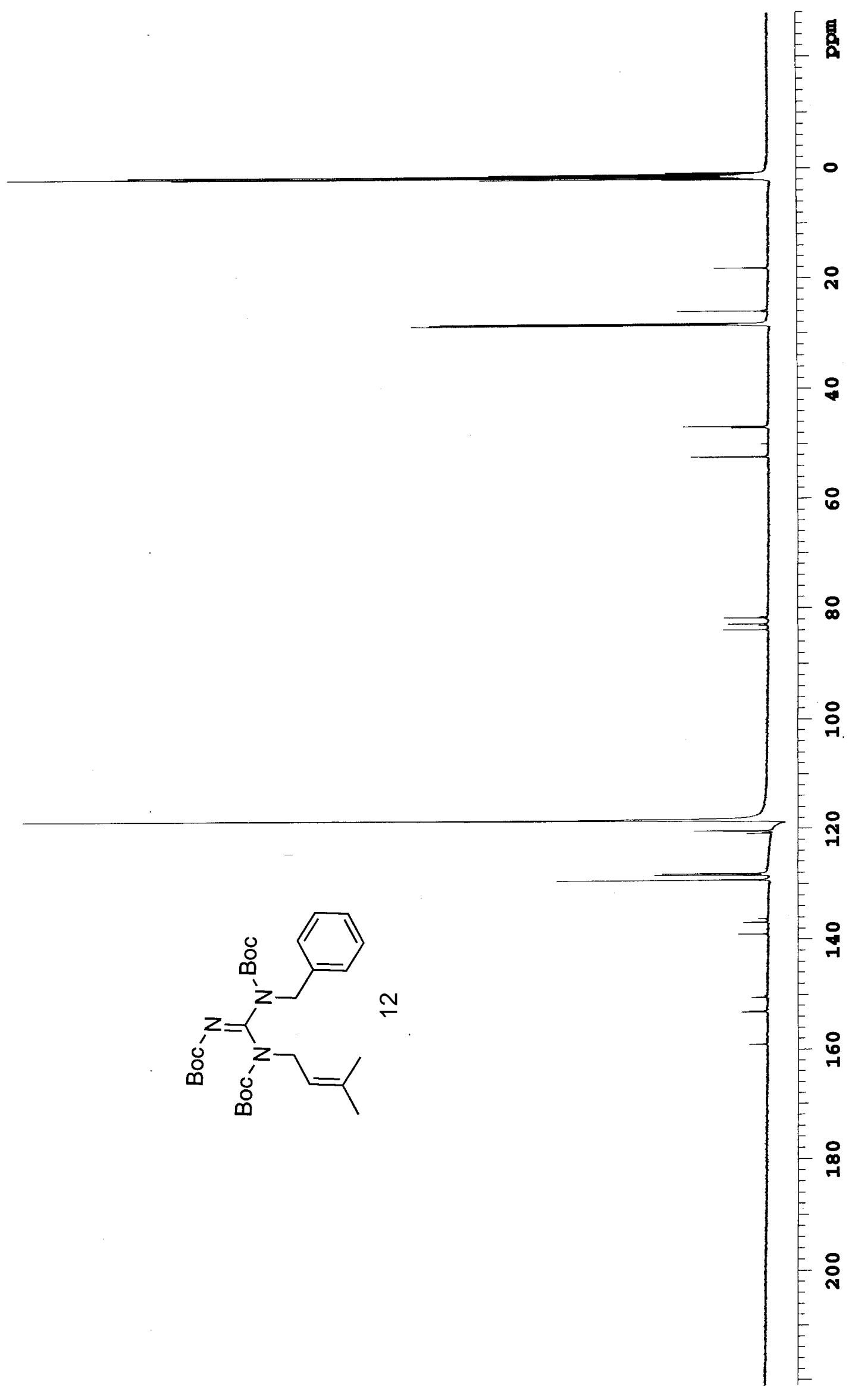

